PASCHOALINA ROMANO

\title{
Farmacocinética do Ácido Micofenólico em transplantados renais idosos
}

Tese apresentada à Faculdade de Medicina da Universidade de São Paulo para obtenção do título de Doutor em Ciências

Programa de Nefrologia

Orientador: Prof. Dr. Elias David-Neto 


\section{Dados Internacionais de Catalogação na Publicação (CIP)}

Preparada pela Biblioteca da

Faculdade de Medicina da Universidade de São Paulo

Creprodução autorizada pelo autor

Romano, Paschoalina

Farmacocinética do Ácido Micofenólico em

transplantados renais idosos / Paschoalina Romano. -

- São Paulo, 2019.

Tese (doutorado)--Faculdade de Medicina da

Universidade de São Paulo.

Programa de Nefrologia.

Orientador: Elias David-Neto.

Descritores: 1.Ácido micofenólico

2.Farmacocinética 3.Monitoramento de medicamentos 4.Disponibilidade biológica 5.Transplante de órgãos 6. Técnicas cromatográficas

$\mathrm{USP} / \mathrm{FM} / \mathrm{DBD}-284 / 19$

Responsável: Erinalva da Conceição Batista, CRB-8 6755 
À minha família com todo amor, por me acompanharem e apoiarem durante todas as etapas da minha vida. 


\section{AGRADECIMENTOS}

À minha família amada e sempre unida, Filomena e Lisanto (in memorian) meus pais, que sempre incentivaram, protegeram e ensinaram a importância da verdade, da honestidade e da amizade para uma vida feliz.

Aos meus irmãos Nicola, Paolo (in memorian,sempre à frente do seu tempo) Giuseppina e cunhada Regiane pelo apoio e amizade.

À minha sobrinha Mariana, a grande alegria de todos nós e uma benção pela inteligência e bom humor e com uma carreira brilhante pela frente, de ajuda ao próximo.

Ao meu orientador, Prof. Dr. Elias David-Neto, pelo apoio durante todo o desenvolvimento dessa tese, um líder que sabe como conduzir, que com dedicação e inteligência aprimora todo o trabalho da equipe.

Aos amigos Prof. Dr. Nairo Massakazu Sumita e Dra. Maria Elizabete Mendes, Diretor e Chefe, e ao Dr. Nilo José Coelho Duarte, responsável pelo setor de Toxicologia, todos do Laboratório de Bioquímica Clínica da Divisão de Laboratório Central (LIM 03) da Faculdade de Medicina da Universidade de São Paulo, pelo incentivo em toda a minha carreira e apoio integral neste estudo.

Ao Prof. Dr. Alberto Duarte, Diretor da Divisão de Laboratório Central (LIM 03) da Faculdade de Medicina da Universidade de São Paulo com admiração pelo seu trabalho administrativo e incentivo.

Aos meus amigos Pérsio de Almeida R. Ebner, Maria Severina dos Santos, Márcio dos Santos Garcia, Ricardo Alexandre dos Santos, Alexandre Sant Anna e Maurílio Pacheco Neto pelo carinho e pelos ótimos momentos de convívio. O empenho e a ajuda de vocês fez com que este trabalho ficasse melhor, começamos juntos na implantação de novos métodos para melhoria do diagnóstico e continuamos evoluindo. 
Aos médicos da Unidade de Transplante Renal, principalmente, Dra. Francine B. $C$ .Lemos , Dr. Nelson Zocoler Galante, Dra. Patrícia Soares de Souza e Dra. Carluce Gualberto ventura, pela competência profissional e por estarem sempre prontos para ouvir, tirar dúvidas e ajudar.

Ao Grupo de Pesquisa Clínica da Unidade de Transplante Renal, que tem seriedade e amor na condução de estudos de grande relevância científica. Meu agradecimento sincero ao Prof. Dr. Elias (chefe), às farmacêuticas, Ana e Fernanda, à enfermeira, Prof. Dra.Fabiana Agena (por toda a logística e apoio estrutural deste trabalho), à secretária, Joana Cabrera e a auxiliar de enfermagem Margarete Soares da Silva, pessoas maravilhosas, fizeram com que eu me sentisse como parte desta equipe multiprofissional, de muito orgulho para mim.

Aos amigos da Divisão de Laboratório Central do Hospital das Clínicas da FMUSP, onde começou meu interesse por pesquisa. Meus agradecimentos pela competência com que executam as tarefas e pelo cuidado com que cuidam dos pacientes, competência e motivação a cada novo desafio.

Às funcionárias do setor de Pós-graduação da Nefrologia do Hospital das Clínicas da FMUSP por sua dedicação, atenção e gentileza. À senhora Fátima Libanio, que fez os levantamentos de todos os dados de prontuário dos pacientes. Deixo aqui minha admiração.

Aos funcionários da Biblioteca Central da Faculdade de Medicina da USP, pelo carinho e dedicação com que realizam suas funções, obrigado pelo apoio e gentileza.

Ao Serviço de Documentação Científica da FMUSP e ao Sr. Josué Moreira de Souza pela diagramação, edição e impressão dos exemplares desta tese e ajuda constante.

Aos pacientes que participaram deste estudo pelo desprendimento, confiança e senso humanitário para ajudar o próximo.

Ao Marcus Vinicius e Weidson pela ajuda estatística. 
"A coisa mais moderna que existe nessa vida é envelhecer". 


\section{NORMATIZAÇÃO}

Esta dissertação ou tese está de acordo com as seguintes normas, em vigor no momento desta publicação:

Referências: adaptado de International Committee of Medical Journals Editors (Vancouver).

Universidade de São Paulo. Faculdade de Medicina. Divisão de Biblioteca e Documentação. Guia de apresentação de dissertações, teses e monografias. Elaborado por Anneliese Carneiro da Cunha, Maria Julia de A. L. Freddi, Maria F. Crestana, Marinalva de Souza Aragão, Suely Campos Cardoso,Valéria Vilhena. 3a ed. São Paulo: Divisão de Biblioteca e Documentação; 2011.

Abreviaturas dos títulos dos periódicos de acordo com List of Journals Indexed in Index Medicus. 


\section{SUMÁRIO}

Lista de Abreviaturas

Lista de Figuras

Lista de Tabelas

Resumo

Abstract

1 INTRODUÇÃ

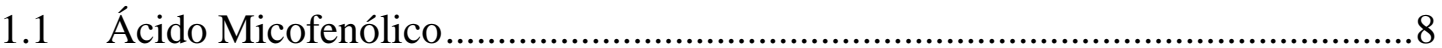

1.2 Método e Validação de LC-MS/MS para análise de MPA ...............................12

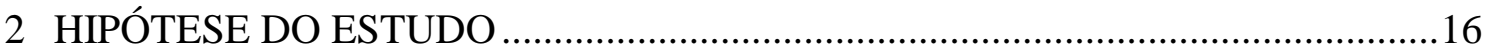

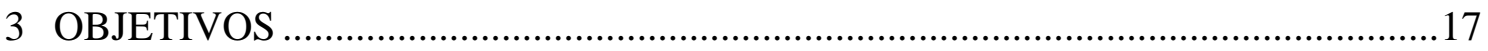

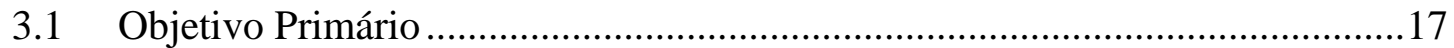

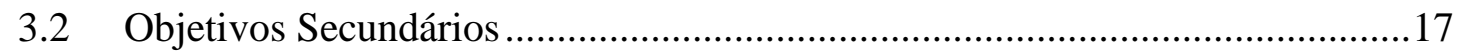

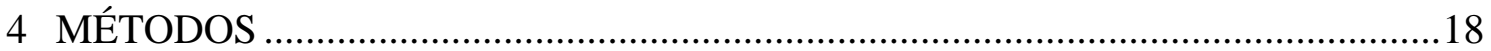

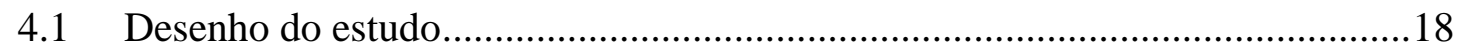

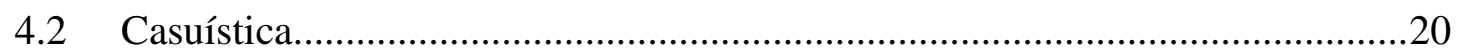

4.3 Critérios de Inclusão e Exclusão ..........................................................................21

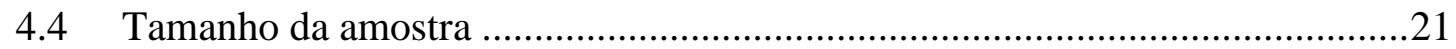

4.5 Função Renal e Parâmetros Laboratoriais .......................................................22

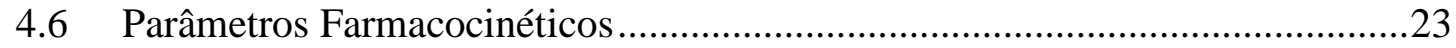

4.7 Amostras para análises farmacocinéticas .........................................................24

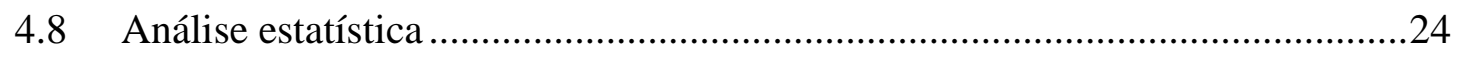

4.9 Desenvolvimento do Método de LC-MS/MS para análise das concentrações plasmáticas de MPA e MPAG...................................................26

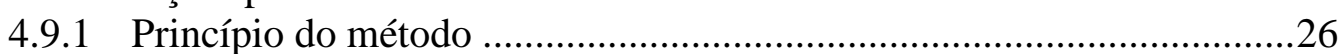

4.9.2 Desenvolvimento do método LC-MS/MS para MPA/MPAG...............27

4.9.3 Validação do Método LC-MS/MS para MPA .......................................28

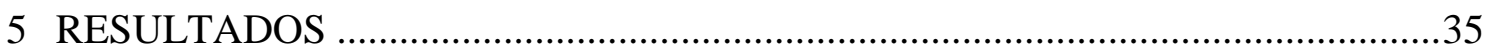

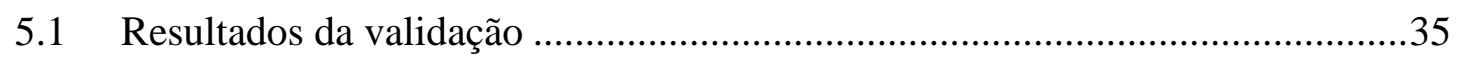

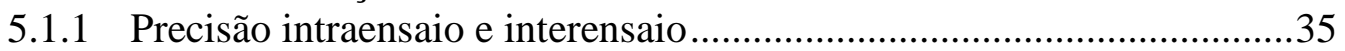

5.1.2 Linearidade, Limite de detecção e Sensibilidade analítica......................36

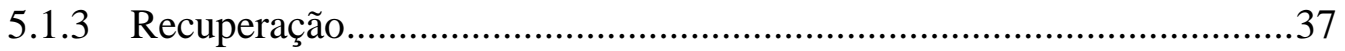

5.1.4 Comparação do método LCMS/MS na DLC com LC-MS/MS em Laboratório de referência..................................................................38

5.1.5 Estabilidade da concentração de MPA em plasma, carryover, robustez e efeito matriz 


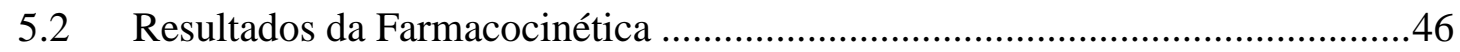

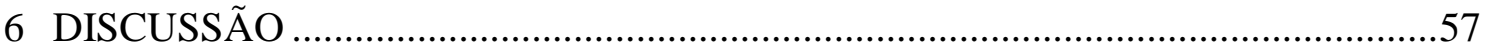

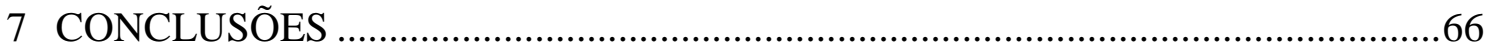

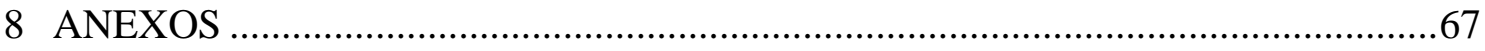

ANEXO 1 - Local do Trabalho e Recursos Financeiros ............................................67

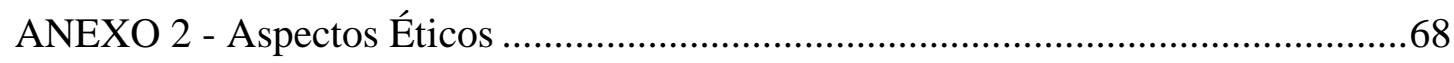

ANEXO 3 - Parecer Consubstanciado do CEP .........................................................69

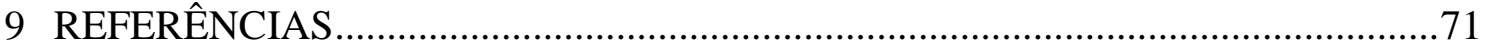

APÊNDICE

Apêndice 1- Artigo publicado 


\section{LISTA DE ABREVIATURAS}

AcMPAG Acil glucoronídeo de MPAG

AUC Área sob a curva concentração-tempo pós-dose

Co Concentração pré-dose

C20 Concentração plasmática em vinte minutos após a dose

C40 Concentração plasmática em quarenta minutos após a dose

C60 Concentração plasmática na primeira hora após a dose

C90 Concentração plasmática em 90 minutos após a dose

C120 Concentração plasmática na segunda hora após a dose

C180 Concentração plasmática na terceira hora após a dose

C240 Concentração plasmática na quarta hora após a dose

C360 Concentração plasmática na sexta hora após a dose

C480 Concentração plasmática na oitava hora após a dose

C600 Concentração plasmática na décima hora após a dose

C720 Concentração plasmática na décima segunda hora após a dose

Cmax Concentração plasmática máxima

EC-MPS Micofenolato Sódico com revestimento gastrorresistente

EMIT Técnica múltipla de imunoensaio enzimático

ICN Inibidor de calcineurina

IMPDH Enzima inosina monofosfato dehidrogenase

LC-MS/MS Cromatografia líquida de alta resolução acoplada à espectrometria de massas sequencial

MDRD Modification of Diet in Renal Disease

MMF Micofenolato Mofetil

MPA Ácido Micofenólico

MPAG Metabólito glucoronídeo fenólico de MPA

$\mathbf{m} / \mathbf{z} \quad$ Relação massa-carga de íons

NCE Nefropatia crônica do enxerto

PK Farmacocinética

PRED Prednisona

RA Rejeição Aguda

TAC Tacrolimo

Tmax Tempo necessário para atingir a máxima concentração plasmática

UGT Enzima uridina difosfato glucuronosiltransferase. 


\section{LISTA DE FIGURAS}

Figura 1. Esquema das coletas para análises da farmacocinética - Grupo de estudo (Idoso e Controle)

Figura 2. Desenho do estudo

Figura 3. Representação gráfica da linearidade dos calibradores e diferenças residuais em relação ao valor nominal de 5 replicatas de cada calibrador

Figura 4. Comparabilidade das concentrações plasmáticas de MPA entre dois diferentes laboratórios que utilizam LC-MS/MS em equipamentos de diferentes fabricantes

Figura 5. Comparabilidade das concentrações plasmáticas de MPAG entre dois diferentes laboratórios que utilizam LC-MS/MS em equipamentos de diferentes fabricantes

Figura 6. Concentração média \pm DP de MPA ajustado por dose e peso $(\mu \mathrm{g} / \mathrm{mL}$ por $\mathrm{mg} / \mathrm{kg}$ ) durante os 720 minutos imediatamente após a dose oral de EC-MPS, 7 dias após o transplante renal em idosos e adultos jovens

Figura 7. Concentração média \pm DP de MPA ajustado por dose e peso $(\mu \mathrm{g} / \mathrm{mL}$ por $\mathrm{mg} / \mathrm{kg}$ ) durante os 720 minutos imediatamente após a dose oral de EC-MPS, 30 dias após o transplante renal em idosos e adultos jovens

Figura 8. Concentração média \pm DP de MPA ajustado por dose e peso $(\mu \mathrm{g} / \mathrm{mL}$ por $\mathrm{mg} / \mathrm{kg}$ ) durante os 720 minutos imediatamente após a dose oral de EC-MPS, 60 dias após o transplante renal em idosos e adultos jovens

Figura 9. Concentração média \pm DP de MPA ajustado por dose e peso $(\mu \mathrm{g} / \mathrm{mL}$ por $\mathrm{mg} / \mathrm{kg}$ ) durante os 720 minutos imediatamente após a dose oral de EC-MPS , 90 dias após o transplante renal em idosos e adultos jovens

Figura 10. Concentração média \pm DP de MPA ajustado por dose e peso $(\mu \mathrm{g} / \mathrm{mL}$ por $\mathrm{mg} / \mathrm{kg}$ ) durante os 720 minutos imediatamente após a dose oral de EC-MPS, 180 dias após o transplante renal em idosos e adultos jovens

Figura 11. $\mathrm{AUC}_{0-12 \mathrm{~h}} \quad(\mu \mathrm{g} \cdot \mathrm{h} / \mathrm{mL}) \quad$ calculada pelo método trapezoidal comparativamente à AUC estimada com $\mathrm{C}_{0} \cdot \mathrm{C}_{40} \cdot \mathrm{C}_{90} \cdot \mathrm{C}_{120}(\mu \mathrm{g} \cdot \mathrm{h} / \mathrm{mL})$ e Erro de Concordância estimado por Bland-Altman 


\section{LISTA DE TABELAS}

Tabela 1. Resultados de MPA obtidos para precisão intraensaio e interensaio de $(\mathrm{CV} \%)$

Tabela 2. Limite de detecção, sensibilidade analítica e linearidade de MPA ( $n=20)$

Tabela 3. Teste de recuperação por adição de concentração conhecida de padrão em amostras de plasma sem MPA $(n=5)$

Tabela 4. Estabilidade da amostra (porcentagem de perda ao longo do tempo) 40

Tabela 5. Análise de Arraste (Carryover) entre amostras

Tabela 6. Robustez do método

Tabela 7. Efeito matriz para MPA

Tabela 8. Características demográficas iniciais dos grupos de estudo.

Tabela 9. Parâmetros bioquímicos e funcionais nos cinco períodos longitudinais pós-transplante em pacientes idosos e de controles

Tabela 10. Doses e concentrações de drogas imunossupressoras combinados ao MPA em cada período pós-transplante.

Tabela 11. Resumo descritivo dos parâmetros farmacocinéticos de MPA avaliados em cinco períodos longitudinais em transplantados renais idosos e jovens

Tabela 12. Segundo pico de MPA em cada período de coleta após o transplante renal nos grupos de idosos e controles

Tabela 13. MPAG-AUC ${ }_{0-720 \text { min }}$ e relação MPAG/MPA em cada período de coleta após o transplante renal nos dois grupos estudados

Tabela 14. Doses diárias de EC-MPS e a $\mathrm{AUC}_{0-720 \min }$ de MPA nos cinco períodos longitudinais em pacientes idosos e de controles

Tabela 15. Correlação entre MPA $\mathrm{AUC}_{0-12 \mathrm{~h}}$ calculada pelo método trapezoidal e MPA AUC estimada com estratégia reduzida de tempo de coleta de amostras 


\section{RESUMO}

Romano P. Farmacocinética do Ácido Micofenólico em transplantados renais idosos [Tese]. São Paulo: Faculdade de Medicina, Universidade de São Paulo; 2019.

O número de transplantados idosos aumentou desde a última década. No entanto, a farmacocinética do ácido micofenólico (MPA), não está bem esclarecida para esta população. Em estudos anteriores demonstramos uma diminuição da depuração total de tacrolimo (TAC) e everolimo (EVL) em uma população de transplantados renais idosos. Este estudo teve como objetivo avaliar potenciais diferenças farmacocinéticas de MPA em transplantados idosos comparada à de adultos Nesta análise, realizamos curvas farmacocinéticas (PK) de MPA em uma análise longitudinal nos dias 7, 30, 60, 90 e 180 dias após o transplante renal, em pacientes utilizando a formulação de micofenolato sódico com revestimento gastrorresistente (EC-MPS). A concentração plasmática de MPA foi analisada por Cromatografia Líquida de Ultra Desempenho acoplada à espectrometria de massas/massas (UPLC-MS/MS), após a validação do método. As farmacocinéticas (PKs) foram analisadas por métodos não compartimentais, utilizando o programa estatístico Phoenix WinNonlin ${ }^{\circledR}$. O segundo pico de absorção de MPA e a razão MPA/ metabólito glucoronídeo fenólico de MPA (MPAG) também foram avaliados, além de estudarmos uma estratégia para estimar a $\mathrm{AUC}_{0-12 \mathrm{~h}}$, através de uma equação abreviada de coletas. Todos os pacientes receberam tacrolimo e prednisona. Foram incluídos neste estudo 44 pacientes idosos e 31 adultos jovens (grupo controle). Os pacientes idosos apresentaram média de idade de 65 33 anos, enquanto no grupo controle a média de idade foi de $35 \pm 6$ anos. O grupo idoso era em sua maioria, do sexo masculino e caucasianos. Entre os parâmetros bioquímicos a média de albumina sérica foi menor nos idosos do que nos controles. Analisando os parâmetros farmacocinéticos, a depuração média de MPA não diferiu entre idosos e controles, em qualquer período analisado (média de todos os períodos de $0,31 \pm 0,17 \mathrm{~L} / \mathrm{h} / \mathrm{kg}$ vs $0,30 \pm 0,25 \mathrm{~L} / \mathrm{h} / \mathrm{kg}(\mathrm{p}=0,7240)$, em idosos e controles, respectivamente). Do mesmo modo, a exposição ao MPA, medida pela área sob a curva de concentração -tempo, de 12 horas, ajustada (por dose / peso corporal), não diferiu entre os grupos em qualquer período (média de todos os períodos de 4,68 $\pm 3,61$ e $5,95 \pm 4,29 \mu \mathrm{g} \cdot \mathrm{h} / \mathrm{mL} / \mathrm{mg} / \mathrm{Kg}$ $(p=0,6128)$ em idosos e controles, respectivamente). Esses dados mostram que a MPA-PK em idosos não difere da de receptores jovens, transplantados renais. Diferentemente de TAC e EVL que são metabolizados por fase I (citocromo P), a fase II de glucuronidação, metabolismo hepático preferencial desta droga, aparentemente não é afetada pelo envelhecimento.

Descritores: Ácido micofenólico, Farmacocinética, Monitoramento de medicamentos, Disponibilidade biológica, Transplante de órgãos, Técnicas cromatográficas. 


\begin{abstract}
Romano P. Pharmacokinetics of Mycophenolic Acid in Elderly Renal Transplant Recipients [Thesis] São Paulo: "Faculdade de Medicina, Universidade de São Paulo"; 2019.

Elderly patients are increasingly receiving kidney transplants. However, the pharmacokinetics of the MPA in this population has not been clearly elucidated. We have demonstrated, in other studies, a lower total body clearance of tacrolimus (TAC) and everolimus (EVL), in the elderly transplanted population. In this analysis, we have studied the longitudinal (7, 30, 60, 90 and 180 days), 12-hour pharmacokinetics (PK) of MPA, under the EC-MPS formulation, in 44 elderly renal transplant recipients compared with 31 younger adult recipients, to verify potential PK differences. Ultra Performance Liquid Chromatography coupled to a mass spectrometer in tandem (UPLC-MS/MS), after validation, was used for MPA measurements. Non-compartmental PKs were analyzing using software Phoenix WinNonlin ${ }^{\circledR}$. The second MPA peak, the ratio MPAG/MPA and a strategy to estimate the $\mathrm{AUC}_{0-12 \mathrm{~h}}$, in this population were also analyzed. All patients received TAC and prednisone. The Elderly group was 30 years older than younger group and had more males and Caucasians. Mean serum albumin were lower in the Elderly than in Controls. The mean MPA clearance was not different between elderly and younger adults at any analyzed period (mean from all periods $0.31 \pm 0.17 \mathrm{~L} / \mathrm{h} / \mathrm{kg}$ vs $0.30 \pm 0.25 \mathrm{~L} / \mathrm{h} / \mathrm{kg}$ ( $\mathrm{p}=0.7240$ ) for elderly and controls, respectively). In the same way, MPA exposure, as measured by the adjusted (by dose/bodyweight) MPA area under the 12 hours, time-concentration curve did not differ between groups at any period (mean from all periods $4.68 \pm 3.61 \mathrm{vs} 5.95 \pm 4.29 \mu \mathrm{g} \cdot \mathrm{h} / \mathrm{mL} / \mathrm{mg} / \mathrm{kg}(\mathrm{p}=0.6128)$ for elderly and controls, respectively). These data show that the MPA-PK is not different in elderly recipients. Differently from tacrolimus and everolimus, which are metabolized by phase I, the phase-II glucuronidation of this drug seems not to be affected by aging.
\end{abstract}

Descriptors: Mycophenolic Acid, Pharmacokinetics, Therapeutic drug monitoring, Biological availability, Organ transplantation, Chromatographic techniques. 


\section{INTRODUÇÃO}

O envelhecimento populacional é hoje um fenômeno mundial. No Brasil, pode ser exemplificado por um aumento da participação da população acima de 60 anos no total da população nacional de 4,1\% em 1940 para 10,8\% em 2010. Os dados da Organização das Nações Unidas (ONU) demonstram que a população mundial crescerá cerca de $50 \%$ (para nove bilhões) até 2050 . No mesmo período, a população acima de 60 anos terá aumentado $350 \%$, sendo que a maior parte desse aumento ocorrerá nos países em desenvolvimento, cada vez mais urbanizados ${ }^{(1)}$. Nos últimos 20 anos, o idoso brasileiro teve a sua expectativa de sobrevida aumentada, e redução do seu grau de deficiência física ou mental ${ }^{(2)}$.

No entanto, não somente aspectos positivos do envelhecimento passaram a ser observados nos últimos anos. Com o aumento da expectativa de vida, ocorreu aumento de doenças crônicas prevalentes na sociedade moderna e industrializada, como diabetes mellitus (DM) e doenças cardiovasculares (DCV) sendo estas as principais causas de óbito na população idosa conjuntamente às neoplasias ${ }^{(3)}$. Na população idosa, a prevalência de doença renal crônica tem aumentado com possível associação a DM e DCV. As principais causas de doença renal crônica terminal (DRC) são a nefropatia diabética e a nefroesclerose hipertensiva. A opção para estes casos é o tratamento dialítico ou o transplante renal $^{(3,4)}$. 
Os indivíduos idosos podem ser beneficiados com o transplante renal, aumentando assim a sua expectativa de vida quando comparada aos indivíduos que permanecem em diálise ${ }^{(3)}$.

Estudos anteriores demonstraram que, em pacientes idosos, o tempo prolongado de diálise pode diminuir o bem-estar e suas funcionalidades ${ }^{(5)}$. Este fato pode ser atribuído ao procedimento e aos efeitos biopsicossociais da doença crônica e às múltiplas doenças e comorbidades associadas à idade do paciente ${ }^{(6-8)}$.

Três estudos ${ }^{(9-11)}$ demonstraram benefícios marcantes na qualidade de vida em pacientes idosos após o transplante renal, incluindo melhora no estado nutricional e na execução de tarefas domésticas.

O conhecimento da resposta imune deste grupo de indivíduos e a individualização do esquema imunossupressor é um desafio. O transplante bem sucedido depende da supressão farmacológica adequada do sistema imune, evitando efeitos colaterais excessivos assim como processos infecciosos oportunistas e malignidades, o que poderia reduzir a sobrevida do receptor ${ }^{(12)}$.

Os inibidores de calcineurina (ICN) ciclosporina (CSA) e tacrolimo (TAC) representam as bases da imunossupressão em transplantes de órgãos sólidos e mais comumente associados ao MPA. Evitar a rejeição aguda (RA), a nefrotoxicidade relacionada aos ICN, infecção por vírus e a incidência de tumores (associados à altas doses de imunossupressores) tem sido o objetivo de vários estudos ${ }^{(13,14)}$.

Com o aumento progressivo da população idosa portadora de doenças crônicas, muitos deles estão em programas de transplante de rim, fígado, coração e pulmão. Esta tendência é mais acentuada para transplante renal ${ }^{(15)}$.

Em uma análise de 20 anos realizada no Serviço de Transplante Renal do Hospital das Clínicas da Faculdade de Medicina da Universidade de São Paulo 
(HCFMUSP) entre os anos de 1990 e 2009, divididos em períodos de cinco anos (quinquênios), observou-se que o número de pacientes com idade superior ou igual 60 anos e que foram submetidos ao transplante renal neste período, aumentou de $10 \%$ para $17 \%{ }^{(16)}$.

Além das patologias relacionadas ao envelhecimento como o surgimento de tumores, demência, depressão, hiperplasia prostática benigna, entre outros, o cuidado do paciente idoso transplantado requer atenção especial com relação ao balanço imunossupressor total, evitando queda acentuada da resposta imune frente aos diversos agentes infecciosos oportunistas.

A involução tímica começa com a idade de um ano e avança com o decorrer da idade $^{(17)}$. Apesar de uma atrofia significativa do timo no envelhecimento, ele mantém a capacidade de produzir células $\mathrm{T}$ nä̈ve. No entanto, a produção de células $\mathrm{T}$ declina com a idade como efeito da Imunossenescência ${ }^{(18)}$. Além disso, o envelhecimento está ligado às células $\mathrm{T}$ de memória efetora $\mathrm{CD} 8^{\text {pos }}$, que podem ser utilizadas como biomarcadores de disfunção de enxerto ao longo prazo ${ }^{(19)}$.

Freitas e colaboradores em estudo comparando população de idosos e adultos jovens saudáveis com adultos que apresentavam doença renal terminal e idosos com doença renal terminal demonstraram que, tanto o envelhecimento quanto a doença renal terminal resultaram na diminuição da contagem absoluta de linfócitos $\mathrm{T}$ e $\mathrm{B}$, deslocamento do perfil de memória, com efeitos divergentes em células T e B reguladoras, que estão aumentadas, sugerindo que em receptores idosos, regimes de imunossupressão que favoreçam a preservação de células $\mathrm{T}$ e $\mathrm{B}$ reguladoras podem melhorar os resultados clínicos ${ }^{(20)}$.

Em um estudo, com a população idosa brasileira, com 366 pacientes idosos (60-78 anos) comparados com 366 pacientes no grupo controle jovem (18-59), a 
sobrevida do paciente foi menor no grupo idoso, aproximadamente $76,6 \%(87,7 \%$ no grupo controle), enquanto que a sobrevida global do enxerto foi de $52,9 \%$ entre os idosos e 72,2\% entre os pacientes do grupo controle, em 5 anos de seguimento. A causa de óbito mais frequente foi infecção, seguida de DCV e neoplasias, mas estes achados foram semelhantes nos dois grupos. $\mathrm{O}$ esquema imunossupressor inicial utilizado neste estudo foi tacrolimo, micofenolato mofetil (MMF) e prednisona ${ }^{(21)}$.

A farmacocinética de imunossupressores, como o ácido micofenólico (MPA), princípio ativo de MMF e EC-MPS, foi pouco estudada na população de transplantados renais idosos, sendo estes estudos importantes para adequação da imunossupressão nesta população ${ }^{(22-24)}$.

A imunossupressão em transplantes, usualmente se faz com o uso de múltiplos fármacos imunossupressores. A característica que estes fármacos possuem de atuar em sítios diferentes, faz com que a associação de vários fármacos resulte em efeitos sinérgicos $^{(25)}$. O sinergismo entre fármacos possibilita a utilização de doses menores de cada um deles, contribuindo para a diminuição dos eventos adversos e amplificação de seus efeitos benéficos.

Atualmente a imunossupressão é realizada de forma individualizada. Os diferentes protocolos de utilização de imunossupressores incluem a escolha entre CSA ou TAC, MMF ou Micofenolato Sódico (MPS), bem como inibidores do mammalian Target of Rapamycin (mTOR) (everolimo ou sirolimo) ${ }^{(26)}$. Estes fármacos são utilizados em diferentes combinações e doses, levando-se em consideração a condição do paciente e do enxerto ${ }^{(27-33)}$. A combinação de agentes imunossupressores prescritos para pacientes é derivada de estudos clínicos, no entanto, pode ser necessário modificar o tratamento para torná-los eficazes de acordo com seus efeitos secundários e estado geral do paciente, função do enxerto e da expectativa de vida ${ }^{(34)}$. 
O desenvolvimento de imunossupressores potentes e as combinações de drogas resultaram em baixa incidência de rejeição aguda do enxerto e aumento da sobrevida dos pacientes transplantados ${ }^{(13)}$. A eficácia e segurança do uso de MPA em transplantados renais foram amplamente estudada ${ }^{(35-37)}$.

Muitos estudos foram realizados para estipular janelas terapêuticas para os diferentes imunossupressores em diferentes populações ${ }^{(14,38-42)}$. Nos idosos a janela terapêutica de imunossupressão parece ser ainda mais estreita quando comparada aos pacientes transplantados renais jovens ${ }^{(43)}$.

No entanto, pacientes idosos possuem diferenças fisiológicas que podem contribuir para alterações no metabolismo e na absorção de drogas imunossupressoras ${ }^{(44-46)}$. O impacto da idade sobre o metabolismo de fármacos foi pouco estudado ${ }^{(47)}$. Alguns fatores em idosos, como alteração do fluxo sanguíneo hepático, podem afetar a farmacocinética da maioria dos imunossupressores ${ }^{(48,49)}$. O metabolismo hepático diminui com a idade, possivelmente devido à diminuição da massa hepática (ao redor de 20-30\%) e à diminuição do fluxo sanguíneo hepático em torno de $20-50 \%{ }^{(50)}$.

A diminuição na quantidade de água corpórea total em idosos e da concentração plasmática proteica contribuem para alterações no volume de distribuição, assim como alterações no transporte de diversos fármacos no sangue, consequentemente, o efeito do fármaco aumenta em intensidade e sua duração diminui. Assim como a diminuição da massa corporal, pode reduzir a ligação de fármacos ao músculo e o acúmulo de fármacos lipossolúveis no tecido adiposo. Adicionalmente, há diminuição do fluxo sanguíneo, acarretando em mudanças nas fases I e II do metabolismo de medicamentos, o que ocasiona o prolongamento da meia-vida de alguns fármacos e alteração na biodisponibilidade dos que sofrem metabolismo de primeira passagem. A função renal comprometida, em pacientes idosos, também pode afetar a excreção de medicamentos ${ }^{(51)}$. 
A diminuição da atividade do citocromo $\mathrm{P} 450$, em idosos implica em redução da dose de inibidores de calcineurina (TAC e CSA) e de esteróides. Atualmente não existem protocolos sobre a melhor opção para imunossupressores em idosos, após a realização de transplante renal $^{(15)}$.

Poucos estudos têm abordado esta necessidade clínica de comparar a combinação de drogas imunossupressoras em pacientes idosos ${ }^{(52)}$.

A prática clínica atual indica que a terapia imunossupressora deve ser individualizada por paciente, através da monitorização terapêutica e não baseada na idade do paciente no momento do transplante.

Os estudos na literatura geralmente foram realizados em amostras populacionais com pequeno número de pacientes idosos, são na sua maioria, estudos observacionais ou retrospectivos, e incluem protocolos de minimização de fármacos ${ }^{(15,32,53)}$.

Com o aumento da idade também ocorre diminuição da secreção do ácido gástrico, da superfície do epitélio intestinal, da função intestinal motora e do fluxo sanguíneo esplâncnico ${ }^{(54-56)}$.

Contudo, para a maioria dos fármacos que são absorvidos por difusão passiva não ocorre redução na absorção, com o envelhecimento (idade-dependente). A redução do fluxo sanguíneo esplâncnico pode ainda prolongar o tempo de absorção de TAC $^{(54)}$ alterando a sua concentração máxima (Cmax) seja em amplitude seja em tempo (Tmax).

Pouco se sabia sob o efeito do envelhecimento na farmacocinética de TAC. Staatz e Tett resumiram os estudos disponíveis de farmacocinética do TAC enfocando os pacientes idosos transplantados (um estudo em transplante de rim, um de medula óssea e três estudos com transplante hepático) e encontraram que o processo de envelhecimento teve pouco impacto sobre a farmacocinética de TAC (biodisponibilidade, volume de distribuição e na depuração), quando comparada com outras variáveis como função do fígado e tempo de transplante, polifarmácia e outras comorbidades ${ }^{(57)}$. 
A variação interindividual de TAC foi relacionada aos polimorfismos do gene ABCB1 e CYP3A5 em receptores chineses de transplante de fígado, sugerindo que a avaliação dos genes ABCB1 e CYP3A5 pode fornecer uma ferramenta eficiente para individualizar a dose e que as proteínas de transporte localizadas nas membranas plasmáticas de vários tecidos são determinantes importantes na absorção e na eliminação de fármacos. As variáveis encontradas para explicar a variabilidade interindividual de TAC, foram relatadas em outros estudos ${ }^{(57-59)}$. Mas não há evidências que poderiam afetar o metabolismo de MPA.

Em estudo anterior, demonstramos que o envelhecimento afeta o metabolismo de TAC diminuindo a sua depuração hepática ${ }^{(60)}$, indivíduos idosos necessitam de doses bem menores desta droga para atingir a janela terapêutica. Não existe disponibilidade de comprimidos de 0,5mg em muitos países o que deve levar a um repensar da indústria farmacêutica sobre a melhor concentração para esta formulação.

Do mesmo modo, o envelhecimento também altera o metabolismo de everolimo. Nossos dados indicam que os receptores de transplante renal idosos que iniciaram everolimo um mês após o transplante, com concentração de tacrolimo no estado de equilíbrio, apresentaram parâmetros farmacocinéticos no grupo idoso, estáveis sem alterações significativas na dose ou exposição, durante os 6 primeiros meses após o transplante renal. Porém, $\mathrm{C}_{0}$ foi comparado entre idosos e adultos jovens e o $\mathrm{C}_{0}$ de $\mathrm{EVL}$ normalizado por dose foi maior no grupo de idosos, indicando que pacientes idosos atingem maiores concentrações de EVL, com doses menores que os controles mais jovens. $^{(61)}$. 


\section{1 Ácido Micofenólico}

O ácido micofenólico (MPA), um produto do fungo Penicilium, isolado em 1896, purificado em 1913 tem efeito imunossupressor conhecido desde 1969, e uso clínico possível após a síntese de um éster denominado micofenolato mofetil (MMF), que foi introduzido entre as drogas imunossupressoras, no início dos anos 90. O EC-MPS é uma pró-droga semisintética que libera MPA na circulação ${ }^{(25)}$.

Contrariamente ao MMF que necessita de pH ácido no estômago para liberar $\operatorname{MPA}^{(62,63)}$, o micofenolato sódico é principalmente absorvido no intestino delgado e é facilmente dissolvido em $\mathrm{pH}$ neutro.

A biodisponibilidade de MPA, após administração oral varia de $81 \%$ a $94 \%$. MPA é principalmente excretado na urina como metabolito MPAG $(87 \%)^{(64)}$. A glucuronidação do MPA em MPAG-7-O-glucuronídeo (MPAG) ocorre principalmente no fígado, mas também nos rins e intestinos. O MPAG é principalmente excretado na urina por secreção tubular ativa e filtração glomerular.

Após a administração as formulações de Micofenolato (Mofetil ou Sódico), são rapidamente hidrolisadas para ácido micofenólico (MPA), que após conjugação resulta em seu metabólito inativo o glucoronídeo fenólico de MPA (MPAG) e em acilglucoronídeo de MPA (AcMPAG), este último apresenta atividade imunossupressora.

A formulação de EC-MPS é completamente hidrolisada para MPA, por esterases presentes no intestino, sangue, fígado e tecidos ${ }^{(65,66)}$.

O MPA exerce seu efeito imunossupressor através da inibição reversível da enzima inosina monofosfato dehidrogenase ${ }^{(67)}$ especificamente envolvida na proliferação de linfócitos $\mathrm{T}$ e $\mathrm{B}^{(68)}$. 
A farmacocinética do MPA é caracterizada por grande variabilidade intra e inter individual da concentração plasmática, também confirmada em nossos estudos $\operatorname{anteriores}^{(32,69-74)}$.

O pico de absorção de MPA ocorre entre 1 a 2 horas após a ingestão da droga, e um segundo pico ocorre entre 6 e 12 horas após ingestão da droga. O segundo pico resulta da recirculação entero-hepática de MPAG que, após hidrólise, é novamente convertido em MPA no trato gastrointestinal ${ }^{(41,75)}$ e contribui com $40 \%$ da área sob a curva total de MPA. A área sob a curva (AUC) concentração-tempo de MPA resulta de três processos: absorção entérica e de esterificação do MMF; recirculação enterohepática de MPA e pelo metabolismo e eliminação de MPA ${ }^{(76)}$.

Em humanos, a interferência no ciclo entero-hepático pode reduzir a AUC concentração-tempo de MPA em 35 a 40\%. O MPAG é excretado pelos rins e a AUC de MPA aumenta nos casos de insuficiência renal ${ }^{(41,66,77,78)}$.

O tacrolimo e a ciclosporina afetam o metabolismo de MPA . Em estudo com pacientes transplantados renais recebendo TAC e MMF, foram encontrados níveis significativamente mais altos de ácido micofenólico, quando comparados com aqueles recebendo CSA e MMF. O maior metabólito do MPA, o glucoronídeo fenólico de MPA (MPAG), tem concentração plasmática significativamente mais baixa em receptores que utilizam TAC, sugerindo uma inibição específica do metabolismo de MPA para MPAG ${ }^{(79,80)}$.

Esta diferença no metabolismo de MPA quando associado a CSA ou TAC levou à redução da dose de MMF quando associado ao TAC.

No entanto, em estudo, com análise de MPA pelo método $\mathrm{EMIT}^{(81)}$, avaliando 52 pacientes, nos seis primeiros meses após o transplante, demonstrou que, cerca de $80 \%$ dos valores de MPA-AUC estiveram abaixo do limite de $36 \mu \mathrm{g} \cdot \mathrm{h} / \mathrm{mL}$ no dia 7 
quando a dose de $1500 \mathrm{mg} /$ dia de MMF foi empregada e no dia 180, ainda $35 \%$ das curvas estavam abaixo de $36 \mu \mathrm{g} \cdot \mathrm{h} / \mathrm{mL}$. Quando se empregou a dose de $2000 \mathrm{mg} / \mathrm{dia}$ de MMF, menos de $15 \%$ das curvas estavam abaixo do limite inferior no dia 180 , tanto no grupo TAC quanto CSA. Sugerindo que a proposta de empregar doses menores de MMF, na primeira semana, quando tacrolimo é usado deveria ser revista.

A ciclosporina, associada ao MMF pode diminuir as concentrações plasmáticas de MPA por supressão do transporte de MPAG pela bile. A ciclosporina interfere na excreção biliar de drogas, e pode interferir na excreção de MPAG, provavelmente, por inibição da proteína 2 associada à resistência para múltiplas drogas (MRP2, multidrug resistance-associated protein 2). Com menor quantidade de MPAG na circulação entero-hepática, a exposição ao MPA, avaliada através da área sob a curva de concentração-tempo (AUC), pode estar diminuída ${ }^{(41)}$.

A utilização de vários fármacos imunossupressores, em pacientes transplantados renais, requer maior habilidade de monitorização, através de medidas farmacocinéticas que melhorem a eficácia destas drogas. A monitorização permitiu que fossem estabelecidas janelas terapêuticas para cada imunossupressor, as quais são utilizadas como indicadores para evitar episódios de rejeição aguda e efeitos adversos como no caso da $\mathrm{CSA}^{(39)}$ ou do $\mathrm{TAC}^{(82)}$.

A necessidade de monitorização terapêutica em receptores de transplante renal para individualizar a dose foi sugerida em vários estudos ${ }^{(78,79,83-86)}$.

Os parâmetros farmacocinéticos de MPA mudam com o tempo após transplante e são influenciados pela função renal, concentração de albumina e interações medicamentosas ${ }^{(85)}$. Estudos sugeriram que a prática atual de dose fixa de MPA é inadequada e que dever-se-ia realizar monitoramento da concentração plasmática, assim como outros imunossupressores, monitorados rotineiramente ${ }^{(32,74,85)}$. 
A argumentação de que a monitorização de MPA pode ser dispensável é baseada somente em estudos de prevenção de rejeição aguda. Ocorre que grande parte dos pacientes tornam-se superexpostos ao MPA com área sob a curva (AUC) $>60 \mu \mathrm{g} . \mathrm{h} / \mathrm{mL}$ após o primeiro mês de transplante e a superexposição pode ser responsável pela alta incidência de infecção em transplantados. Infecção é a maior causa de morte com enxerto funcionante em nosso meio ${ }^{(87)}$

Alguns estudos sugerem, que a dose de 12 horas, no período inicial pós-transplante deve ser adaptada para obtenção de MPA-AUC superior ou igual $33 \mu \mathrm{g} . \mathrm{h} / \mathrm{mL}$, necessária para prevenir episódios de rejeição, principalmente em pacientes pediátricos ${ }^{(42,88)}$. Foi também relatado que uma concentração máxima (Cmax) inferior ou igual $8 \mu \mathrm{g} / \mathrm{mL}$ em adultos, pode minimizar o surgimento de efeitos adversos ${ }^{(89)}$.

Em estudo com 40 receptores de transplante renal, estáveis que receberam Ciclosporina e EC-MPS durante um mês, os pesquisadores observaram na PK-MPA, Tmax de 2,5 horas; Cmax de 33,4 $\mu \mathrm{g} / \mathrm{mL} ; \mathrm{AUC}_{0-12 \mathrm{~h}}$ de 74,7 $\mu \mathrm{g} \cdot \mathrm{h} / \mathrm{mL}$ e Cmin de $1,7 \mu \mathrm{g} / \mathrm{mL}^{(90)}$.

A farmacocinética de TAC, CSA, EVL ou sirolimo podem ser afetadas pelo envelhecimento, mas a idade parece não afetar a farmacocinética de PRED e MPA ${ }^{(22)}$, assim como não afeta a farmacocinética de outras drogas submetidas principalmente à glucoronidação, como a morfina ${ }^{(91)}$. Por outro lado, TAC, MPA e PRED são transportados através das membranas celulares pela mesma bomba de efluxo de drogas (glicoproteína P), o que pode interferir com a taxa de absorção de drogas ${ }^{(92)}$

Existe uma carência de estudos comprovando ou não estas características do metabolismo de MPA em idosos.

Miura e colaboradores realizaram análises farmacocinéticas comparando grupo de idosos e não idosos e não encontraram diferenças nos resultados de MPA. Embora a razão de área sob a curva de MPAG/MPA mais elevada encontrada em pacientes idosos, 
a diferença não foi significativa. No entanto o grupo de idosos era formado por apenas 12 indivíduos (63,3 $\pm 3,3$ anos) enquanto o grupo de adultos jovens era de 41 indivíduos $\left(31,5 \pm 5\right.$ anos) e o grupo de meia idade com 57 indivíduos $\left(50,0 \pm 5,3\right.$ anos ${ }^{(22)}$. Os estudos, nesta faixa etária, foram realizados com tamanho amostral pouco expressivo e na maioria destes estudos os pacientes receberam $\mathrm{MMF}^{(22-24)}$.

A monitorização das concentrações plasmáticass de MPA, após administração de doses fixas tem como metodologia padrão a análise por HPLC (CLAE- cromatografia líquida de alta eficiência), e mais recentemente a cromatografia líquida acoplada à espectrometria de massas sequencial ${ }^{(93,94)}$. Os dois métodos são métodos baseados na separação cromatográfica de moléculas em fase líquida. O que diferencia os dois métodos é o tipo de detector utilizado, ultravioleta (UV) para o HPLC e detector de massas, pela relação massa/carga (m/z) para LC-MS/MS. Concentrações plasmáticas de MPA analisadas por LC-MS/MS apresentam mais sensibilidade e especificidade, para aplicação em estudos farmacocinéticos, este método analítico foi por este motivo, desenvolvido para este estudo.

\subsection{Método e Validação de LC-MS/MS para análise de MPA}

A capacidade de fornecer resultados analíticos confiáveis, exatos e precisos são papéis centrais da equipe de um laboratório clínico. Dados da validação analítica são úteis na introdução de uma nova droga, no apoio aos estudos de formulações distintas, na monitorização e determinação dos níveis terapêuticos de drogas. A validação tem impacto direto na qualidade dos tratamentos instituídos. Ela também possibilita documentação consistente para eventuais auditorias médicas ou de protocolos de pesquisa. 
As informações do desempenho do método LC-MS/MS para MPA estão disponíveis na literatura, mas isto não é suficiente para a sua implantação na rotina

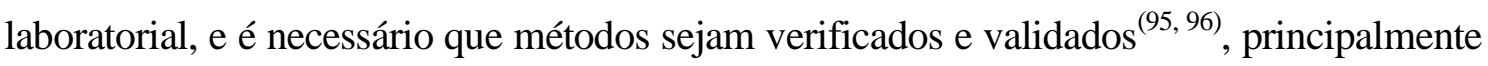
quando são desenvolvidos no próprio laboratório, com solventes preparados pelo usuário e em diferentes condições, o que pode gerar resultados inadequados e, consequentemente, ajustes inadequados nas doses de EC-MPS administradas.

A necessidade de acompanhamento terapêutico demanda a escolha do melhor método laboratorial disponível e que atenda às necessidades do corpo clínico.

A validação de um método consiste na realização de uma série de testes, com a finalidade de se documentar o desempenho do método em relação à exatidão, precisão e intervalo analítico de medida, garantindo que este método atenda às necessidades clínicas e seja confiável.

Os parâmetros que devem ser analisados na avaliação do desempenho do método são: Precisão intraensaio (repetibilidade do método) e interensaio (reprodutibilidade do método), Linearidade ou Limite Superior de Quantificação e Limite Inferior de Quantificação (que permitem determinar o intervalo analítico em que os valores podem ser obtidos sem modificação da amostra), Limite de detecção (capacidade do método em diferenciar resultados muito próximos de zero), Recuperação (capacidade de um método mensurar a quantidade do analito corretamente), estudo de efeito matriz da amostra (se há modificação de ionização da molécula na matriz estudada). Os testes de validação e critérios de aceitação de resultados devem ser efetuados segundo normas nacionais e internacionais $^{(97-101)}$.

A espectrometria de massas apresenta um desempenho superior quando comparada aos imunoensaios disponíveis, com menor custo de reagentes e maior especificidade, ajudando na quantificação, por exemplo, de imunossupressores na mesma 
corrida de análises ${ }^{(102)}$. Uma aplicação para o método LC-MS/MS foi a determinação, na mesma análise laboratorial, de quatro imunossupressores: ciclosporina A (CSA), tacrolimo, sirolimo e everolimo ${ }^{(103-108)}$.

Métodos foram desenvolvidos para reduzir o tempo de análise, sem utilizar alta pressão e vazão, sendo chamados de cromatografia líquida de ultra performance (UPLC) que possibilita a redução do volume de amostras de pacientes e solventes utilizados ${ }^{(107)}$

Desde que este método para análise de imunossupressores foi descrito pela primeira vez, houve considerável interesse em incluir, o ácido micofenólico (MPA) nestas análises. Com pequenas modificações, o mesmo equipamento pode ser utilizado para determinar ciclosporina, tacrolimo, sirolimo e everolimo no sangue total e MPA no plasma, sem comprometer a sensibilidade e especificidade do método, possibilitando ainda, a quantificação do metabólito de MPA, o MPAG.

A espectrometria de massas sequencial acoplada à cromatografia líquida (LC-MS/MS) é, atualmente, o método mais específico disponível para análise de MPA.

Estudos na literatura, utilizando métodos imunoenzimáticos, para análises farmacocinéticas de MPA, encontraram concentrações aproximadamente, 10-30\% superiores, quando comparadas aos métodos cromatográficos HPLC e LC-MS/MS (65, 78, 88, 109-112).

A diferença entre as metodologias é atribuída à reação cruzada do anticorpo presente nos métodos imunoenzimáticos, como o método EMIT, com o metabólito AcMPAG, e foi relatado que essa diferença, pode estar relacionada não apenas ao método de análise, mas também à eliminação de AcMPAG realizada pelos rins, pacientes com função renal reduzida podem ter resultados superestimados em relação a pacientes com a função renal preservada ${ }^{(112)}$. 
A eficácia dos dois métodos na prevenção de rejeição aguda, nos seis primeiros meses após o transplante renal, foi verificada por vários estudos ${ }^{(88,109,112,113)}$. Alguns autores sugeriram que o metabólito AcMPAG pode ser responsável por efeitos adversos, podendo ser importante a sua determinação na monitorização de MPA ${ }^{(65,110)}$, mas há a dificuldade de obter padrões certificados para este metabólito.

A variação interindividual foi comparável na fase inicial (21\%) pós-transplante, e na fase estável (22\%) com análises realizadas por HPLC ou EMIT, concluindo que MPA-AUC $\mathrm{A}_{0-12 \mathrm{~h}}$ e $\mathrm{C}_{0}$ encontraram-se significativamente associados ao risco de rejeição aguda, independentemente da metodologia empregada, e que os dois métodos apresentaram eficácia clínica comparável.

O método de LC-MS/MS foi validado para a realização dos estudos farmacocinéticos de MPA, através de parâmetros que expressam a sua absorção, a velocidade de absorção e eliminação, na população de transplantados renais idosos, comparativamente a um grupo de adultos jovens. 


\section{HIPÓTESE DO ESTUDO}

Os parâmetros farmacocinéticos do Ácido Micofenólico em idosos transplantados renais são semelhantes aos obtidos em adultos jovens transplantados renais ao longo do tempo pós transplante. 


\section{OBJETIVOS}

\subsection{Objetivo Primário}

$\checkmark$ Avaliar a farmacocinética de MPA em pacientes idosos comparada a pacientes adultos jovens nos dias 7, 30, 60, 90 e 180 após o transplante renal.

\subsection{Objetivos Secundários}

$\checkmark$ Desenvolvimento e Validação da metodologia de LC-MS/MS para análise das concentrações plasmáticas de MPA;

$\checkmark$ Estimativa de equações para o cálculo de área sob a curva (AUC) de MPA na população idosa, para estratégia reduzida de coletas de amostras. 


\section{MÉTODOS}

Este projeto de pesquisa foi aprovado pela Comissão de Ética em Pesquisa para Análise de Projetos de Pesquisa (CAPPesq) como subprojeto, parecer número 1.230.099 de16/09/2015 pertencente ao Projeto Temático: Imunossupressão no Transplante Renal do Idoso - Tempo de repensar aprovado pela CAPPesq em 23/08/2012.

Trata-se de um estudo unicêntrico, prospectivo, longitudinal realizado no Serviço de Transplante Renal do Hospital das Clínicas da Faculdade de Medicina da Universidade de São Paulo (STR-HCFMUSP).

Todos os pacientes transplantados renais no período de setembro de 2012 a dezembro de 2015 que apresentaram os critérios de inclusão foram convidados a participar do estudo.

\subsection{Desenho do estudo}

O EC-MPS foi iniciado com dose de $720 \mathrm{mg}$ duas vezes ao dia e ajustado apenas de acordo com a resposta clínica, por nefrologistas treinados para avaliar efeitos adversos secundários associados ao uso de MPA.

As MPA-PK foram realizadas nos dias 7, 30, 60, 90 e 180, após o transplante renal. Os pacientes receberam EC-MPS (Myfortic ${ }^{\circledR}$-Novartis, Basel-Switzerland) duas vezes ao 
dia, às 8:00horas e às 20:00horas. No dia anterior aos estudos de $\mathrm{PK}$, os pacientes foram orientados a jantar, tomar sua dose de EC-MPS exatamente às 20:00 horas e jejuar até a dose do dia seguinte. Água foi permitida. Os pacientes chegaram ao hospital às 6:30 da manhã. Os estudos de PK começaram às 8 horas da manhã. Logo a seguir da primeira coleta $\left(\mathrm{C}_{0}\right)$, o EC-MPS, o tacrolimo $\left(\right.$ Tarfic $^{\circledR}$, Libbs Farmacêutica, São Paulo, Brasil) e prednisona foram administrados. Duas horas após, o café da manhã foi oferecido, assim como os fármacos não imunossupressores. As demais refeições foram ofertadas conforme a rotina do hospital.

As amostras de sangue venoso foram coletadas através de um cateter permanente colocado numa veia do braço. Nos tempos após a dose de: 0, 20, 40, 60, 90, 120, 180, 240, 360, 480, 600 e 720 minutos (0-12 horas) após a dose oral matinal de ECMPS (Figura 1). As concentrações de ácido micofenólico (MPA) obtidas nesses períodos foram denominadas de concentrações $\mathrm{C}_{0}$ a $\mathrm{C}_{12 \mathrm{~h}}$. Nem todos os pacientes realizaram todos os estudos de PK devido a várias razões (entre elas a randomização para outro braço do estudo).

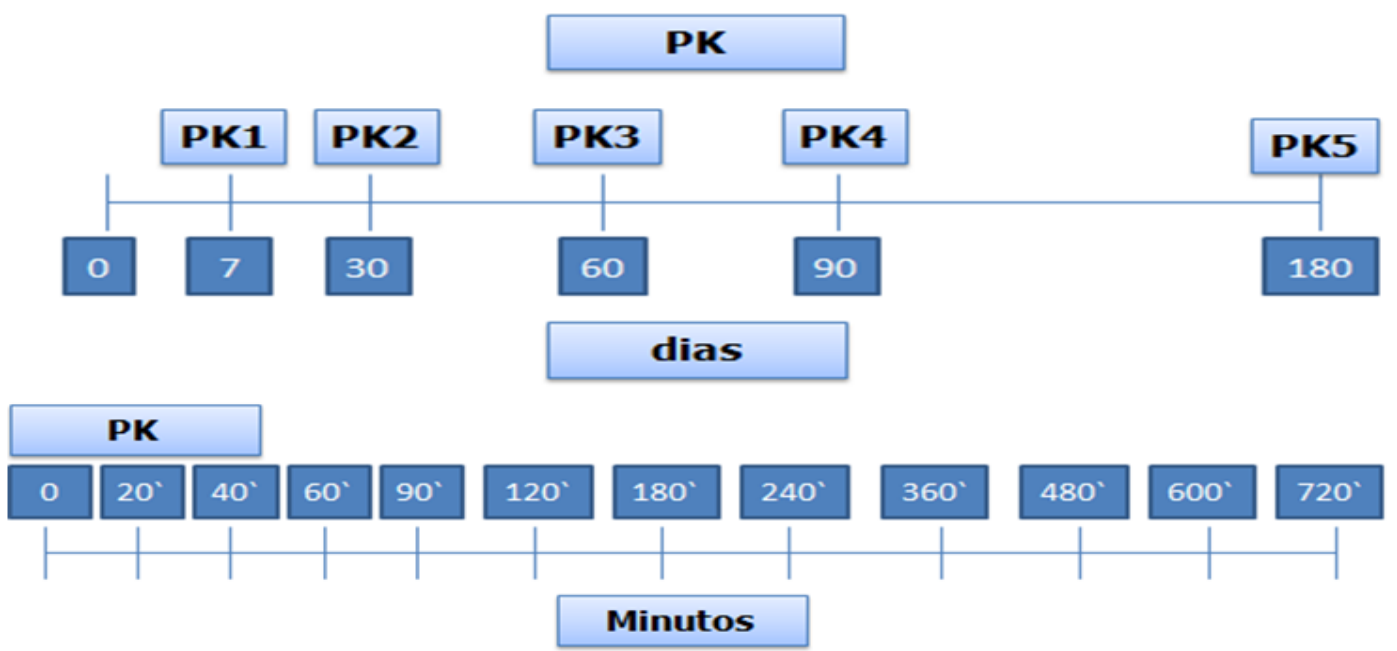

Figura 1. Esquema das coletas para análises da farmacocinética - Grupo de estudo (Idoso e Controle) 
Pacientes que foram randomizados para o braço everolimo/tacrolimo, realizaram apenas as PKs de MPA em 7 e 30 dias. Uma parte do grupo Idoso, foi convertido para everolimo/tacrolimo no dia 37 após transplante (Figura 2).

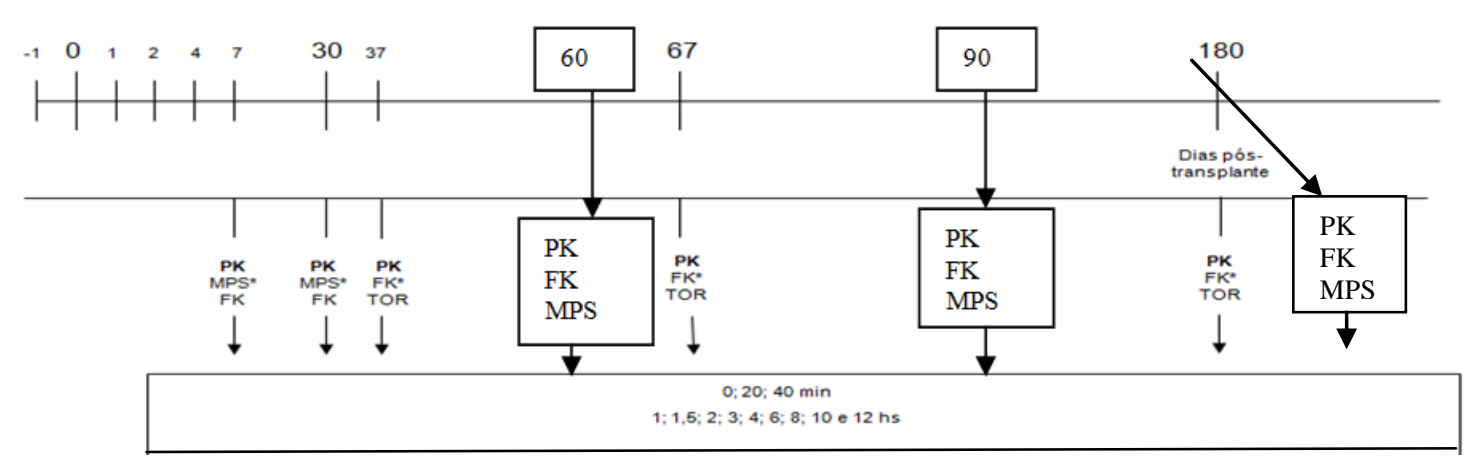

Figura 2. Desenho do estudo

\subsection{Casuística}

Os dados dos pacientes foram obtidos do prontuário eletrônico do Serviço do Serviço de Transplantes Renal do Hospital das Clínicas da Faculdade de Medicina da Universidade de São Paulo (STR-HCFMUSP). Os sujeitos foram convidados através de contato pessoal, no momento do transplante para participar do estudo. Os sujeitos de pesquisa que preencheram os critérios de inclusão e não preencheram os critérios de exclusão foram convidados a participar do sub estudo, assinando o Termo de Consentimento Livre e Esclarecido (TCLE) e informado sobre os objetivos e procedimentos do estudo a serem realizados. 


\subsection{Critérios de Inclusão e Exclusão}

\section{Critérios de Inclusão}

Todos os pacientes receptores de transplante renal de doador vivo ou falecido, do sexo masculino ou feminino, com idade maior ou igual a 60 anos no grupo de idosos e com idade entre 18 - 45 anos no grupo controle.

\section{Critérios de Exclusão}

- Alergia a qualquer um dos medicamentos propostos;

- $\quad$ Pacientes com qualquer infecção ativa incluindo HBV, HCV e HIV;

- Hepatopatia de qualquer origem.

Os pacientes idosos que participaram deste estudo foram os que participaram do estudo nEverOld - Transplante Renal no Idoso (ensaio clínico Trials.gov NCT 01631058), um ensaio clínico randomizado em um único centro, comparando TAC/ /Micofenolato Sódico com revestimento gastrorresistente (EC-MPS) com TAC baixas doses/ Everolimo (EVL) em receptores idosos com idade superior ou igual 60 anos. Nos dois grupos os pacientes receberam Prednisona.

\subsection{Tamanho da amostra}

Todos os pacientes inscritos no braço TAC/EC-MPS foram convidados a participar do estudo MPA-PK. Assim como os receptores adultos jovens com idade de 18 a 45 anos, transplantados em nosso centro durante o mesmo período do registro do 
ensaio nEverOld, que concordaram em participar do estudo, formaram o grupo controle de adultos jovens.

Estudos de PK com voluntários sadios, em geral, estudos do tipo cruzado, utilizam-se de no mínimo 24 indivíduos ${ }^{(114)}$. Como subestudo de um grande projeto, incluímos todos os pacientes que concordaram em participar deste subestudo. Estimamos que uma população idosa de 37 pacientes seria adequada para o estudo da farmacocinética de MPA, através da análise do número de pacientes atendidos por ano no STR-HCFMUSP, com uma taxa de não aceitação adicionada de desistência até o final do primeiro mês, de $20-30 \%$, pois esta é a taxa usual de desistência de pacientes em outros ensaios clínicos do grupo de pesquisa no STR-HCFMUSP.

\subsection{Função Renal e Parâmetros Laboratoriais}

A função renal foi avaliada pelas concentrações de creatinina sérica (método de Jaffé), com calibrador pelo método de referência de diluição isotópica seguida por espectrometria de massa (ID-MS)) e pela equação Modification of Diet in Renal Disease (MDRD-4) em todos os pacientes e em todos os períodos de PK.

Aspartato aminotransferase (AST), Alanina aminotransferase (ALT), Tempo de protrombina, Albumina sérica e Hemoglobina também foram avaliados. 


\subsection{Parâmetros Farmacocinéticos}

Além das concentrações de MPA de 0 até 12 horas, nos períodos após transplante definidos acima, foram determinados os seguintes parâmetros farmacocinéticos utilizando métodos não compartimentais das concentrações de MPA:

- Tau (horas): tempo da curva farmacocinética completa (12hs);

- $\mathbf{A U C}_{\mathbf{0}-12 \mathrm{hs}}(\boldsymbol{\mu g} \cdot \mathbf{h} / \mathbf{m L})$ : Área sob a curva no intervalo de 12 horas ;

- Tmax (horas): Tempo em que ocorre a máxima concentração;

- Cmax ( $\mu \mathrm{g} / \mathrm{mL})$ : Concentração máxima;

- Cmin ( $\mu \mathrm{g} / \mathrm{mL})$ : Concentração mínima;

- Cavg ( $\mu \mathbf{g} / \mathbf{m L})$ : concentração média do fármaco no estado de equilíbrio (= $\left.\mathrm{AUC}_{0-12 \mathrm{~h}} / \mathrm{Tau}\right)$

- \% de flutuação: = Grau de flutuação no estado de equilíbrio = $100 *($ CmaxCmin) / Cavg. No período de 0 - 12h (Tau);

- HL_Lambda_z (horas): Meia-vida aparente terminal ou seja, meia-vida de eliminação $\left(\mathrm{t}_{1 / 2}\right)$ do fármaco;

- Clss_F (L/ h / kg): Estimativa da depuração corporal total normalizada pelo peso de cada paciente .

OBS: para modelos extravasculares, a fração da dose absorvida não pôde ser estimada, então a depuração avaliada neste estudo é na verdade depuração/ F, onde F é a fração da dose absorvida. 


\subsection{Amostras para análises farmacocinéticas}

As amostras com 2,0 mL de sangue dos pacientes foram obtidas através de uma veia do antebraço, a qual permaneceu puncionada durante todo o tempo da coleta. As amostras foram coletadas em frasco contendo um anticoagulante, ácido etilenodiamino tetra-acético (EDTA) da marca BD ${ }^{\circledR}$.

Após a coleta de sangue, a amostra foi encaminhada ao laboratório de Toxicologia da Divisão de Laboratório Central do Hospital das Clínicas da Faculdade de Medicina da Universidade de São Paulo, centrifugada a 1258g que corresponde 2500 rotações por minuto (rpm) por 5 minutos. O plasma foi separado das hemácias e transferido para um frasco de plástico previamente identificado com nome e tempo de coleta da curva farmacocinética. Estas amostras foram conservadas em temperatura de $-30^{\circ} \mathrm{C}$ até o momento da análise, por um período não superior a 15 dias.

\subsection{Análise estatística}

Os parâmetros farmacocinéticos foram analisados em uma abordagem não compartimental utilizando o método trapezoidal, com o programa Phoenix WinNonlin®, versão 6.3 (Pharsight Corporation, Mountain View, CA, EUA), e as estatísticas foram analisadas usando o pacote estatístico IBM SPSS Statistical Software, versão 18 (IBM SPSS, Inc.Chicago, IL, EUA). Para todas as comparações, o nível de significância $\alpha$ foi estabelecido em $5 \%(\mathrm{p}<0,05)$.

Devido ao fato de que mais de uma MPA-PK estava disponível para cada paciente, avaliamos as diversas medidas comparando o comportamento dos dois grupos ao longo do 
tempo, através da técnica de Análise de Variância para Modelos Mistos (Mixed Model ANOVA), a qual considera que o mesmo paciente foi avaliado diversas vezes ao longo do tempo e também considera a questão de não termos todas as informações de todos os pacientes, nos cinco períodos após o transplante. Foram avaliadas as diferenças entre os dois grupos, períodos e interação entre grupos e período (isto é, examinando se os grupos se comportaram de maneira similar ao longo do tempo) ${ }^{(115)}$.

Para os testes estatísticos assumimos um valor de significância de 0,05 o qual equivale a uma confiança de $95 \%$. Assumindo, que houve diferença significativa se valor de $\mathrm{p}<0,05$.

Alguns parâmetros também foram ajustados para dose e peso corporal antes de realizar as comparações entre os grupos.

Os dados contínuos foram expressos como a média \pm desvio padrão (DP) e os dados categóricos apresentados como frequência e porcentagem, nas tabelas e figuras deste estudo.

Para a análise do segundo pico de MPA, considerou-se uma elevação da concentração plasmática de MPA superior a 4,20\% (precisão obtida na validação do método para o intraensaio) em relação à concentração da coleta prévia.

A porcentagem de pacientes dentro da janela terapêutica MPA (AUC 30-60 $\mu \mathrm{g} \cdot \mathrm{h} / \mathrm{mL}$ ) foi analisada para ambos os grupos.

A $\mathrm{AUC}_{0-12 \mathrm{~h}}$ foi comparada por regressão linear através do coeficiente de explicação da regressão $\left(r^{2}\right)$ e metodologia de Bland-Altman, com alguns dos tempos de coleta após a dose, para tentar encontrar estratégias simplificadas de coleta que pudessem predizer a $\mathrm{AUC}_{0-12 \mathrm{~h}}$ calculada pelo método trapezoidal, de forma adequada.

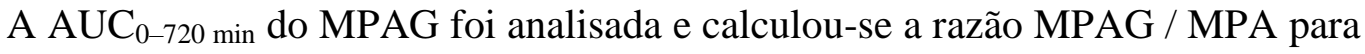
verificar se existiam potenciais diferenças na glucoronidação entre as duas populações estudadas. 


\subsection{Desenvolvimento do Método de LC-MS/MS para análise das concentrações plasmáticas de MPA e MPAG}

\subsubsection{Princípio do método}

O método LCMS/MS estuda moléculas, pela formação de íons em fase gasosa, com ou sem fragmentação, que são caracterizados por suas relações massa carga e abundâncias relativas. A fonte de íons, gera íons em fase gasosa a partir de moléculas em fase sólida, líquida ou gasosa. A ionização pode gerar íons positivos e/ou negativos. As formas principais de ionização são: Ejeção ou captura de elétrons e protonação ou desprotonação.

O termo geral "ionização por pressão atmosférica" (API) inclui a ionização por eletropulverização (ESI), a qual fornece a base para vários métodos, capazes de criar íns. A amostra é dissolvida em solvente polar e/ou apolar e bombeada através de um capilar de aço inoxidável que transporta entre 2000 e 4000 volts (V). O líquido se transforma em aerossol, à medida que sai do capilar à pressão atmosférica, os aerossóis fluem para o espectrômetro de massa, induzidos pelos efeitos combinados da atração eletrostática e do vácuo.

A tensão do cone, dependente do composto, foi otimizada para MPA, para produzir um íon de massa nominal de MPA + amônia $[\mathrm{M}+\mathrm{NH} 4]^{+}$, ou seja, por protonação em modo Eletrospray (eletropulverização) positivo (ESI). A dissociação induzida por colisão do íon precursor é facilitada por energia produzida pelo gás argônio e a colisão produz um íon produto característico de MPA. Essas informações foram aplicadas ao experimento de Monitoramento de Múltipla Reação (MMR), selecionado para qualificar e quantificar o MPA. 


\subsubsection{Desenvolvimento do método LC-MS/MS para MPA/MPAG}

Um método simples e sensível, de cromatografia Líquida de ultra performance acoplada à espectrometria de massas de repetição (UPLC-MS/MS) foi adaptado e desenvolvido para as nossas condições laboratorais e validado para a medição confiável de MPA em amostras de plasma humano. A interferência potencial devido à conversão na fonte do seu metabolito principal MPAG para MPA foi adequadamente controlada através de parâmetros de massa optimizados. A ionização e detecção de MPA e de seu deuterado, utilizado como padrão interno (PI) foi realizada em um espectrômetro de massa Acquity $\mathrm{TM}^{\circledR}$ da Waters (MA, USA), equipado com interface de pulverizador do íon turbo e operado no modo eletrospray íon positivo. A quantificação foi realizada utilizando o modo de monitorização de reação múltipla (MRM) para monitorizar as transições de íons de produto $\rightarrow$ precursor para MPA m/z foram: $338,1 \rightarrow 207,1$ e padrão interno, MPA deuterado, $\mathrm{m} / \mathrm{z} 341,2 \rightarrow 210,1$. As transições de qualificação $\mathrm{m} / \mathrm{z}$ para MPA foram 338,1 $\rightarrow 159,0$ e MPA d3 341,2 $\rightarrow 306,1$. As transições de íons de produto $\rightarrow$ precursor para MPAG $\mathrm{m} / \mathrm{z}$ foram: $514,2 \rightarrow 206,9$ e de qualificação $514,2 \rightarrow 321,1$

Estas razões $\mathrm{m} / \mathrm{z}$ foram determinadas pelo sinal mais intenso observado quando a varredura completa do espectrômetro de massas, foi aplicada com uma infusão contínua de uma solução padrão para cada composto de $9,46 \mu \mathrm{g} / \mathrm{mL}$ para MPA e de 222,0 $\mu \mathrm{g} / \mathrm{mL}$ para MPAG, utilizando uma fonte de íons por electropulverização operando em modo positivo (ESI). O Tempo de retenção (velocidade com que o MPA sai da coluna cromatográficas) foi de 0,25 $\pm 0,05$ minutos. A coleta de dados, integração de picos cromatográficos e cálculos foram realizados usando o software Mass Lynx versão 4, Waters Corporation. 
As condições cromatográficas do método incluíram o uso de duas fases móveis: Fase (A): acetato de amônia $2 \mathrm{mM}$ em $\mathrm{H}_{2} \mathrm{O}$ e $0,1 \%$ de ácido fórmico (pH 3,0) e Fase (B): acetato de amônia $2 \mathrm{mM}$ em metanol e $0,1 \%$ de ácido fórmico (pH 3,0). A taxa de fluxo de solvente de $0,400 \mathrm{~mL} / \mathrm{min}$, eluição da amostra por gradiente aplicado 0-1,5 min, inicial de $50 \%$ de fase móvel A e 50\% de fase móvel B. A reação ocorre com temperatura da coluna cromatográfica de $55^{\circ} \mathrm{C}$, a coluna cromatográfica utilizada foi uma C18 2,1 x $10 \mathrm{~mm}$ (TDM, Waters $\left.{ }^{\circledR}\right)$.

As condições de MS/MS para análise das amostras foram: aquisição em tempo de corrida cromatográfica de 2,5 minutos; energia de fragmentação $25 \mathrm{~V}$; tempo de digitalização 0,1 Segundos; banda de energia $\mathrm{m} / \mathrm{z}$ 0,1. O instrumento foi configurado para múltiplas varreduras de massas (MRM). De acordo com a relação m/z.

Controles e calibradores foram armazenados em alíquotas de $50 \mu \mathrm{L}$, na temperatura de $-30^{\circ} \mathrm{C}$, descongeladas no momento das análises, mantidos em estoque de acordo com a validade recomendada.

\subsubsection{Validação do Método LC-MS/MS para MPA}

A validação da metodologia foi realizada, após o desenvolvimento e otimização das massas de MPA e MPAG para garantir a especificidade do método, na Divisão de Laboratório Central da Faculdade de Medicina da Universidade de São Paulo (DLC-HCFMUSP).

O preparo de amostras, controles e calibradores usou um protocolo, com $50 \mu \mathrm{L}$ de plasma de paciente, controles e calibradores com adição de $20 \mu \mathrm{L}$ de PI (MPA

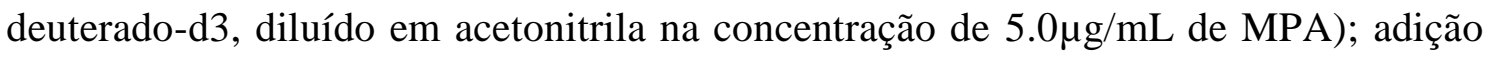
de $200 \mu \mathrm{L}$ de sulfato de zinco na concentração $\quad 0,1 \mathrm{M}$ diluído em metanol (200mL) e 
água $(800 \mathrm{~mL})$ e posterior adição de $500 \mu \mathrm{L}$ de acetonitrila grau LCMS/MS. As amostras foram submetidas à homogeneização em equipamento vórtex por 30 segundos e centrifugadas em 1600g (15000rpm) por 8 minutos.

Todos os solventes e sais utilizados possuíam grau de pureza superior a 99,9\% (grau LC-MS).

\section{Calibração}

Na calibração, foram utilizados três concentrações de calibradores e um branco (matriz isenta de MPA e MPAG) específico da marca Chromsystem ${ }^{\circledR}$ Inc. Munique, Alemanha em plasma contendo ácido micofenólico (MPA) e seu metabólito glucoronídeo de MPA (MPAG) com concentrações conhecidas (zero; 0,97; 3,89 e 9,46 $\mu \mathrm{g} / \mathrm{mL}$ ) de Ácido Micofenólico e MPAG (0; 18,2; 88,3 e $220 \mu \mathrm{g} / \mathrm{mL})$, em matriz plasma.

Os controles utilizados foram pool de amostras de plasma em três concentrações diferentes abrangendo concentrações altas, médias e baixas de MPA e MPAG.

O padrão interno (PI), denominado de internal standard (IS) utilizado foi o deuterado: Mycophenolic acid - d3 da marca Sigma-Aldrich ${ }^{\circledR}$, adicionado em todas as amostras, calibradores e controles analisados para verificar erros de ionização.

O volume de Injeção da amostra no LC-MS/MS, após extração foi de $20 \mu \mathrm{L}$.

Os calibradores foram colocados em ordem crescente na bandeja de amostras do equipamento, definida para a posição de cada um na bandeja. A seguir, foram verificadas as leituras dos calibradores que deveriam estar dentro dos limites definidos pelo fabricante (com desvios do valor esperado inferiores à 15\%). Quando algum calibrador não é aceito, o equipamento mostra um desvio superior, sendo necessária a repetição da curva de calibração. 
A calibração é definida como o processo para testar um método analítico, com a finalidade de estabelecer uma relação entre a concentração conhecida de um analito (calibrador) e o valor medido na amostra. A calibração relaciona-se com a exatidão do método. No caso de LC-MS/MS as áreas dos cromatogramas da curva de calibração, relacionam-se diretamente com as áreas obtidas das amostras.

A calibração foi realizada em cada rodada de análises e repetida quando os controles não responderam dentro da faixa de referência aceitável (média estipulada mais ou menos dois desvios padrão), ou quando ocorreu a mudança de lote das Fases móveis.

Os controles de ácido micofenólico em três concentrações conhecidas, em matriz de plasma foram analisados em cada corrida de análises, e os resultados avaliados em termos da média $\pm 2 \mathrm{DP}$. Foram adotadas, para análise dos resultados do controle, as regras múltiplas de Westgard ${ }^{(116)}$.

$\mathrm{Na}$ análise foram pipetados $500 \mu \mathrm{L}$ da amostra já extraída, em frascos (vials) do equipamento, como descrito no protocolo acima (livre de interferentes, como fosfolípides ou proteínas, que podem causar supressão iônica).

Os resultados em concentração são obtidos por comparação da leitura da área da amostra com a leitura da área dos calibradores, observados na curva de calibração.

Em todas as amostras, aos calibradores e controles foi acrescentado padrão interno (MPA deuterado-d3), sendo as áreas compensadas pelo padrão interno (PI), através da equação: área do analito*(PI concentração/PI área) e, assim, garantindo que a ionização ocorreu corretamente.

A validação do método seguiu os critérios estabelecidos pelo Clinical Laboratory Improvement Act (CLIA) ${ }^{(117)}$ e do Clinical Laboratory Standard Institute $(\mathrm{CLSI})^{(99-101) .}$ Estes critérios são os mesmos adotados pela ANVISA ${ }^{(96)}$. 
A precisão de um método é definida como a concordância entre resultados de replicatas das análises.

A precisão foi avaliada utilizando-se os controles de qualidade, obtidos de pools de amostras de pacientes. Para evitar efeito de matriz diferente do plasma nos resultados, usamos, também, amostras de pacientes transplantados renais estáveis, para o estudo da precisão intraensaio e interensaio.

Em todos os testes de validação, foram calculadas: as médias, desvio-padrão e coeficiente de variação dos valores obtidos. A média e o desvio-padrão foram calculados com a ajuda de programa Excell versão 5.O(Microsoft ${ }^{\circledR}$, Windows XP) e o coeficiente de variação é obtido através da razão do desvio padrão/média multiplicado por 100.

Foram utilizados para as análises de validação e comparabilidade entre métodos os softwares EP Evaluator ${ }^{\circledR}$ versão 9 (Data Innovations LLC, Estados Unidos) e Minitab $^{\circledR}$ versão 15, Inc., Estados Unidos)

Estudou-se a precisão intraensaio através da análise, no mesmo dia, de 20 replicatas dos três níveis de controle. Foram realizadas duas corridas no mesmo dia, para minimizar erros devido à presença de interferentes (corrente elétrica e variação de temperatura).

A precisão interensaio foi determinada em cinco dias consecutivos, sendo realizada a análise dos três níveis de controle em quatro replicatas a cada dia (2 pela manhã e 2 à tarde). Os coeficientes de variação para os testes intra e interensaio foram considerados adequados quando resultou valor menor do que $15 \%$ e quando o desvio padrão (DP) de um par de resultados em duplicata, na mesma corrida analítica, não foi maior que $5,5 \%{ }^{(118)}$. Em termos de relevância clínica, são considerados desvios aceitáveis, aqueles abaixo dos coeficientes de variação de variabilidade biológica aceitáveis, que não estão descritos na literatura para este imunossupressor e por esse motivo, utilizamos os critérios do 
Colégio Americano de Patologia Clínica da variação entre participantes deste exame de proficiência $(25 \%)$.

O limite de detecção (LD) foi determinado após a análise do branco de solvente, acetonitrila, em 20 replicatas. O coeficiente de variação adequado é de $20 \%$ entre as leituras das replicatas. Para LC-MS/MS o Limite de detecção foi definido como a menor concentração acima de zero de MPA e que pode ser detectada numa razão de sinal/ruído > 3, tendo como referência a linha base do cromatograma.

O limite Inferior de Quantificação (LLQ) foi avaliado através de diluições seriadas de uma mesma amostra (calibrador $0,97 \mu \mathrm{g} / \mathrm{mL}$ ) até a verificação do menor valor detectável pelo método, com coeficiente de variação entre 20 replicatas, inferior a $15 \%$.

A linearidade foi determinada através de diluição de amostra com valor conhecido de MPA $(9,6 \mu \mathrm{g} / \mathrm{mL})$, e as análises foram realizadas em 20 replicatas. A diluição foi realizada com calibrador de valor zero até a verificação do maior valor detectável pelo método. O resultado obtido foi considerado adequado quando apresentou reprodutibilidade sem a necessidade de diluição, e o coeficiente de variação entre as leituras das replicatas, foi inferior a $15 \%$.

Um método é linear quando a recuperação de diluições seriadas é linearmente proporcional à concentração real da amostra.

O intervalo analítico foi definido através do menor valor detectável e quantificável (LQ) e do valor máximo detectável (linearidade ou limite superior de quantificação).

A estabilidade da amostra foi verificada em três amostras previamente analisadas e com valores conhecidos, estocadas em câmara-fria a $-30^{\circ} \mathrm{C}$. Foram realizadas as dosagens em 7, 30, 60 e 90 dias, e os resultados analisados em termos percentuais de perda em relação à concentração obtida no tempo zero. Este teste foi considerado aceitável quando a perda foi inferior a $10 \%$ do valor inicial. 
Estudou-se a recuperação do método, adicionando um calibrador de valor conhecido a uma amostra sem MPA. Foram considerados valores de recuperação aceitáveis níveis de 90 a 110\% de recuperação, em relação ao valor esperado. Neste teste empregamos calibradores com concentrações de: 0,97; 3,39 e 9,46 $\mu \mathrm{g} / \mathrm{mL}$, os quais foram adicionados à amostra sem MPA.

Após a validação do método, foram, ainda, avaliadas amostras de plasma de pacientes transplantados renais que receberam EC-MPS/tacrolimo e prednisona, para comparação entre as metodologias LC-MS/MS desenvolvida na DLC e LC-MS/MS desenvolvida em outro laboratório de referência, para análise de MPA. O estudo comparativo entre os resultados obtidos foi realizado através da correlação de Pearson e pelo Erro de concordância avaliado pelo índice de erro, o qual correlaciona a média de dois métodos com a diferença entre eles. O equipamento utilizado em outro laboratório para as análises por LC-MS/MS foi um triplo quadrupolo, porém de modelo diferente do utilizado na DLC.

\section{Efeito Matriz}

O efeito de matriz para MPA foi estudado comparando as recuperações de MPA em amostras de padrão em acetonitrila, com as de matrizes de MPA adicionadas de padrão com PI, após extração. Efeito da matriz em percentagem $=($ resposta dos analitos adicionados após extração / resposta dos padrões no solvente -1 ) * 100, se < 20\%, não há interferência da matriz nos resultados obtidos.

O efeito matriz é utilizado para verificar a eficiência de ionização do analito no detector, que pode causar alterações negativas ou positivas no sinal do detector, devido à supressão iônica ou acréscimo de sinal. Este efeito interfere na quantificação dos analitos e deixa de ser confiável pela alteração causada na precisão, exatidão e detecção do método. 
O preparo de amostra, principalmente a etapa de limpeza ou extração, é essencial para reduzir o efeito matriz pela remoção dos interferentes.

Alternativas, para a diminuição do efeito matriz consistem em construir a curva analítica na própria matriz, diluir a amostra, utilizar padrão interno, aperfeiçoar a separação cromatográfica e alterar as condições do detector, como modo de ionização, tipo de fonte ou transições MRM não interferentes.

\section{Contaminação entre amostras sequenciais por arraste (Carryover)}

A contaminação entre amostras, foi avaliada por análises repetidas de 10 alíquotas de amostra padrão de concentração alta $(\mathrm{H})$ e 11 alíquotas de concentração baixa (L) (na seguinte sequência: $\mathrm{L}(\mathrm{n}=3), \mathrm{H}(\mathrm{n}=2), \mathrm{H}(\mathrm{n}=2), \mathrm{L}(\mathrm{n}=1), \mathrm{H}(\mathrm{n}=2)$, $\mathrm{L} L(\mathrm{n}=1), H(\mathrm{n}=2), \mathrm{L}(\mathrm{n}=1)$, verificando se o sistema de lavagem entre amostras do equipamento foi eficaz ${ }^{(119)}$.

\section{Robustez do Método LC-MS/MS}

A robustez de um método analítico é a capacidade de suportar pequenas e deliberadas variações dos parâmetros analíticos.

Foi realizada com a comparabilidade entre os resultados em 3 amostras diferentes, avaliadas em 5 replicatas cada uma, após modificação da fase móvel B, substituindo o solvente orgânico metanol por acetonitrila, foram calculadas as médias, desvios-padrão e coeficiente de variação entre os resultados. 


\section{RESULTADOS}

\subsection{Resultados da validação}

Antes dos estudos farmacocinéticos de MPA, realizamos a validação do método, para confiança dos resultados obtidos.

\subsubsection{Precisão intraensaio e interensaio}

A tabela 1 descreve a precisão intra e interensaio do método LC-MS/MS.

O coeficiente de variação intraensaio variou de $3,60 \%$ a 4,20\%, e o interensaio de $3,13 \%$ a $9,70 \%$ para MPA.

Tabela 1. Resultados de MPA obtidos para precisão intraensaio e interensaio de (CV\%)

\begin{tabular}{cccccccccc}
\hline & & \multicolumn{3}{c}{ Intraensaio } & \multicolumn{4}{c}{ Interensaio } \\
\cline { 3 - 9 } $\begin{array}{c}\text { Controles } \\
(\mathbf{n = 2 0})\end{array}$ & $\begin{array}{c}\text { Concentração } \\
\text { Esperada } \\
(\boldsymbol{\mu g} / \mathbf{m L})\end{array}$ & $\begin{array}{c}\text { Média } \\
(\boldsymbol{\mu g} / \mathbf{m L})\end{array}$ & $\mathbf{D P}$ & $\begin{array}{c}\mathbf{C V} \\
(\boldsymbol{\%})\end{array}$ & $\begin{array}{c}\text { Concentração } \\
\text { Esperada } \\
(\boldsymbol{\mu g} / \mathbf{m L})\end{array}$ & $\begin{array}{c}\text { Média } \\
(\boldsymbol{\mu g} / \mathbf{m L})\end{array}$ & $\mathbf{D P}$ & $\begin{array}{c}\mathbf{C V} \\
(\boldsymbol{\%})\end{array}$ \\
\hline $\begin{array}{c}\text { Controle } \\
\text { baixo }\end{array}$ & 1,00 & 0,99 & 0,04 & 3,60 & 1,20 & 1,19 & 0,12 & 9,70 \\
$\begin{array}{c}\text { Controle } \\
\text { médio }\end{array}$ & 2,30 & 2,23 & 0,08 & 3,80 & 2,08 & 2,06 & 0,11 & 5,20 \\
$\begin{array}{c}\text { Controle } \\
\text { alto }\end{array}$ & 5,80 & 5,50 & 0,23 & 4,20 & 5,78 & 5,76 & 0,18 & 3,13 \\
\hline
\end{tabular}

DP: desvio padrão; CV(\%): coeficiente de variação para três níveis diferentes de controle e para plasma contendo ácido micofenólico (MPA). 
O método apresenta boa precisão intra e interensaio, com CV abaixo de $15 \%$ para todos os níveis de controles e para a amostra de plasma.

\subsubsection{Linearidade, Limite de detecção e Sensibilidade analítica}

A tabela 2 apresenta os dados dos testes de linearidade, sensibilidade analítica e limite de detecção.

O método LC-MS/MS apresentou-se como linear até o valor de 9,43 $\mu \mathrm{g} / \mathrm{mL}$, próximo ao valor mais alto da curva de calibração $(9,46 \mu \mathrm{g} / \mathrm{mL})$, a figura 3 , demonstra a linearidade.

Do mesmo modo, o método demonstrou ser sensível para detectar valores iguais ou superiores a $0,20 \mu \mathrm{g} / \mathrm{mL}$. O limite de detecção foi de 0,10 para leitura do branco do solvente.
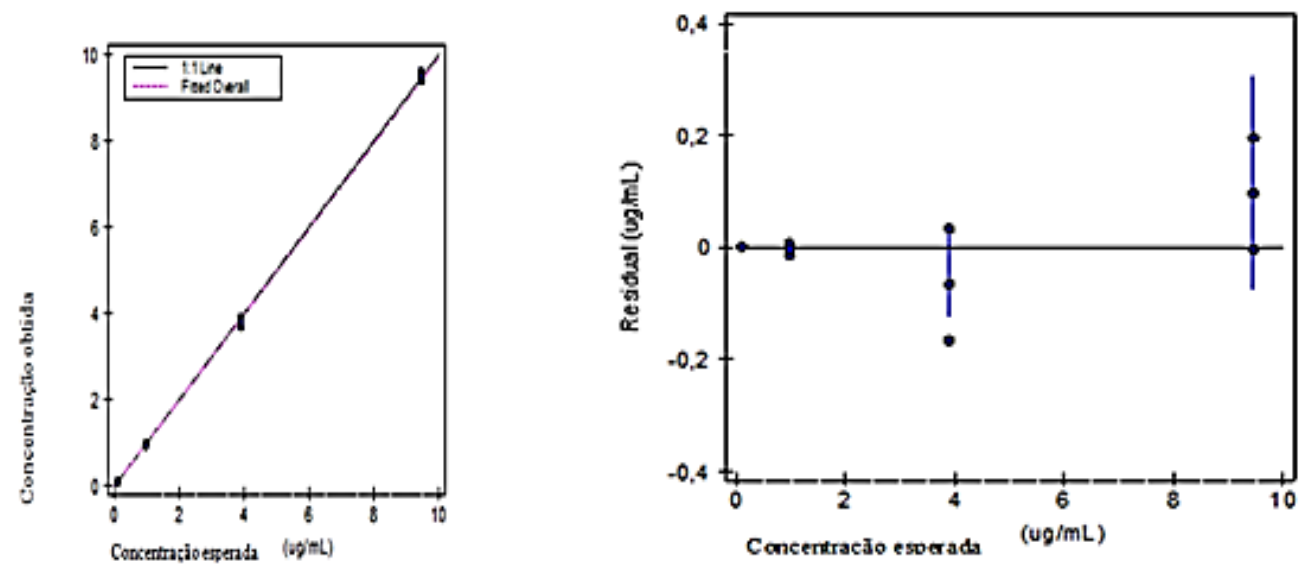

Figura 3. Representação gráfica da linearidade dos calibradores e diferenças residuais em relação ao valor nominal de 5 replicatas de cada calibrador 
A inclinação da curva foi de 0,91 ; intercepto de 0,00 e coeficiente de determinação $\left(\mathrm{r}^{2}\right)>0,98$, o máximo de desvio em relação ao valor esperado foi de $1,5 \%$ para um máximo aceitável de 2,0\%, demonstrando a linearidade do método. Os resíduos devem estar distribuídos ao redor da média dentro dos limites $0 \pm 0,2$.

Tabela 2. Limite de detecção, sensibilidade analítica e linearidade de MPA (n=20)

\begin{tabular}{lccc}
\hline & Média $(\boldsymbol{\mu g} / \mathbf{m L})$ & DP & CV $(\boldsymbol{\%})$ \\
\hline Limite de detecção & 0,097 & 0,004 & 4,85 \\
Limite de & 0,203 & 0,011 & 5,28 \\
Quantificação & 9,43 & & \\
Linearidade & 0,096 & 1,02 \\
\hline
\end{tabular}

DP: desvio padrão da média, $\mathrm{CV}(\%)$ : coeficiente de variação

\subsubsection{Recuperação}

A tabela 3 demonstra os valores esperados, obtidos, e a porcentagem de recuperação para três níveis de controles, quando adicionados a uma amostra de plasma sem MPA (volume/volume: 1/1). Todos os valores estão compreendidos entre $90 \%$ e $110 \%$.

Tabela 3. Teste de recuperação por adição de concentração conhecida de padrão em amostras de plasma sem MPA $(n=5)$

\begin{tabular}{ccccc}
\hline $\begin{array}{c}\text { Adição de MPA } \\
(\mu \mathrm{g} / \mathrm{mL})\end{array}$ & $\begin{array}{c}\text { MPA esperado } \\
(\mu \mathrm{g} / \mathrm{mL})\end{array}$ & $\begin{array}{c}\text { MPA obtido } \\
(\mu \mathrm{g} / \mathrm{mL})\end{array}$ & $\begin{array}{c}\text { Recuperação } \\
(\boldsymbol{\%})\end{array}$ & $\mathbf{C V}(\boldsymbol{\%})$ \\
\hline 9,46 & 4,73 & 4,72 & 99,8 & 4,2 \\
3,89 & 1,95 & 1,85 & 94,9 & 4,8 \\
0,97 & 0,49 & 0,46 & 93,9 & 6,2 \\
\hline
\end{tabular}

A recuperação obtida está dentro dos limites aceitáveis de 90-110\% e com coeficiente de variação entre as replicatas (5) inferior à $15 \%$. 


\subsubsection{Comparação do método LCMS/MS na DLC com LC-MS/MS em Laboratório de referência}

As Figuras 4 e 5 representam a comparação entre cromatografia líquida acoplada à espectrofotometria de massas sequencial (LC-MS/MS), de dois diferentes laboratórios, para a quantificação de MPA plasmático em 29 amostras e para 20 amostras para MPAG.
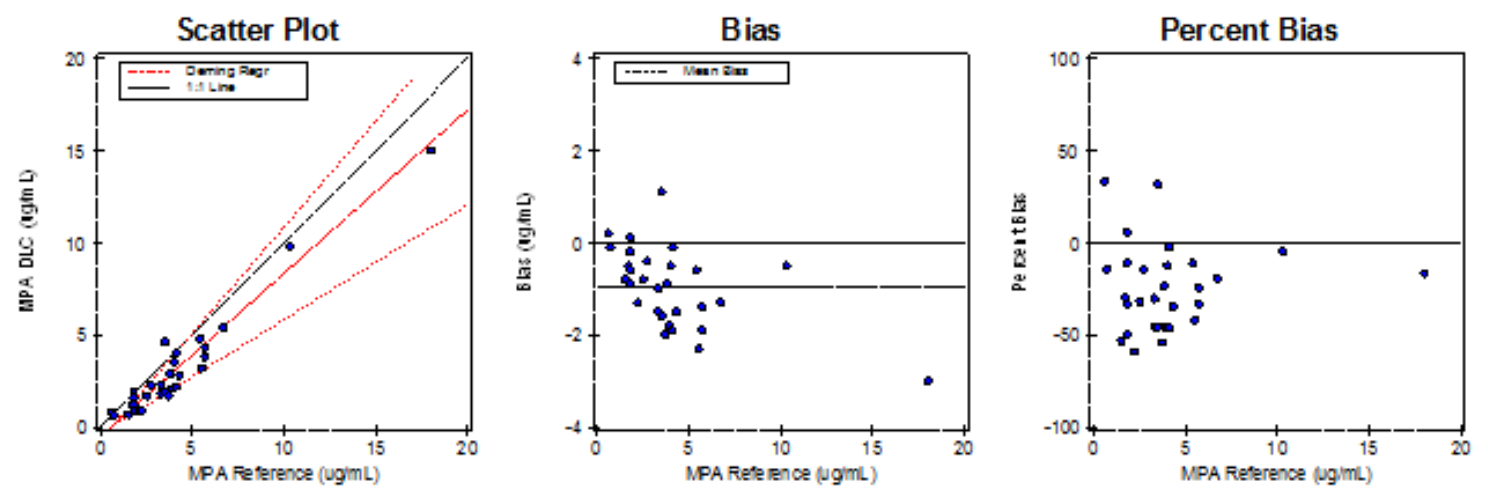

O coeficiente de correlação ( $r$ ) foi de 0,$9697 ; r^{2}=0,938$; a tendência (viés ou bias) de $-0,97(-26,95 \%$ ); as médias do laboratório de referência foram de $4,07 \pm 3,35 \mu \mathrm{g} / \mathrm{mL}$ e na DLC de $3,10 \pm 2,98 \mu \mathrm{g} / \mathrm{mL}$ $(p=0,251)$, onde LC-MS/MS referência $=0,677+1,09$ MPA LC-MS/MS na DLC.

Figura 4. Comparabilidade das concentrações plasmáticas de MPA entre dois diferentes laboratórios que utilizam LC-MS/MS em equipamentos de diferentes fabricantes 

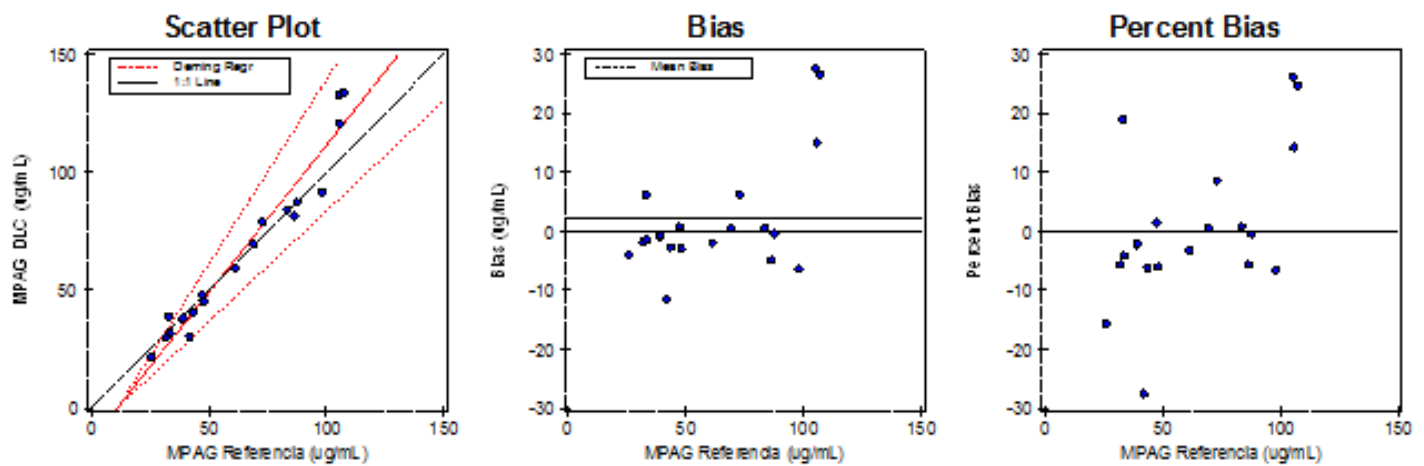

O coeficiente de correlação (r) foi de 0,$9727 ; \mathrm{r}^{2}=0,946$; a tendência (viés ou bias) de 2,17 (-3,39\%); as médias do laboratório de referência foram de $62,91 \pm 28,20 \mu \mathrm{g} / \mathrm{mL}$ e na DLC de $65,08 \pm 35,02 \mu \mathrm{g} / \mathrm{mL}(p=0,830)$, LC-MS/MS referência $=11,9+0,783$ MPAG LC-MS/MS na DLC.

Figura 5. Comparabilidade das concentrações plasmáticas de MPAG entre dois diferentes laboratórios que utilizam LC-MS/MS em equipamentos de diferentes fabricantes

O metabólito MPAG foi validado e obtivemos para precisão intraensaio CV de $1,1-4,1 \%$; precisão interensaio $C V=2,6-6,0 \%$; para o teste de recuperação por adição

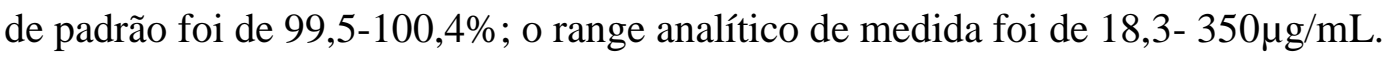

\subsubsection{Estabilidade da concentração de MPA em plasma, Carryover, Robustez e Efeito matriz}

Os resultados de estabilidade de três amostras de plasma, aleatórias com concentração de $2,0 \mu \mathrm{g} / \mathrm{mL}, 4,5 \mu \mathrm{g} / \mathrm{mL}$, e $6,2 \mu \mathrm{g} / \mathrm{mL}$, foram testadas após conservação em freezer $\left(-30^{\circ} \mathrm{C}\right)$, as alíquotas foram descongeladas apenas no momento da análise e amostras sem nenhum tipo de conservante, estão descritos na tabela 4. Observou-se que a diferença foi maior em amostras com valores mais baixos, e que a menor porcentagem 
de perda ocorre em até 30 dias. Após este prazo, as perdas em amostras de baixa concentração podem estar próximas de $10 \%$.

Tabela 4. Estabilidade da amostra (porcentagem de perda ao longo do tempo)

\begin{tabular}{|c|c|c|c|c|c|c|c|c|c|c|c|c|}
\hline $\begin{array}{c}\text { Valor } \\
\text { esperado } \\
(\mu \mathrm{g} / \mathrm{mL})\end{array}$ & $\begin{array}{c}7 \text { dias } \\
(\mu \mathrm{g} / \mathrm{mL})\end{array}$ & $\mathrm{CV}(\%)$ & $\%$ & $\begin{array}{c}30 \text { dias } \\
(\mu \mathrm{g} / \mathrm{mL})\end{array}$ & $\operatorname{CV}(\%)$ & $\%$ & $\begin{array}{c}60 \text { dias } \\
(\mu \mathrm{g} / \mathrm{mL})\end{array}$ & $\mathrm{CV}(\%)$ & $\%$ & $\begin{array}{c}90 \operatorname{dias} \\
(\mu \mathrm{g} / \mathrm{mL})\end{array}$ & $\operatorname{CV}(\%)$ & $\%$ \\
\hline 2,0 & 2,10 & 5,8 & 5 & 2,14 & 9,2 & 7 & 2,15 & 8.9 & 7,5 & 2,19 & 9,6 & 9,5 \\
\hline 4,5 & 4,50 & 7,2 & 0 & 4,50 & 7,9 & 0 & 4,80 & 8,5 & 6,7 & 4,89 & 8,0 & 8,7 \\
\hline 6,0 & 6,22 & 6,8 & 3,8 & 6,42 & 7,2 & 7 & 6,52 & 7,9 & 4,82 & 6,60 & 8,2 & 10 \\
\hline
\end{tabular}

$\mathrm{CV}=$ coeficiente de variação entre as triplicatas (\%); diferença em relação ao primeiro dia da análise (\%)

As análises de estabilidade de amostras foram efetuadas em triplicatas. A diferença no período avaliado de 90 dias, foram inferiores ao limite de $10 \%$ em relação ao valor esperado, no dia da análise da amostra.

Na tabela 5 estão demonstrados os resultados de Arraste entre amostras para avaliar se o sistema de lavagens do equipamento é suficiente para garantir a integridade dos resultados em uma bateria de análises de MPA, sem que ocorra a contaminação entre amostras.

Tabela 5. Análise de Arraste (Carryover) entre amostras

\begin{tabular}{lcc}
\hline & Média & DP \\
\hline A=Alta-Baixa concentração & 0,32 & 0,72 \\
B=Baixa- Baixa concentração & 0,16 & 0,22 \\
Arraste entre amostras & 0,16 & \\
Erro limite & 0,66 & \\
Aprovado & $\operatorname{sim}$ & \\
\hline
\end{tabular}

DP: desvio padrão 
Como o Arraste entre amostras (diferença entre as médias A e B) foi menor que o erro limite (3 DP da média de B), não há contaminação cruzada entre amostras e o sistema de lavagens do equipamento é eficaz.

Tabela 6. Robustez do método

\begin{tabular}{cccc}
\hline $\begin{array}{c}\text { Concentração } \\
\text { esperada }(\boldsymbol{\mu g} / \mathbf{m L})\end{array}$ & $\begin{array}{c}\text { Concentração obtida } \\
\text { em Fase móvel } \\
\text { Metanol }(\boldsymbol{\mu g} / \mathbf{m L})\end{array}$ & $\begin{array}{c}\text { Concentração obtida } \\
\text { em Fase móvel } \\
\text { Acetonitrila }(\boldsymbol{\mu g} / \mathbf{m L})\end{array}$ & $\begin{array}{c}\text { Acurácia } \\
\%\end{array}$ \\
\hline $\mathbf{1 , 6 0}$ & 1,66 & 1,74 & 104,8 \\
$\mathbf{2 , 5 0}$ & 2,44 & 2,54 & 104,1 \\
$\mathbf{5 , 7 0}$ & 5,70 & 5,78 & 101,4 \\
\hline
\end{tabular}

Acurácia $(\%)$ = concentração esperada - obtida /concentração esperada *100

Foram realizadas análises com três amostras enviadas pelo Colégio Americano de Patologia (CAP) para o exame de proficiência em cinco replicatas. O método demonstrou ser robusto para enfrentar modificações de solventes polares. Consideramos adequada uma acurácia de 80-120\%.

Tabela 7. Efeito matriz para MPA

\begin{tabular}{lcccc}
\hline $\begin{array}{l}\text { MPA esperado } \\
(\mu \mathrm{g} / \mathrm{mL})\end{array}$ & $\mathbf{0 , 4 9}$ & $\mathbf{1 , 9 5}$ & $\mathbf{4 , 7 3}$ & $\begin{array}{c}\text { Média do } \\
\text { Efeito matriz (\%) }\end{array}$ \\
\hline Em acetonitrila & 0,48 & 1,94 & 4,73 & \\
\% recuperação & 98,5 & 99,4 & 99,9 & \\
\hline Em branco de matriz após extração & 0,48 & 1,93 & 4,70 & 0,34 \\
\% recuperação & 98,5 & 99,2 & 99,7 & \\
\hline
\end{tabular}


O cálculo do efeito matriz em 10 replicatas de cada calibrador, em acetonitrila sem extração e em branco de matriz de plasma (sem MPA) foi menor que $20 \%$, portanto não há efeito da matriz na ionização das moléculas e a extração é eficaz, na remoção de proteínas e fosfolipídios. Nossos calibradores são comerciais e adicionados na matriz plasma e não em solventes, o que ajuda a diminuir o efeito matriz nas análises de MPA e MPAG.

Com os resultados validados para a análise de MPA, e certificação do Colégio Americano de Patologia Clínica para a análise de MPA, os resultados da farmacocinética foram avaliados com exatidão e precisão.

\section{Características demográficas}

A Tabela 8 mostra os dados demográficos dos pacientes deste estudo.

Tabela 8. Características demográficas iniciais dos grupos de estudo.

\begin{tabular}{lccc}
\hline & $\begin{array}{c}\text { Controles } \\
\mathbf{n = 3 1}\end{array}$ & $\begin{array}{c}\text { Idosos } \\
\mathbf{n = 4 4}\end{array}$ & $\boldsymbol{p}$ \\
\hline Gênero (F/M) & $20 / 11$ & $16 / 28$ & 0,031 \\
Idade (Anos) média $\pm \mathrm{DP}$ & $35 \pm 6$ & $65 \pm 3$ & 0,003 \\
Peso corporal (em Kg, no dia 7); média $\pm \mathrm{DP}$ & $66,0 \pm 18,0$ & $70,0 \pm 13,0$ & 0,060 \\
Etnia & & & \\
$\quad$ Caucasianos & 15 & 34 & \\
$\quad$ Afro-Brasileiros & 15 & 6 & \\
$\quad$ Orientais & 0 & 2 & \\
Doadores (falecidos/vivos) & $20 / 11$ & $41 / 3$ & 0,005 \\
\hline
\end{tabular}


A idade foi em média 30 anos superior no grupo idoso. Os grupos também diferiram em outras características. O grupo idoso foi composto em sua maioria por homens brancos e que receberam em maior porcentagem rins de doadores falecidos enquanto o grupo controle apresentou a maioria de pacientes do sexo feminino, com distribuição equilibrada em termos de raça e receberam mais rins de doadores vivos do que o grupo idoso. O peso corporal no idoso tendeu a ser maior do que no grupo controle, porém sem diferenças estatisticamente significativas $(p=0,06)$.

A Tabela 9 mostra a função renal e as características hepáticas destes grupos. Os pacientes idosos demonstraram uma estimativa de filtração glomerular (MDRD-4 equação) estatisticamente menor do que o grupo controle, em todos os períodos após transplante. Da mesma forma, os níveis de hemoglobina no sangue foram menores no idoso, mas estatisticamente significativos apenas aos 60 dias após o transplante. As enzimas hepáticas (AST, ALT) e o tempo de protrombina foram muito semelhantes entre os grupos. Por outro lado, a albumina sérica foi, em qualquer momento, menor no grupo idoso e estatisticamente menor nos períodos 30 e 60 dias. 
Tabela 9. Parâmetros bioquímicos e funcionais nos cinco períodos longitudinais pós-transplante em pacientes idosos e de controles

\begin{tabular}{|c|c|c|c|c|c|c|c|c|c|c|c|}
\hline \multirow[t]{2}{*}{ Dias } & \multicolumn{2}{|c|}{7} & \multicolumn{2}{|c|}{30} & \multicolumn{2}{|c|}{60} & \multicolumn{2}{|c|}{90} & \multicolumn{2}{|c|}{180} & \multirow[t]{2}{*}{$\begin{array}{l}\text { valor } \\
\text { de } p\end{array}$} \\
\hline & $\begin{array}{c}\text { Idosos } \\
\text { n=42 } \\
\text { (Média } \pm D P)\end{array}$ & $\begin{array}{c}\text { Controles } \\
\qquad \begin{array}{c}\mathbf{n}=\mathbf{3 0} \\
\text { (Média } \pm \mathrm{DP})\end{array}\end{array}$ & $\begin{array}{c}\text { Idosos } \\
\text { n=37 } \\
\text { (Média } \pm D P \text { ) }\end{array}$ & $\begin{array}{l}\text { Controles } \\
\qquad \mathbf{n = 2 4} \\
(\text { Média } \pm \mathrm{DP})\end{array}$ & $\begin{array}{c}\text { Idosos } \\
\text { n=22 } \\
\text { (Média } \pm \mathrm{DP})\end{array}$ & $\begin{array}{l}\text { Controles } \\
\qquad \mathbf{n = 2 2} \\
\text { (Média } \pm \mathrm{DP} \text { ) }\end{array}$ & $\begin{array}{c}\text { Idosos } \\
\text { n=18 } \\
\text { (Média } \pm D P \text { ) }\end{array}$ & $\begin{array}{l}\text { Controles } \\
\qquad \begin{array}{c}n=19 \\
(\text { Média } \pm D P)\end{array}\end{array}$ & $\begin{array}{c}\text { Idosos } \\
\text { n=17 } \\
\text { (Média } \pm D P \text { ) }\end{array}$ & $\begin{array}{l}\text { Controles } \\
\qquad \begin{array}{c}\text { n=14 } \\
\text { (Média } \pm D P)\end{array}\end{array}$ & \\
\hline 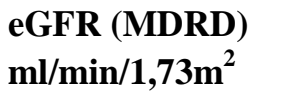 & $11,2 \pm 7,4$ & $23,6 \pm 26,3$ & $35,4 \pm 20,1$ & $44,2 \pm 18,1$ & $44,6 \pm 21,2$ & $51,1 \pm 18,0$ & $44,6 \pm 15,8$ & $50,5 \pm 21,1$ & $45,2 \pm 17,5$ & $52,0 \pm 22,4$ & 0,062 \\
\hline AST (IU/L) & $19 \pm 10$ & $18 \pm 11$ & $21 \pm 8$ & $17 \pm 8$ & $17 \pm 8$ & $176 \pm 8$ & $17 \pm 6$ & $18 \pm 8$ & $24 \pm 16$ & $19 \pm 7$ & 0,047 \\
\hline ALT (IU/L) & $31 \pm 27$ & $38 \pm 35$ & $20 \pm 1$ & $18 \pm 7$ & $19 \pm 14$ & $22 \pm 14$ & $20 \pm 6$ & $21 \pm 7$ & $25 \pm 22$ & $21 \pm 12$ & 0,056 \\
\hline $\begin{array}{l}\text { Tempo de } \\
\text { Protrombina } \\
\text { (\% do normal) }\end{array}$ & $89 \pm 14$ & $93 \pm 10$ & $89 \pm 21$ & $87 \pm 11$ & $76 \pm 26$ & $93 \pm 14$ & $86 \pm 13$ & $88 \pm 10$ & $90 \pm 16$ & $88 \pm 10$ & 0,061 \\
\hline $\begin{array}{l}\text { Albumina Sérica } \\
\text { (g/dL) }\end{array}$ & $3,4 \pm 0,5$ & $3,5 \pm 0,5$ & $4,1 \pm 0,4$ & $4,4 \pm 0,3$ & $3,9 \pm 0,3$ & $4,4 \pm 0,3$ & $3,9 \pm 0,5$ & $4,3 \pm 0,5$ & $3,9 \pm 0,5$ & $4,2 \pm 0,5$ & 0,001 \\
\hline $\begin{array}{l}\text { Hemoglobina } \\
(\mathrm{g} / \mathrm{dL})\end{array}$ & $8,6 \pm 1,6$ & $8,9 \pm 1,7$ & $9,6 \pm 1,8$ & $10,3 \pm 19$ & $10,6 \pm 1,6$ & $11,6 \pm 1,8$ & $11,2 \pm 1,8$ & $12,0 \pm 2,5$ & $11,5 \pm 2,2$ & $12,1 \pm 2,4$ & 0,029 \\
\hline
\end{tabular}

Os dados são apresentados como média \pm DP; eGFR, taxa de filtração glomerular estimada (calculada com a equação de 4 variáveis MDRD); AST: aspartato aminotransferase; ALT: alanina aminotransferase; $\mathrm{DP}=$ desvio padrão. 
A tabela 10 mostra a concentração mínima de tacrolimo $\left(\mathrm{C}_{0}\right)$ e a dose de prednisona $(\mathrm{mg} / \mathrm{dia})$. As diferenças nas concentrações de tacrolimo $\left(\mathrm{C}_{0}\right)$ e nas doses de prednisona (mg/dia) não foram estatisticamente significativas entre os dois grupos, durante os períodos do estudo.

Tabela 10. Doses e concentrações de drogas imunossupressoras combinados ao MPA em cada período pós-transplante

\begin{tabular}{|c|c|c|c|c|c|c|c|c|c|c|}
\hline \multirow[t]{2}{*}{ Dias } & \multicolumn{2}{|c|}{7} & \multicolumn{2}{|c|}{30} & \multicolumn{2}{|c|}{60} & \multicolumn{2}{|c|}{90} & \multicolumn{2}{|c|}{180} \\
\hline & $\begin{array}{c}\text { Idosos } \\
\text { n=42 } \\
\text { (Média } \pm D P \text { ) }\end{array}$ & $\begin{array}{l}\text { Controles } \\
\qquad \mathbf{n = 3 0} \\
(\text { Média } \pm D P)\end{array}$ & $\begin{array}{c}\text { Idosos } \\
\text { n=37 } \\
\text { (Média } \pm D P \text { ) }\end{array}$ & $\begin{array}{l}\text { Controles } \\
\qquad \mathbf{n = 1 4} \\
\text { (Média } \pm D P)\end{array}$ & $\begin{array}{c}\text { Idosos } \\
\text { n=22 } \\
\text { (Média } \pm D P \text { ) }\end{array}$ & $\begin{array}{l}\text { Controles } \\
\qquad \mathbf{n = 2 2} \\
\text { (Média } \pm D P)\end{array}$ & $\begin{array}{c}\text { Idosos } \\
\text { n=18 } \\
\text { (Média } \pm D P \text { ) }\end{array}$ & $\begin{array}{l}\text { Controle } \\
\text { n=19 } \\
\text { (Média } \pm D P \text { ) }\end{array}$ & $\begin{array}{c}\text { Idosos } \\
\text { n=17 } \\
\text { (Média } \pm D P \text { ) }\end{array}$ & $\begin{array}{c}\text { Controles } \\
\text { n=14 } \\
\text { (Média } \pm \text { DP) }\end{array}$ \\
\hline Tacrolimo $\left(C_{0}\right) \mathrm{ng} / \mathrm{mL}$ & $7,7 \pm 6,0$ & $5,9 \pm 2,5$ & $6,4 \pm 3,2$ & $7,4 \pm 4,6$ & $7,1 \pm 3,9$ & $7,7 \pm 5,0$ & $5,8 \pm 3,5$ & $6,3 \pm 3,4$ & $4,7 \pm 2,6$ & $5,2 \pm 2,2$ \\
\hline Prednisona dose (mg/dia) & $27,4 \pm 8,4$ & $26,4 \pm 11,2$ & $6,1 \pm 3,9$ & $5,3 \pm 1,2$ & $6,5 \pm 5,3$ & $5,4 \pm 6,34$ & $6,4 \pm 5,3$ & $5,2 \pm 1,5$ & $6,3 \pm 5,3$ & $5,1 \pm 1,2$ \\
\hline
\end{tabular}

$\mathrm{DP}=$ desvio padrão 


\subsection{Resultados da Farmacocinética}

Estudou-se um total de 264 PKs de ácido micofenólico com coletas de 0 - 12 horas após a dose. Inicialmente com 42 idosos comparados com 31 receptores mais jovens que receberam Micofenolato Sódico (EC-MPS)/Tacrolimo(TAC)/Prednisona em cinco

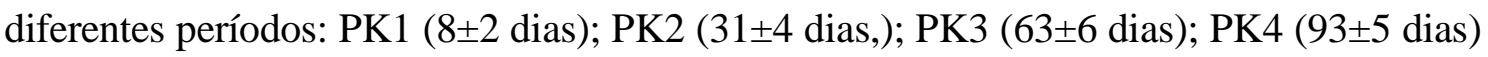
e PK5 (185 \pm 10 dias).

\section{Farmacocinética do Ácido Micofenólico (MPA)}

Na Tabela 11 estão demonstrados os parâmetros da farmacocinética (PK) para os dois grupos, em cada período de tempo após o transplante. O número de pacientes avaliados, em cada grupo, em um período específico é exibido na tabela.

A dose de EC-MPS ajustada por peso corporal foi estatisticamente menor no grupo de idosos $(p=0,0492)$, entre períodos $(p=0,001)$, mas sem interação entre grupos *períodos $(p=0,3257)$.

A concentração antes da dose $\left(\mathrm{C}_{0}\right)$ foi numericamente mais baixa no grupo idoso em todos os períodos pós-transplante. No entanto, ao longo dos primeiros 6 meses não foi estatisticamente diferente entre períodos $(p=0,0971)$, entre grupos $(p=0,063) \mathrm{e}$ sem interação períodos * grupos $(p=0,819)$.

A concentração máxima $(\mathrm{Cmax})$ foi numericamente menor no idoso em todos os períodos avaliados. Ao longo dos primeiros 6 meses, a Cmax foi menor no grupo de idosos entre períodos $(\mathrm{p}=0,003)$, entre grupos $(p=0,007)$ e sem interação entre períodos * grupos $(\mathrm{p}=0,745)$. 
Da mesma forma, Cmax ajustada por dose e peso $(\mathrm{mg} / \mathrm{kg})$ tendeu a ser menor entre grupos $(p=0,051)$, mas foi menor entre períodos $(p=0,002)$ sem interação períodos* grupos $(p=0,589)$.

O tempo para atingir a máxima absorção (Tmax) não apresentou diferenças estatisticamente significativas em todos os períodos avaliados. Ao longo dos primeiros 6 meses, a Tmax foi semelhante entre períodos $(p=0,6173)$, entre grupos $(p=0,8720)$ e sem interação entre períodos * grupos $(\mathrm{p}=0,9790)$.

A $\mathrm{AUC}_{0-720 \mathrm{~min}(0-12 \mathrm{hs})}$ absoluta no idoso foi menor durante os primeiros 6 meses ( $p=0,0168)$. Ao analisar, separadamente cada período, a diferença foi estatisticamente significativa em 30, 90 e 180 dias após o transplante.

No entanto, a área sob a curva ajustada pela dose e peso, adj $\mathrm{AUC}_{0-720 \mathrm{~min}}$, embora numericamente menor aos 7, 30, 90 e 180 dias não apresentou diferença estatisticamente significativa quando avaliados os dados dos dois grupos por períodos $(p=0,553)$, entre grupos $(p=0,177)$ e por períodos $*$ grupos $(p=0,512)$. Estes dados estão demonstrados graficamente nas Figuras 6, 7, 8, 9 e 10.

A Depuração Corporal Total de MPA (Total Body Clearance) estimada (L/h/Kg) não apresentou diferenças estatisticamente significativas entre os grupos $(p=0,5006)$, mas foi menor entre períodos $(\mathrm{p}=0,0084)$ e não apresentou diferenças estatisticamente significativas na interação entre período*grupo $(p=0,7237)$.

A Meia-Vida de eliminação de MPA estimada, não apresentou diferenças estatisticamente significativas entre grupos $(p=0,7166)$, entre períodos $(p=0,3504) \mathrm{e}$ sem interação entre períodos*grupos $(p=0,4281)$.

A Porcentagem de flutuação foi similar nos dois grupos em todos os períodos avaliados. Nos seis primeiros meses foi menor no grupo de idosos, com diferenças estatisticamente significativas entre períodos $(p=0,0006)$, mas não entre grupos $(p=0,9159)$ e sem interação entre períodos* grupos $(p=0,9213)$. 
Tabela 11. Resumo descritivo dos parâmetros farmacocinéticos de MPA avaliados em cinco períodos longitudinais em transplantados renais idosos e jovens

\begin{tabular}{|c|c|c|c|c|c|c|c|c|c|c|c|c|c|}
\hline \multirow[t]{2}{*}{ Parâmetros da PK } & \multicolumn{2}{|c|}{$\begin{array}{c}7 \text { Dias } \\
\text { (Média } \pm D P)\end{array}$} & \multicolumn{2}{|c|}{$\begin{array}{c}30 \text { Dias } \\
(\text { Média } \pm D P)) \\
\end{array}$} & \multicolumn{2}{|c|}{$\begin{array}{c}60 \text { Dias } \\
(\text { Média } \pm D P) \\
\end{array}$} & \multicolumn{2}{|c|}{$\begin{array}{c}90 \text { Dias } \\
(\text { Média } \pm D P) \\
\end{array}$} & \multicolumn{2}{|c|}{$\begin{array}{c}180 \text { Dias } \\
(\text { Média } \pm D P)\end{array}$} & \multirow{2}{*}{$\begin{array}{c}\begin{array}{c}\text { Valor } \\
\text { de } p\end{array} \\
\text { Período }\end{array}$} & \multirow{2}{*}{$\begin{array}{c}\text { Valor } \\
\text { de } p\end{array}$} & \multirow{2}{*}{$\begin{array}{c}\text { Valor } \\
\text { de } \boldsymbol{p}\end{array}$} \\
\hline & $\begin{array}{c}\text { Idosos } \\
\mathrm{n}=42\end{array}$ & $\begin{array}{c}\text { Controles } \\
\mathbf{n}=30\end{array}$ & $\begin{array}{c}\text { Idosos } \\
\mathbf{n}=37\end{array}$ & $\begin{array}{c}\text { Controles } \\
n=24\end{array}$ & $\begin{array}{c}\text { Idosos } \\
\mathrm{n}=22\end{array}$ & $\begin{array}{c}\text { Controles } \\
\mathrm{n}=\mathbf{2 2}\end{array}$ & $\begin{array}{c}\text { Idosos } \\
\mathrm{n}=18\end{array}$ & $\begin{array}{c}\text { Controles } \\
n=19\end{array}$ & $\begin{array}{c}\text { Idosos } \\
\mathrm{n}=17\end{array}$ & $\begin{array}{c}\text { Controles } \\
n=14\end{array}$ & & & \\
\hline $\begin{array}{l}\text { EC-MPS dose } \\
\text { diária } \\
(\mathrm{mg} / \mathrm{dia})\end{array}$ & $1388 \pm 150$ & $1392 \pm 156$ & $1382 \pm 157$ & $1320 \pm 252$ & $1276 \pm 288$ & $1325 \pm 204$ & $1280 \pm 254$ & $1307 \pm 215$ & $1080 \pm 337$ & $1208 \pm 268$ & $<0,001$ & 0,2730 & 0,2526 \\
\hline $\begin{array}{l}\text { EC-MPS dose } \\
(\mathrm{mg} / \mathrm{Kg} / \mathrm{dia})\end{array}$ & $10,41 \pm 2,47$ & $11,25 \pm 3,21$ & $10,79 \pm 2,23$ & $11,25 \pm 2,74$ & $9,87 \pm 2,99$ & $11,05 \pm 2,58$ & $9,62 \pm 2,55$ & $10,81 \pm 2,69$ & $8,03 \pm 2,57$ & $10,58 \pm 3,01$ & $<0,001$ & 0,0492 & 0,3257 \\
\hline $\begin{array}{l}\mathrm{AUC}_{\text {Tau }} \\
(\mu \mathrm{g} \cdot \mathbf{h} / \mathbf{m L})\end{array}$ & $45,63 \pm 55,15$ & $62,62 \pm 53,98$ & $40,64 \pm 21,69$ & $63,01 \pm 50,97$ & $55,26 \pm 36,41$ & $62,20 \pm 41,63$ & $43,5 \pm 14,32$ & $63,01 \pm 38,08$ & $33,46 \pm 21,86$ & $58,30 \pm 33,94$ & 0,6587 & 0,0168 & 0,8786 \\
\hline $\begin{array}{l}\mathrm{AUC}_{\text {Tau_D }} \\
(\boldsymbol{\mu g} \cdot \mathbf{h} / \mathbf{m L} / \mathbf{m g} / \mathbf{K g})\end{array}$ & $4,67 \pm 6,82$ & $6,53 \pm 6,68$ & $3,80 \pm 2,08$ & $5,62 \pm 4,22$ & $6,27 \pm 5,21$ & $5,62 \pm 3,36$ & $4,55 \pm 1,36$ & $5,94 \pm 3,50$ & $4,12 \pm 2,59$ & $6,02 \pm 3,67$ & 0,5128 & 0,1773 & 0,6128 \\
\hline$C_{\max }(\mu \mathrm{g} / \mathrm{mL})$ & $10,90 \pm 11,11$ & $13,75 \pm 8,72$ & $14,29 \pm 9,73$ & $20,59 \pm 15,02$ & $18,73 \pm 10,77$ & $21,25 \pm 19,35$ & $17,86 \pm 11,91$ & $22,05 \pm 12,36$ & $12,05 \pm 7,64$ & $20,24 \pm 8,51$ & 0,0028 & 0,0066 & 0,7452 \\
\hline $\begin{array}{l}\mathrm{C}_{\max \_\mathrm{D}} \\
(\mu \mathrm{gg} / \mathrm{mL} / \mathrm{mg} / \mathrm{kg})\end{array}$ & $1,10 \pm 1,32$ & $1,35 \pm 1,00$ & $1,35 \pm 0,96$ & $1,91 \pm 1,40$ & $1,98 \pm 1,00$ & $1,94 \pm 1,70$ & $1,82 \pm 1,02$ & $2,10 \pm 1,24$ & $1,44 \pm 0,72$ & $2,09 \pm 0,95$ & 0,0024 & 0,0513 & 0,5899 \\
\hline $\mathbf{T}_{\max }(\mathbf{h})$ & $2,06 \pm 2,12$ & $2,33 \pm 2,70$ & $2,52 \pm 1,75$ & $2,65 \pm 1,88$ & $2,18 \pm 1,14$ & $2,21 \pm 1,56$ & $2,10 \pm 0,84$ & $2,02 \pm 0,95$ & $2,65 \pm 2,49$ & $2,32 \pm 1,08$ & 0,6173 & 0,8720 & 0,9790 \\
\hline $\mathrm{C}_{0}(\mu \mathrm{g} / \mathrm{mL})$ & $1,63 \pm 2,21$ & $2,43 \pm 2,68$ & $1,11 \pm 0,71$ & $1,82 \pm 2,07$ & $1,40 \pm 1,17$ & $1,9 \pm 1,49$ & $1,17 \pm 0,73$ & $1,44 \pm 1,20$ & $0,86 \pm 0,61$ & $1,95 \pm 2,04$ & 0,0971 & 0,0639 & 0,8193 \\
\hline $\mathrm{C}_{\text {avg }}(\mu \mathrm{g} / \mathrm{mL})$ & $3,81 \pm 4,59$ & $5,22 \pm 4,50$ & $3,38 \pm 1,81$ & $5,24 \pm 4,26$ & $4,59 \pm 3,03$ & $5,18 \pm 3,47$ & $3,62 \pm 1,19$ & $5,25 \pm 3,17$ & $2,79 \pm 1,83$ & $4,86 \pm 2,83$ & 0,6634 & 0,0166 & 0,8818 \\
\hline \%Fluctuation & $269 \pm 144$ & $302 \pm 239$ & $402 \pm 253$ & $413 \pm 257$ & $400,62 \pm 208$ & $372 \pm 185$ & $440 \pm 229$ & $405 \pm 145$ & $445 \pm 214$ & $425 \pm 156$ & 0,0006 & 0,9159 & 0,9213 \\
\hline HL_lambda_z (h) & $7,36 \pm 3,28$ & $8,15 \pm 6,26$ & $9,84 \pm 10,13$ & $7,19 \pm 4,75$ & $10,95 \pm 17,23$ & $10,93 \pm 11,36$ & $8,95 \pm 9,13$ & $7,38 \pm 3,3$ & $8,07 \pm 6,89$ & $13,99 \pm 9,89$ & 0,3504 & 0,7166 & 0,4281 \\
\hline Clss_F $_{\text {F }}(\mathbf{L} / \mathbf{h} / \mathbf{k g})$ & $0,40 \pm 0,26$ & $0,38 \pm 0,43$ & $0,35 \pm 0,20$ & $0,31 \pm 0,25$ & $0,23 \pm 0,13$ & $0,28 \pm 0,23$ & $0,24 \pm 0,10$ & $0,26 \pm 0,22$ & $0,33 \pm 0,18$ & $0,23 \pm 0,13$ & 0,0084 & 0,5006 & 0,7237 \\
\hline
\end{tabular}

$\mathrm{DP}=$ desvio padrão; Tau (horas): tempo da curva completa (12hs); $\mathrm{AUC}_{0-12 \mathrm{hs}}(\mu \mathrm{g} \cdot \mathrm{h} / \mathrm{mL}$ ): Área sob a curva no intervalo de 12 horas; Tmax (horas): Tempo em que ocorre a máxima concentração Cmax $(\mu \mathrm{g} / \mathrm{mL})$ : Concentração máxima;Cmin $(\mu \mathrm{g} / \mathrm{mL})$ : Concentração mínima; Cavg $(\mu \mathrm{g} / \mathrm{mL}$ ): Área sob curva desde o tempo de dose até Tau dividido por (tempo da dose + Tau); \% De flutuação: $=100 *$ (Cmax-Cmin) / Cavg. Para Cmin e Cmax entre o tempo de dose e Tau; HL_Lambda_z (horas): Meia-vida terminal; Clss_F (L / hr / kg): Estimativa da depuração corporal total normalizada pela dose e peso de cada paciente 


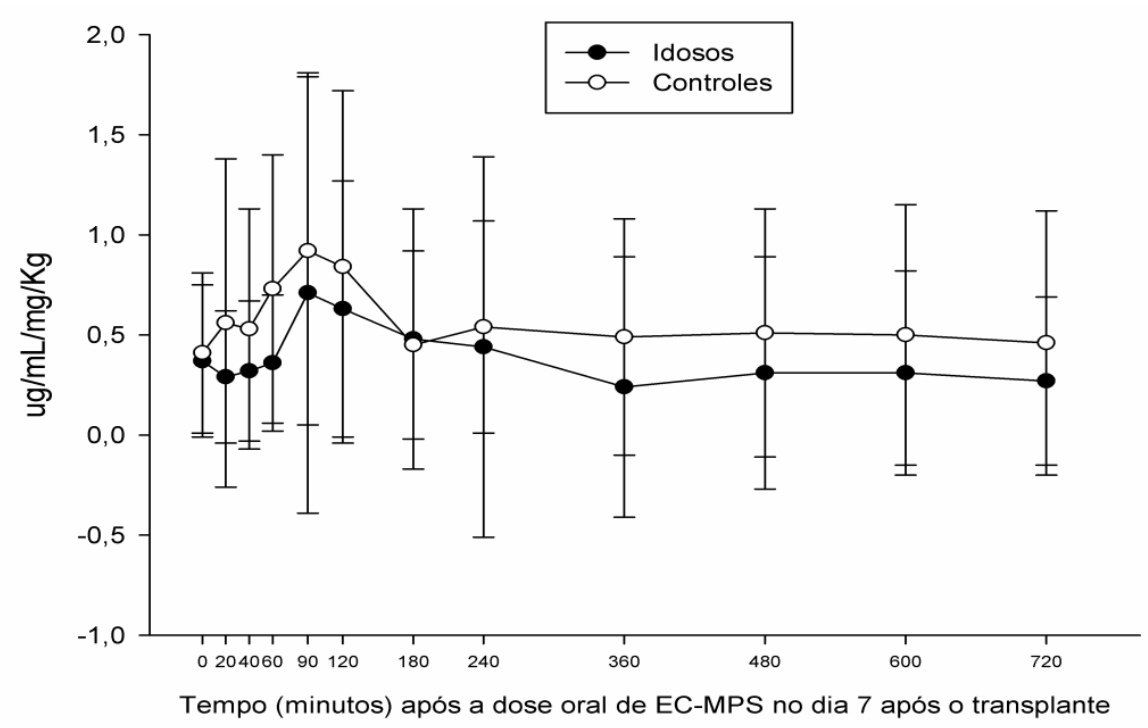

Figura 6. Concentração média \pm DP de MPA ajustado por dose e peso ( $\mu \mathrm{g} / \mathrm{mL}$ por $\mathrm{mg} / \mathrm{kg}$ ) durante os 720 minutos imediatamente após a dose oral de EC-MPS, 7 dias após o transplante renal em idosos e adultos jovens

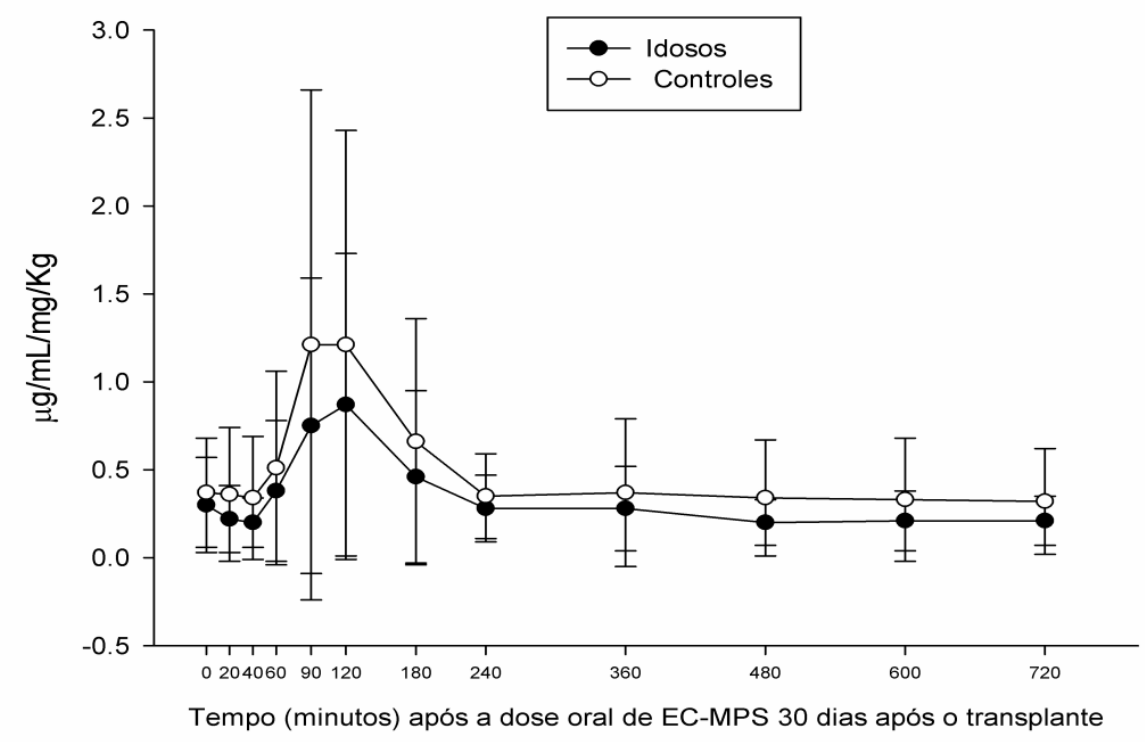

Figura 7. Concentração média \pm DP de MPA ajustado por dose e peso $(\mu \mathrm{g} / \mathrm{mL}$ por $\mathrm{mg} / \mathrm{kg}$ ) durante os 720 minutos imediatamente após a dose oral de EC-MPS, 30 dias após o transplante renal em idosos e adultos jovens 


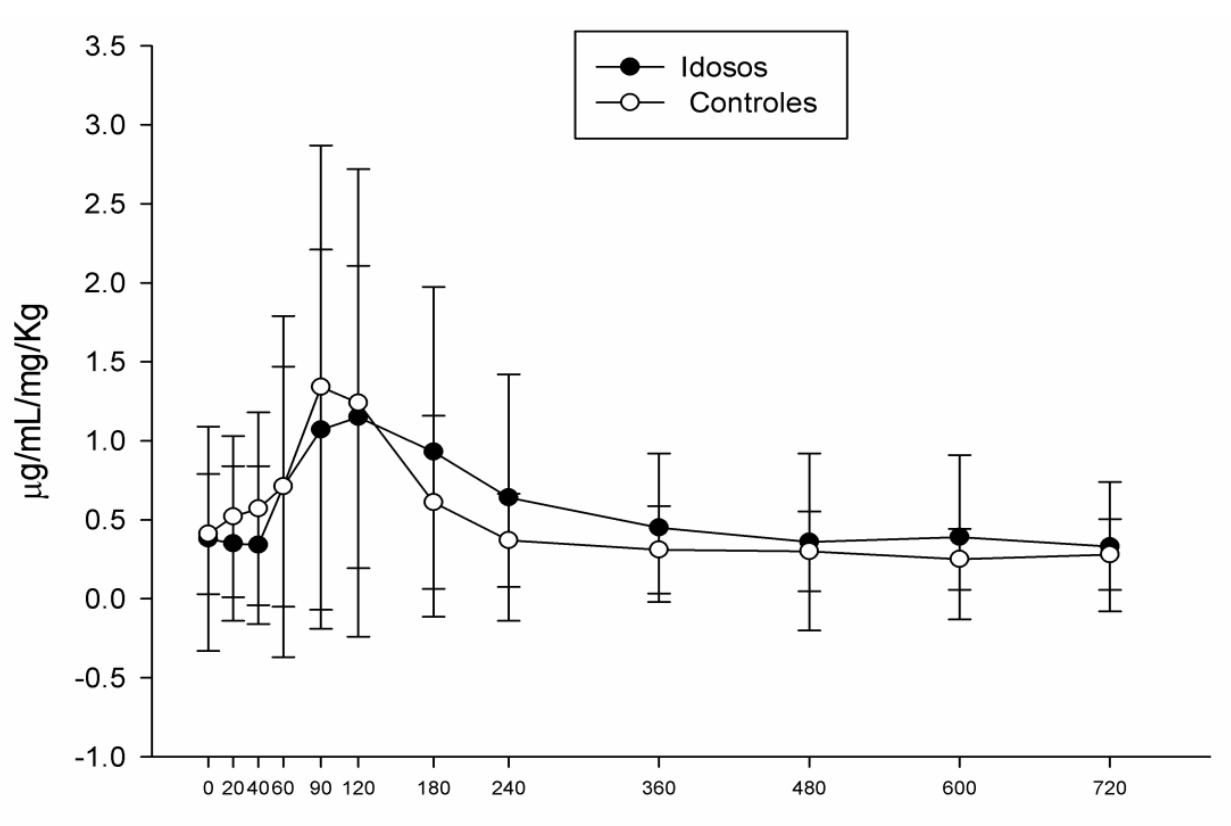

Tempo (minutos) após a dose oral de EC-MPS 60 dias após o transplante

Figura 8. Concentração média \pm DP de MPA ajustado por dose e peso ( $\mu \mathrm{g} / \mathrm{mL}$ por $\mathrm{mg} / \mathrm{kg}$ ) durante os 720 minutos imediatamente após a dose oral de EC-MPS, 60 dias após o transplante renal em idosos e adultos jovens

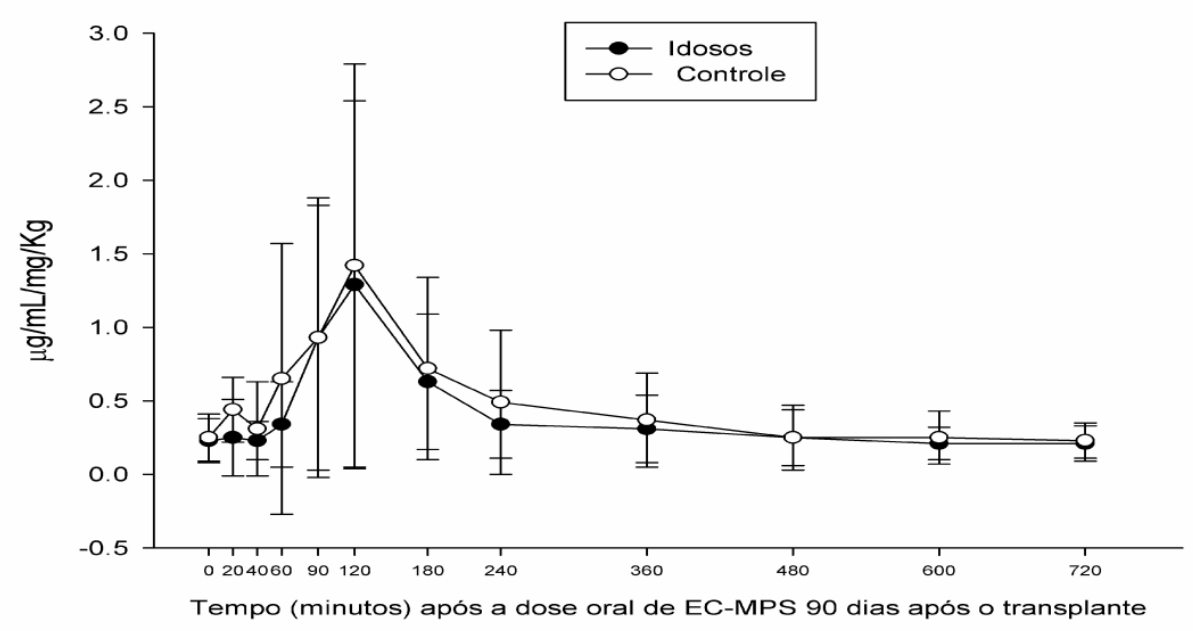

Figura 9. Concentração média \pm DP de MPA ajustado por dose e peso ( $\mu \mathrm{g} / \mathrm{mL}$ por $\mathrm{mg} / \mathrm{kg}$ ) durante os 720 minutos imediatamente após a dose oral de EC-MPS , 90 dias após o transplante renal em idosos e adultos jovens 


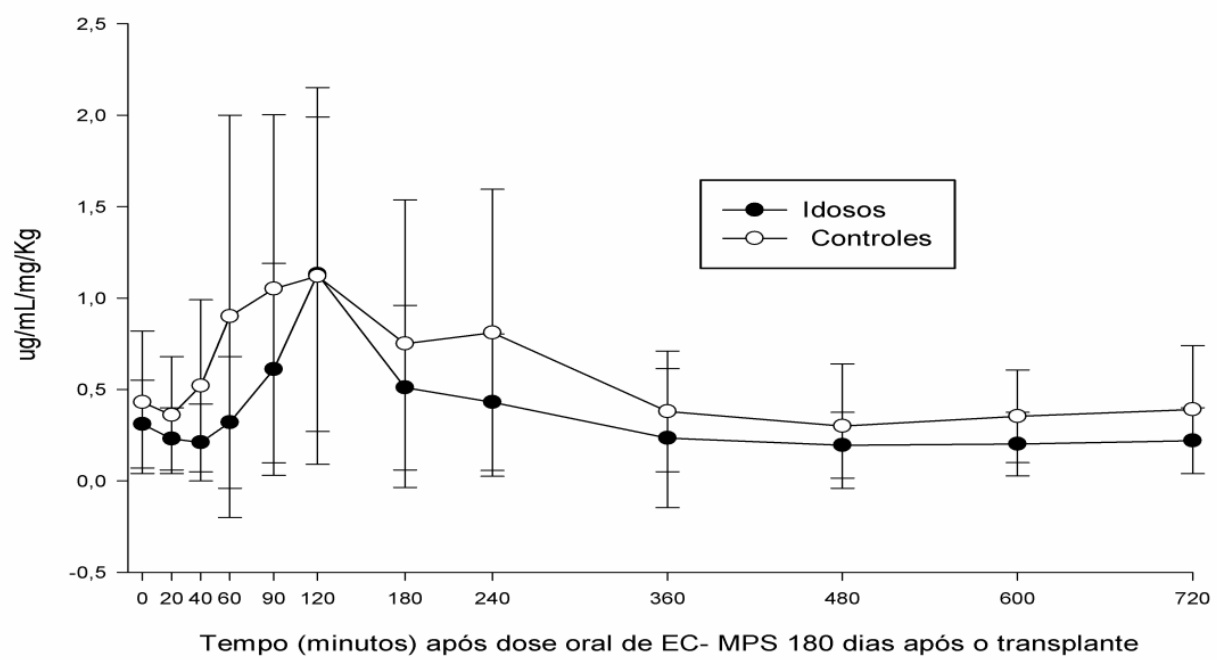

Figura 10. Concentração média \pm DP de MPA ajustado por dose e peso $(\mu \mathrm{g} / \mathrm{mL}$ por $\mathrm{mg} / \mathrm{kg}$ ) durante os 720 minutos imediatamente após a dose oral de EC-MPS, 180 dias após o transplante renal em idosos e adultos jovens

Na tabela 12 demonstramos a presença do segundo pico MPA que foi detectado em uma porcentagem semelhante de pacientes em ambos os grupos (cerca de 70\%) e ocorreu em tempo após a dose, semelhante (média de aproximadamente 9 horas). A média de concentração do segundo pico de MPA representou 30\% nos idosos e 33\% no grupo controle, em relação com a concentração média do primeiro pico de MPA e não foi estatisticamente diferente entre os grupos.

Tabela 12. Segundo pico de MPA em cada período de coleta após o transplante renal nos grupos de idosos e controles

\begin{tabular}{|c|c|c|c|c|c|c|c|c|c|}
\hline $\begin{array}{l}\text { Dias } \\
\text { da } \\
\text { PK }\end{array}$ & $\begin{array}{c}\text { Idosos } \\
\mathbf{n}\end{array}$ & $\begin{array}{c}\mathbf{n}(\%) \\
\text { com } \\
\text { Segundo } \\
\text { Pico }\end{array}$ & $\begin{array}{c}\text { Tempo } \\
\text { para o } \\
\text { Segundo } \\
\text { pico } \\
\text { (hs) } \\
\end{array}$ & $\begin{array}{c}\text { Controles } \\
\mathbf{n}\end{array}$ & $\begin{array}{c}n(\%) \\
\text { com } \\
\text { Segundo } \\
\text { Pico }\end{array}$ & $\begin{array}{c}\text { Tempo } \\
\text { para o } \\
\text { Segundo } \\
\text { pico } \\
\text { (hs) } \\
\end{array}$ & $\begin{array}{c}\text { Média } \pm \mathrm{DP} \\
\text { do Segundo } \\
\text { pico de MPA } \\
(\mu \mathrm{g} / \mathrm{mL}) \\
(\text { Idosos) } \\
\end{array}$ & $\begin{array}{c}\text { Média } \pm \mathrm{DP} \\
\text { do Segundo } \\
\text { pico de MPA } \\
(\mu \mathrm{g} / \mathrm{mL}) \\
(\text { Controles }) \\
\end{array}$ & $\begin{array}{c}\text { valor } \\
\text { de } p\end{array}$ \\
\hline 7 & 42 & $24(57)$ & 9,2 & 30 & $20(57)$ & 8,4 & $4,88 \pm 5,69$ & $7,71 \pm 5,84$ & 0,122 \\
\hline 30 & 37 & $29(78)$ & 9,5 & 24 & $18(74)$ & 9,5 & $3,57 \pm 1,94$ & $5,68 \pm 5,82$ & 0,079 \\
\hline 60 & 22 & $17(77)$ & 9,6 & 22 & $15(68)$ & 9,5 & $5,00 \pm 3,75$ & $6,07 \pm 4,11$ & 0,448 \\
\hline 90 & 18 & $14(78)$ & 9,0 & 19 & $14(74)$ & 9,0 & $3,76 \pm 1,78$ & $5,47 \pm 3,44$ & 0,110 \\
\hline 180 & 17 & $6(35)$ & 9,0 & 14 & $10(71)$ & 9,8 & $4,17 \pm 4,23$ & $5,59 \pm 4,09$ & 0,500 \\
\hline
\end{tabular}


Não foram verificadas diferenças estatisticamente significativas entre os dois grupos, em todos os períodos avaliados após o transplante renal.

A tabela 13 mostra as $\mathrm{AUC}_{0-720 \text { min }}$ de MPAG e a relação MPAG/MPA nos dois grupos estudados, o que reflete a circulação entero-hepática. A relação entre o metabólito primário e a parte ativa da droga (MPAG/MPA) $(\mu \mathrm{g} \cdot \mathrm{h} / \mathrm{mL})$, é um indicador da circulação entero-hepática e foi numericamente, menor no grupo controle em todos os períodos do estudo farmacocinético. Para a $\mathrm{AUC}_{0-720 \min }(\mu \mathrm{g} \cdot \mathrm{h} / \mathrm{mL})$ de MPAG as diferenças foram estatisticamente significativas entre os grupos no dia $7(p=0,039)$ e no dia $60(p=0,020)$.

Tabela 13. MPAG-AUC ${ }_{0-720 \text { min }}$ e relação MPAG/MPA em cada período de coleta após o transplante renal nos dois grupos estudados

\begin{tabular}{|c|c|c|c|c|c|c|c|}
\hline $\begin{array}{l}\text { Dias } \\
\text { da } \\
\text { PK }\end{array}$ & $\begin{array}{c}\text { Idosos } \\
\text { n }\end{array}$ & $\begin{array}{c}\text { Média MPAG } \\
\mathrm{AUC}_{0-720 \min } \\
(\mu \mathrm{g} \cdot \mathrm{h} / \mathrm{mL}) \\
(\mathbf{I d o s o s})\end{array}$ & $\begin{array}{c}\text { Relação } \\
\text { MPAG/MPA } \\
(\mu \mathrm{g} \cdot \mathbf{h} / \mathbf{m L}) \\
(\text { Idosos })\end{array}$ & $\begin{array}{c}\text { Controles } \\
\mathbf{n}\end{array}$ & $\begin{array}{c}\text { Média MPAG } \\
\mathrm{AUC}_{0-720 \mathrm{~min}} \\
(\boldsymbol{\mu g} \cdot \mathbf{h} / \mathbf{m L}) \\
(\text { Controles })\end{array}$ & $\begin{array}{c}\text { Relação } \\
\text { MPAG/MPA } \\
(\mu \mathrm{g} \cdot \mathrm{h} / \mathrm{mL}) \\
(\text { Controles })\end{array}$ & $\begin{array}{c}\text { valor } \\
\text { de } p\end{array}$ \\
\hline 7 & 42 & $2240 \pm 1915$ & 49 & 30 & $1217 \pm 1208$ & 19 & 0,039 \\
\hline 30 & 37 & $938 \pm 685$ & 23 & 24 & $967 \pm 1756$ & 15 & 0,714 \\
\hline 60 & 22 & $1413 \pm 1824$ & 26 & 22 & $593 \pm 3883$ & 10 & 0,020 \\
\hline 90 & 18 & $741 \pm 366$ & 17 & 19 & $629 \pm 332$ & 10 & 0,289 \\
\hline 180 & 17 & $1324 \pm 1136$ & 40 & 14 & $872 \pm 552$ & 15 & 0,150 \\
\hline
\end{tabular}

A Tabela 14 mostra a porcentagem de pacientes em cada grupo que recebeu doses diárias completas ou reduzidas de EC-MPS, bem como o número de pacientes dentro, acima ou abaixo da janela terapêutica estabelecida para MPA $(30-60 \mu \mathrm{g} \cdot \mathrm{h} / \mathrm{mL})^{(120,121)}$. 
De acordo com o desenho do estudo de farmacocinética, as doses diárias de EC-MPS foram mantidas em $1440 \mathrm{mg} /$ dia e apenas foram reduzidas devido à presença de efeitos adversos secundários: gastrointestinais (GI), leucopenia, episódios infecciosos, de acordo com avaliação clínica.

A porcentagem de pacientes com dose diária total de EC-MPS foi reduzida durante os seis primeiros meses em ambos os grupos. No grupo de idosos, o número de pacientes que receberam a dose diária completa de EC-MPS diminuiu de $88 \%$ para 35\% nos seis primeiros meses após o transplante, apesar desta alta frequência de pacientes idosos com dose diária menor que $1440 \mathrm{mg} / \mathrm{dia}$, a porcentagem dentro da janela terapêutica de MPA, aumentou de $50 \%$ para cerca de $70 \%$ do $7^{\circ}$ para o $180^{\circ}$ dia. A taxa de pacientes acima da janela terapêutica de MPA permaneceu em cerca de $17 \%$.

No grupo controle a porcentagem de pacientes que tomaram a dose completa de EC-MPS diminuiu de $90 \%$ para $50 \%$, a porcentagem dentro da janela terapêutica de MPA permaneceu estável e em torno de $30 \%$, e nesse grupo a porcentagem de pacientes acima da janela terapêutica de MPA aumentou progressivamente (Cerca de 40-50\%) do $7^{\circ}$ ao $180^{\circ}$ dia. 
Tabela 14. Doses diárias de EC-MPS e a $\mathrm{AUC}_{0-720 m i n}$ de MPA nos cinco períodos longitudinais em pacientes idosos e de controles

\begin{tabular}{|c|c|c|c|c|c|c|c|c|c|c|}
\hline \multirow{2}{*}{$\begin{array}{c}\text { DIAS DA } \\
\text { FARMACOCINÉTICA }\end{array}$} & \multicolumn{2}{|c|}{7} & \multicolumn{2}{|c|}{30} & \multicolumn{2}{|c|}{60} & \multicolumn{2}{|c|}{90} & \multicolumn{2}{|c|}{180} \\
\hline & $\begin{array}{l}\text { Idosos } \\
\mathrm{n}=\mathbf{4 2}\end{array}$ & $\begin{array}{l}\text { Controles } \\
\qquad \mathbf{n}=\mathbf{3 0}\end{array}$ & $\begin{array}{l}\text { Idosos } \\
\mathbf{n}=\mathbf{3 7}\end{array}$ & $\begin{array}{c}\text { Controles } \\
\qquad \mathbf{n}=\mathbf{2 4}\end{array}$ & $\begin{array}{l}\text { Idosos } \\
\mathbf{n}=\mathbf{2 2}\end{array}$ & $\begin{array}{l}\text { Controles } \\
\qquad \mathbf{n}=\mathbf{2 2}\end{array}$ & $\begin{array}{l}\text { Idosos } \\
\mathbf{n}=\mathbf{1 8}\end{array}$ & $\begin{array}{l}\text { Controles } \\
\qquad \mathbf{n}=19\end{array}$ & $\begin{array}{l}\text { Idosos } \\
\mathrm{n}=17\end{array}$ & $\begin{array}{l}\text { Controles } \\
\qquad \mathbf{n}=14\end{array}$ \\
\hline EC-MPS Dose 1440 mg/dia & $37(88 \%)$ & $27(90 \%)$ & $32(87 \%)$ & $19(79 \%)$ & $15(68 \%)$ & $16(73 \%)$ & $12(64 \%)$ & $13(77 \%)$ & $6(35 \%)$ & $7(50 \%)$ \\
\hline AUC 30-60 $\mu \mathrm{g.h} / \mathrm{mL}$ & $20(54 \%)$ & $9(33 \%)$ & $18(56 \%)$ & $6(31 \%)$ & $8(53 \%)$ & $5(32 \%)$ & $9(75 \%)$ & $4(31 \%)$ & $4(67 \%)$ & $2(28 \%)$ \\
\hline AUC $<30 \mu \mathrm{g} . \mathbf{h} / \mathrm{mL}$ & $11(30 \%)$ & $8(30 \%)$ & $9(28 \%)$ & $5(26 \%)$ & $4(27 \%)$ & $2(12 \%)$ & $1(8 \%)$ & $2(15 \%)$ & $1(17 \%)$ & $2(28 \%)$ \\
\hline AUC $>60 \mu \mathrm{g} . \mathrm{h} / \mathrm{mL}$ & $6(16 \%)$ & $10(37 \%)$ & $5(16 \%)$ & $8(42 \%)$ & $3(20 \%)$ & $9(56 \%)$ & $2(17 \%)$ & $7(54 \%)$ & $1(17 \%)$ & $3(43 \%)$ \\
\hline $\mathbf{p}=$ & \multicolumn{2}{|c|}{ NS } & \multicolumn{2}{|c|}{ NS } & \multicolumn{2}{|c|}{ NS } & \multicolumn{2}{|c|}{ NS } & \multicolumn{2}{|c|}{ NS } \\
\hline EC-MPS Dose $\leq 1080 \mathrm{mg} / \mathrm{dia}$ & $5(12 \%)$ & $3(10 \%)$ & $5(13 \%)$ & $5(21 \%)$ & $7(32 \%)$ & $6(27 \%)$ & $6(33 \%)$ & $6(31 \%)$ & $11(65 \%)$ & $7(50 \%)$ \\
\hline
\end{tabular}

$\mathrm{NS}=$ diferenças estatisticamente não significativas entre os grupos $(\mathrm{p}>0,05)$ 


\section{Equações Abreviadas para Cálculo de MPA-AUC $\mathbf{C}_{0-12 \mathrm{~h}}$}

Analisamos as correlações entre a $\mathrm{AUC}_{0-12 \mathrm{~h}}$, com a combinação de diferentes tempos de coleta após a dose, para encontrar uma equação abreviada que estime a área sob a curva completa obtida pelo método trapezoidal, para EC-MPS na população estudada, o que reduziria os custos para (Tabela 15).

Tabela 15. Correlação entre MPA $\mathrm{AUC}_{0-12 \mathrm{~h}}$ calculada pelo método trapezoidal e MPA AUC estimada com estratégia reduzida de tempo de coleta de amostras

\begin{tabular}{|c|c|c|c|c|}
\hline & $\mathbf{r}^{2}$ & $\begin{array}{c}\text { Validação } \\
\mathbf{r}^{2}\end{array}$ & $\begin{array}{c}\text { Erro } \\
\text { padrão } \\
\text { estimado }\end{array}$ & $\begin{array}{c}\text { Média } \\
\text { AUC } \\
\text { estimada } \\
(\mu \mathrm{g} \cdot \mathbf{h} / \mathbf{m L})\end{array}$ \\
\hline 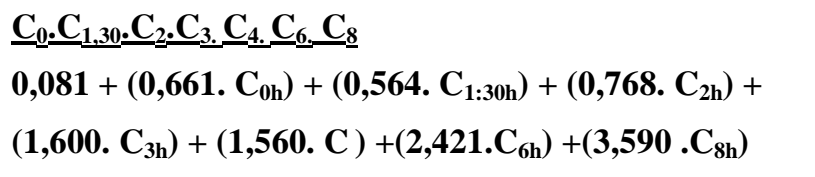 & 0,976 & 0,873 & 6,189 & $52,00 \pm 34,90$ \\
\hline 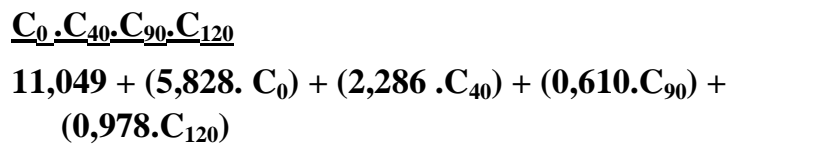 & 0,734 & 0,726 & 17,43 & $51,78 \pm 29,38$ \\
\hline $\begin{array}{l}\underline{C}_{0} \cdot C_{30} \cdot C_{90} \cdot \underline{C}_{120} \\
17,148+\left(1,25 \cdot C_{0}\right)+\left(3,43 \cdot C_{30}\right)+\left(0,477 \cdot C_{90}\right)+\left(1,219 \cdot C_{120}\right)\end{array}$ & 0,646 & 0,612 & 20,73 & $54,55 \pm 30,52$ \\
\hline $\begin{array}{l}\underline{C}_{40} \cdot \underline{C_{120}} \\
20,311+\left(4,660 . C_{40}\right)+\left(1,76 . C_{120}\right)\end{array}$ & 0,612 & 0,585 & 21,25 & $55,66 \pm 31,29$ \\
\hline
\end{tabular}

$r^{2}=$ coeficiente de explicação

A AUC média estimada com $\mathrm{C}_{0}$ e $\mathrm{C}_{120}$ foi de $46,71 \pm 16,17 \mu \mathrm{g} \cdot \mathrm{h} / \mathrm{mL}$, inferior às estimadas nas demais combinações.

A melhor equação que correlaciona a MPA-AUC ${ }_{0-12 h}$ (melhor parâmetro farmacocinético para avaliar a exposição ao MPA) foi a que combina $\mathrm{C}_{0} ; \mathrm{C}_{1: 30} ; \mathrm{C}_{2} ; \mathrm{C}_{3}$; $\mathrm{C}_{4} ; \mathrm{C}_{6}$ e $\mathrm{C}_{8}$ horas após a dose, quando se utiliza EC-MPS, esta equação foi validada na população idosa deste estudo. 
Porém, esta não seria uma equação abreviada, uma vez que o paciente estaria teria que ser submetido a várias coletas. Por este motivo, mesmo com uma correlação menor, a equação abreviada que vai de $\mathrm{C}_{0}$ até $\mathrm{C}_{2}$ horas pode ser mais adequada.

Na figura 11, apresentamos a representação gráfica da melhor equação abreviada testada e validada na população de idosos (59 pacientes) deste estudo.
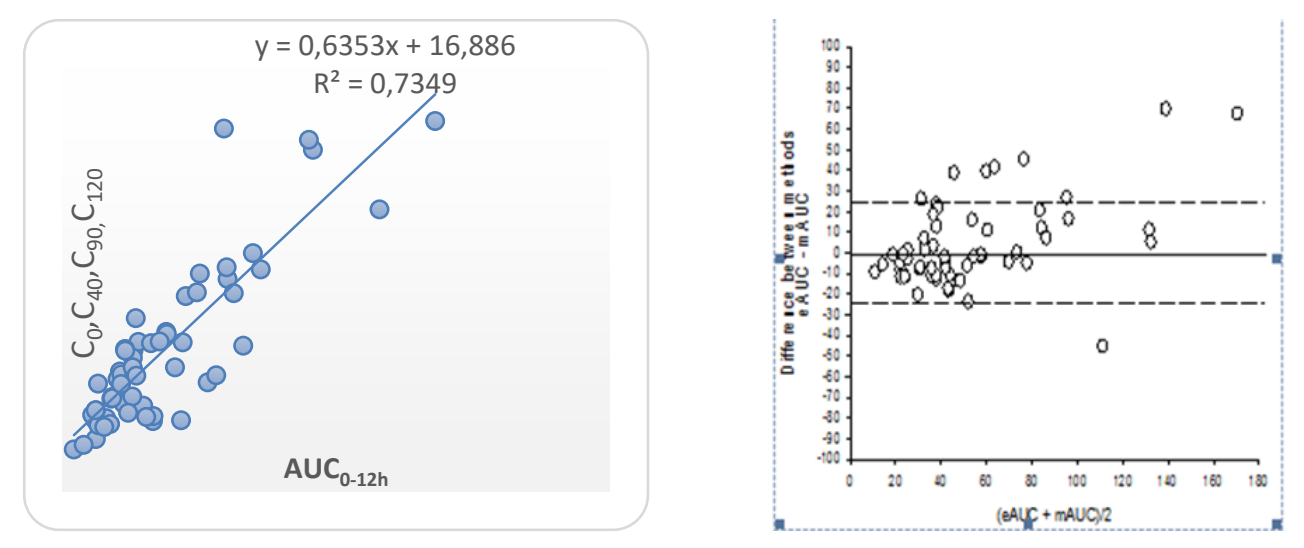

Figura 11. $\mathrm{AUC}_{0-12 \mathrm{~h}}(\mu \mathrm{g} \cdot \mathrm{h} / \mathrm{mL})$ calculada pelo método trapezoidal comparativamente à AUC estimada com $\mathrm{C}_{0} \cdot \mathrm{C}_{40} \cdot \mathrm{C}_{90} \cdot \mathrm{C}_{120}(\mu \mathrm{g} \cdot \mathrm{h} / \mathrm{mL})$ e Erro de Concordância estimado por Bland-Altman 


\section{DISCUSSÃO}

Neste estudo analisamos a farmacocinética longitudinal de MPA em receptores idosos nos primeiros seis meses após transplante renal, em comparação com pacientes adultos jovens. Encontramos no grupo de idosos parâmetros farmacocinéticos de MPA semelhantes aos do grupo controle.

Outros autores relataram resultados semelhantes para a farmacocinética do MPA em receptores idosos.

Tang e colaboradores avaliaram a farmacocinética e a farmacodinâmica do MPA em 26 pacientes idosos que receberam MMF e tacrolimo, em estudo transversal. O envelhecimento não modificou os parâmetros farmacocinéticos do MPA ou da atividade da inosina 5'-monofosfato dehidrogenase (IMPDH) antes ou após o transplante renal $^{(24)}$.

Diferentemente do nosso estudo, este estudo utilizou micofenolato mofetil e analisou apenas a AUC abreviada no sexto dia após o transplante, embora as concentrações mínimas e máximas de MPA tenham sido medidas nas semanas 3, 7 e 20

após o transplante ${ }^{(24)}$. Não há ainda relato de quantos pacientes utilizavam inibidores da bomba de próton e estes inibidores afetam a transformação de MMF para MPA ${ }^{(62)}$.

Da mesma forma, em um estudo de Miura e colaboradores que investigaram a farmacocinética transversal do MPA em 12 pacientes idosos em uso de MMF, os autores não evidenciaram diferenças significativas na farmacocinética ajustada de MPA na comparação entre idosos e um grupo controle mais jovem ${ }^{(22)}$. 
Por outro lado, em um estudo realizado com 24 idosos, transplantados renais, na China, a AUC não ajustada foi significantemente menor do que em jovens submetidos ao transplante renal no mesmo período avaliado ${ }^{(23)}$. É importante notar que neste estudo, o MMF foi administrado em combinação com a ciclosporina, o que poderia explicar os resultados contrastantes aos obtidos por Miura e colaboradores ${ }^{(22)}$.

Embora nosso estudo corrobore com os encontrados por Tang e Miura e seus colaboradores, ele acrescenta informações à literatura, por ser um estudo de AUC completa, ao longo dos seis primeiros meses de transplante, utilizando a associação de EC-MPS e tacrolimo.

Em contraste com o nosso estudo, que foi uma análise longitudinal realizada em diferentes momentos após o transplante renal, os estudos discutidos acima foram análises transversais.

Neste contexto, é interessante notar que ao analisarmos apenas os resultados de MPA-AUC ${ }_{0-12 \mathrm{hs}}$ nos dias $7^{\circ}$ e $30^{\circ}$ dia após o transplante poder-nos-ia levar a concluir, erroneamente, que os pacientes idosos apresentariam uma MPA-AUC $\mathrm{A}_{0-12 \mathrm{hs}}$ mais baixa em comparação à população mais jovem, o que não foi confirmado pela análise longitudinal de seis meses.

O conhecimento do efeito do envelhecimento no metabolismo de drogas, e neste caso um imunossupressor, é crucial, considerando o crescente número de idosos em lista de espera para transplante renal, de coração, pulmão e outros órgãos sólidos ${ }^{(122)}$.

Em nosso estudo, definimos como idosos pacientes que tinham idade igual ou superior à 60 anos, no momento do transplante. Esta definição foi proposta pela Organização Mundial de Saúde (OMS) para idosos na África e outros países em desenvolvimento $^{(123)}$. Apesar de termos utilizado um limiar de idade de 60 anos, nossa coorte de idosos tinha uma média de idade de 65 anos no momento do transplante, 
sendo em torno de 30 anos mais velhos que o grupo controle. Portanto, nossos resultados podem ser extrapolados para pacientes de países desenvolvidos, onde os idosos são considerados com idade superior à 65 anos.

O envelhecimento pode acarretar mudanças no metabolismo de muitas drogas. O fluxo hepático total e funcional diminui com a idade ${ }^{(49)}$, assim como massa hepática ${ }^{(50)}$, levando a uma redução na depuração hepática de algumas drogas.

Nossa população idosa apresentou sinais de redução do tamanho e função hepática, indicados pelas baixas concentrações de albumina sérica, um efeito indireto e indicativo de diminuição da massa hepatocelular.

De fato, alguns autores testaram a função hepática realizando modelagem radiofarmacocinética usando Tc-99m-DTPA-galactosil albumina de soro humano ${ }^{(24)}$, a fim de avaliar a massa hepatocelular, e encontraram uma alta correlação positiva entre a massa hepática e a albumina sérica ${ }^{(125)}$.

Para mostrar que a função hepática é que influencia o metabolismo do MPA e não outros fatores, como peso do paciente e dose do medicamento, normalizamos os parâmetros farmacocinéticos por dose e peso, uma estratégia que usamos em nossos estudos anteriores de populações adultas, idosas e pediátricas ${ }^{(29,60,62)}$.

A distribuição do MPA pode também ser modificada pelo envelhecimento devido a diminuições na albumina sérica e modificações na composição corporal que ocorrem com a idade, como um aumento da proporção de gordura corpórea e uma diminuição da massa magra. Baixas concentrações de albumina podem levar a um aumento da fração livre de MPA, com aumento da depuração corpórea total e diminuição da AUC. Aproximadamente 97-99\% de MPA e 82\% de MPAG estão ligados à albumina ${ }^{(126)}$. 
Por outro lado, drogas são mais afetadas por mudanças na fração livre, que leva ao aumento do volume de distribuição e pela eliminação renal prejudicada, que pode prolongar a meia-vida de drogas e aumentar a probabilidade de efeitos adversos ${ }^{(127)}$.

Inicialmente após o transplante, nossos pacientes idosos mostraram exposições de MPA mais baixas. Isso pode ser atribuído a uma maior fração de MPA livre em pacientes idosos do que em pacientes mais jovens.

Além disso, o MPAG é excretado pelo rim e a função renal dos receptores idosos foi menor neste estudo 7 dias após o transplante (taxa de filtração glomerular estimada (TFGe): $11 \pm 7 \mathrm{~mL} / \mathrm{min} / 1,73 \mathrm{~m}^{2}$ em idosos e $24 \pm 26 \mathrm{~mL} / \mathrm{min} / 1,73 \mathrm{~m}^{2}$ no grupo controle, $\mathrm{p}<0,05)$. Albumina sérica foi menor em idosos e a diferença na albumina sérica entre os grupos foi estatisticamente significativa entre 30 e 60 dias após o transplante.

Os resultados deste estudo de não diferença na PK e metabolismo de MPA, contrasta com nossos demais estudos sobre a PK de tacrolimo e everolimo, na mesma população de idosos, onde demonstramos uma redução da depuração corpórea total e uma exposição maior (ajustada por peso e dose) destas duas drogas na população idosa em comparação com adultos jovens ${ }^{(60,61)}$.

Reduções associadas à idade na atividade da enzima citocromo P450 (CYP) foram descritas ${ }^{(128,129)}$. Nosso centro recentemente estudou em pacientes idosos, a farmacocinética longitudinal de tacrolimo ${ }^{(60)}$ e everolimo ${ }^{(61)}$, ambos metabolizados pelo citocromo P450. Comparado com pacientes mais jovens, pacientes idosos apresentaram redução da depuração corporal total estimado de tacrolimo ${ }^{(60)}$ e everolimo $^{(61)}$. No entanto, alguns autores não observaram uma influência do envelhecimento no metabolismo destas drogas. 
Avaliando todos os parâmetros farmacocinéticos nos cinco períodos de nosso estudo, observamos que a farmacocinética do MPA nos idosos foi semelhante à farmacocinética do MPA nos pacientes jovens ${ }^{(130)}$.

É interessante notar, que nossa população foi quase a mesma que foi investigada em nossos estudos anteriores, sobre a farmacocinética do tacrolimo e everolimo em receptores idosos, sugerindo que o envelhecimento afeta as fases metabólicas das drogas de diferentes maneiras. Tacrolimo e everolimo sofrem metabolismo de fase 1 pelo citocromo P450. Por outro lado, o MPA é metabolizado predominantemente durante a fase 2 no fígado, intestino e rim por uridina-difosfato (UDP) glucuronosiltransferase para um glucuronídeo inativo de MPA (MPAG), o principal metabolito do MPA, excretado pelo rim e bile ${ }^{(131)}$.

As taxas metabólicas de fármacos que sofrem glucuronidação na fase 2, como o MPA, são significativamente mais altas do que as que não sofrem glucuronidação ${ }^{(131)}$, como o tacrolimo e everolimo. Se um fármaco é um alvo para oxidação durante a fase 1 e conjugação na fase 2, a taxa de eliminação é geralmente dependente da fase 1 . Disfunção hepática ligeira geralmente prejudica a depuração de fármacos eliminados pela oxidação, enquanto a glucoronidação não parece ser afetada ${ }^{(132)}$.

Por exemplo, vários estudos relataram que a glucoronidação de fármacos não é afetada na cirrose hepática $^{(91,133)}$. Isso pode explicar porque o envelhecimento parece ter diferentes impactos nas taxas metabólicas de diferentes medicamentos imunossupressores que utilizam diversos mecanismos metabólicos.

Nosso estudo mostrou outras semelhanças na farmacocinética do MPA entre receptores idosos e controles mais jovens, não descrito nos estudos acima citados, a análise do segundo pico de MPA. 
Em pacientes que recebem tacrolimo, o segundo pico de MPA ocorre entre a $6^{\mathrm{a}}$ e a $9^{\text {a }}$ hora. Em nosso estudo, este segundo pico ocorreu em média 9 h após a dose em cerca de $70 \%$ dos pacientes em ambos os grupos, correspondendo a aproximadamente $30 \%$ do Cmax. Estes achados podem sugerir que a atividade da glucoronidase das bactérias intestinais e a reabsorção do MPA também não são modificadas com o envelhecimento.

Neste estudo analisamos o metabólito inativo MPAG-AUC ${ }_{0-720} \min (\mu \mathrm{g} \cdot \mathrm{h} / \mathrm{mL})$ para avaliar MPAG /MPA. Esta razão foi maior nos receptores idosos deste estudo, em relação ao grupo controle, principalmente em 7 dias após o transplante, como descrito acima. No dia 60 após o transplante, observamos um aumento de MPAG nos idosos, porém acompanhada de um aumento de MPA-AUC ${ }_{0-720 \text { min }}(\mu \mathrm{g} \cdot \mathrm{h} / \mathrm{mL})$, em relação aos demais períodos estudados.

Esta relação reflete a glucoronidação nos receptores transplantados deste estudo, a qual não foi afetada pela idade. Baixas concentrações de MPA e altas de MPAG sugerem que o paciente tenha capacidade metabólica ativa da enzima uridina difosfato glucoronosiltransferase (UGT) ${ }^{(134-135)}$.

Outro dado observado foi que os receptores idosos não toleraram a dose de 1440 $\mathrm{mg} /$ dia por um longo período. Depois de seis meses, apenas 35\% dos pacientes estavam recebendo essa dose inicial. A dose foi modificada à critério clínico, de acordo com o efeitos adversos secundários relatados pelos pacientes.

Tem sido sugerido que a dose de MMF deve ser aumentada na primeira semana após o transplante, devido ao fato, de que a maioria dos pacientes que recebem MMF não atinge a concentração alvo de MPA na primeira semana ${ }^{(120)}$. Esta é também a nossa experiência com o MMF. No entanto, no presente estudo, $70 \%$ tanto de idosos quanto dos adultos jovens conseguiram atingir a AUC-MPA alvo $(\geq 30 \mu \mathrm{g} \cdot \mathrm{h} / \mathrm{mL})$ no sétimo dia. A diferença observada na exposição ao MPA na primeira semana entre formulações de 
MMF e EC-MPS pode estar relacionada ao uso regular de inibidores da bomba de prótons (PPI) em pacientes transplantados. Os PPIs diminuem a absorção de MMF mas não $\mathrm{EC}-M P S^{(62)}$.

Após 6 meses, com a redução da dose, 17\% dos pacientes idosos comparados à 43\% dos pacientes do grupo controle estavam superexpostos ao MPA. Estes achados sugerem que a dose de EC-MPS pode ser reduzida após a primeira semana para evitar maior exposição ao MPA e eventos adversos na população idosa.

Deve-se notar que a maioria dos estudos farmacocinéticos de MPA acima mencionados, mas não o presente estudo, foi realizado em pacientes em esquema terapêutico com MMF, ou realizados nas primeiras duas semanas após o transplante, e não descrevem se os pacientes estavam em uso de PPI durante o período inicial após o transplante, o que poderia modificar os resultados farmacocinéticos de MPA ${ }^{(62,63,136,137)}$

O método utilizado, neste estudo, para as análises farmacocinéticas é mais sensível e específico quando comparado com todos os outros métodos desenvolvidos para a estimativa da concentração de MPA no plasma e mais rápido em comparação com vários métodos imunoenzimáticos, $\operatorname{HPLC}^{(69,110)}$ e LC-MS ${ }^{(108,138-143)} \mathrm{em}$ amostras biológicas. O método utilizado apresentou resultados de precisão e exatidão ${ }^{(144)}$ comparáveis aos descritos nos estudos acima e por isso foi possível avaliar com segurança e confiabilidade os resultados obtidos, abrangendo valores mínimos e máximos dos estudos farmacocinéticos.

Monitorar MPA em idosos pode ser seguro e eficaz, para ajustar a dose individual, reduzir o risco de infecções agudas e interações droga-droga nestes pacientes.

No entanto, desenvolver uma equação abreviada para estimar a AUC-MPA sob EC-MPS torna-se difícil uma vez que a absorção desta droga tem grande variabilidade intra e interindividual, resultando em diferentes Cmax e Tmax. 
Em um estudo anterior encontramos que a melhor equação estimada para a AUC foi a que utilizou coletas até 8 horas após a dose ${ }^{(145)}$. No entanto, esta não parece ser uma equação abreviada. Por isso, mesmo com índice de correlação menor a equação com 4 variáveis até a segunda hora parece ser mais adequada. Como a janela terapêutica está definida entre $30-60 \mu \mathrm{g} \cdot \mathrm{h} / \mathrm{mL}^{(121)}$ e o erro padrão desta equação é de $17 \mu \mathrm{g} \cdot \mathrm{h} / \mathrm{mL}$, qualquer valor calculado próximo de 40-50 $\mu \mathrm{g} / \mathrm{h} / \mathrm{mL}$ tem grande chance de estar compreendido na janela terapêutica.

Nos receptores idosos, concentrações alvo diferenciadas, não foram ainda descritas na literatura. Alguns estudos indicam que a janela terapêutica em idosos pode ser mais estreita, porém não há estudos definindo qual seria a melhor faixa para idosos transplantados renais ${ }^{(47,146-148)}$.

Nos estudos farmacocinéticos de MPA em transplante renal, o número de pacientes com idade superior a 60 anos foi pequeno ${ }^{(22,23)}$, mas a concentração alvo de $\mathrm{C}_{0}$ parece ser menor do que em pacientes mais jovens.

As concentrações de MPA antes da dose $\left(\mathrm{C}_{0}\right)$ entre 1,0 e $3,5 \mu \mathrm{g} / \mathrm{mL}$ foram sugeridas para a combinação de MPA e ciclosporina e de 1,9 a 4,0 $\mu \mathrm{g} / \mathrm{mL}$ para a combinação de tacrolimo e $\mathrm{MPA}^{(42)}$. Alguns autores sugeriram que estes níveis de $\mathrm{C}_{0}$ são $30 \%$ maiores em pacientes transplantados renais que utilizam EC-MPS em comparação ao MMF, provavelmente em função do revestimento gastrorresistente ${ }^{(149)}$ ou devido à liberação mais prolongada e isto deveria ser levado em consideração ${ }^{(150)}$.

Nossos estudos de PK foram todos realizados no período da manhã. Existem dados de uma liberação prolongada de MPA com a dose noturna, com concentrações de $\mathrm{C}_{0}$ para MPA mais elevados pela manhã ${ }^{(151)}$, possivelmente influenciado pelo ciclo circadiano ou pela ingestão de alimentos à noite. Esta influência não foi ainda estudada em transplantados renais idosos. 
Novos estudos deverão avaliar as janelas terapêuticas de MPA na população idosa.

Neste estudo, avaliamos a influência de sexo, raça e tipo de doador na depuração corporal total aparente $(\mathrm{L} / \mathrm{h} / \mathrm{Kg})$ e não encontramos diferenças estatisticamente significativas entre períodos do estudo, em relação ao sexo $(p=0,490)$, raça $(p=0,798)$ e tipo de doador $(p=0,432)$, corroborando com os achados de Pescovitch e colaboradores ${ }^{(152)}$ que não encontraram diferenças significativas tanto na AUC do MPA, com função de enxerto estável, quando comparados entre caucasianos e afro-americanos, ou em relação ao sexo.

Os protocolos de imunossupressão requerem uma adaptação à idade, além da prática clínica, uma vez que estes pacientes tem muitas comorbidades associadas, além do uso de outros medicamentos.

De modo geral, nosso estudo demonstrou que EC-MPS pode ser administrado em idosos e adultos jovens, da mesma maneira, rejeitando a hipótese de que a farmacocinética seria diferente em idosos. Não foram verificadas diferenças na absorção de MPA, metabolismo e depuração ajustada pelo peso de MPA e na frequência e intensidade do segundo pico, nas duas populações estudadas.

Futuros ensaios clínicos e o uso de novos biomarcadores deverão incluir transplantados renais idosos para definir, se uma minimização da imunossupressão é segura nos transplantados idosos e estes estudos são necessários para estimar a melhor dose ao longo do tempo após o transplante renal nesta população. 


\section{CONCLUSÕES}

1. Nosso estudo demonstrou que os parâmetros farmacocinéticos de MPA ajustados pela dose e peso, em receptores idosos, que receberam a associação de EC-MPS associado ao tacrolimo e prednisona, não diferem de um grupo controle adulto mais jovem.

2. O método LC-MS/MS para análise das concentrações plasmáticas de MPA é preciso, exato e tem capacidade de detectar concentrações que abrangem valores de $\mathrm{C}_{0}$ e $\mathrm{C}_{\max }$ de MPA

3. Há boa correlação entre $\mathrm{AUC}_{0-12 \mathrm{~h}}$ avaliada pelo método trapezoidal e a equação abreviada utilizando as coletas nos tempos após a dose $\mathbf{C}_{\mathbf{0}} \cdot \mathbf{C}_{\mathbf{4 0}} \cdot \mathbf{C}_{\mathbf{9 0}} \cdot \mathbf{C}_{\mathbf{1 2 0}}$ na população estudada. 


\section{ANEXO 1 - LOCAL DO TRABALHO E RECURSOS FINANCEIROS}

O estudo unicêntrico, prospectivo longitudinal com análise dos dados obtidos entre 2012 a 2015.

A administração de ácido micofenólico via oral e a coleta foram realizadas no serviço de Transplante Renal do HCFMUSP por uma equipe multiprofissional (médicos, farmacêuticos e enfermeiros),

As amostras coletadas foram enviadas à Divisão de Laboratório Central do HCFMUSP, Serviço de Bioquímica Clínica, onde foram analisadas. Após a análise as amostras foram estocadas no laboratório de Bioquímica Clínica até o final da pesquisa ou por tempo que for necessário para confirmações,

Os dados das análises foram gerados com os recursos e infraestrutura já adquiridos pelo Serviço de Transplante Renal que doou o equipamento ao Laboratório Central do HCFMUSP e reagentes adquiridos pelas duas unidades.Os resultados das Análises ficarão armazenados no Serviço de Transplante Renal e laboratório Central e ficarão disponíveis no prontuário dos pacientes que concordaram em participar do estudo, assinando o termo de consentimento livre e esclarecido. 


\section{ANEXO 2 - ASPECTOS ÉTICOS}

Este é um estudo prospectivo, em que os resultados obtidos fazem parte de um estudo Temático intitulado: IMUNOSSUPRESSÃO NO TRANSPLANTE RENAL DO IDOSO - Tempo de repensar, que tem como pesquisador responsável o Prof. Dr. Elias David Neto,

Por ser este estudo uma análise de dados e análise de metodologia empregada, não traz diretamente nenhum dano ao paciente. Contudo, o micofenolato mofetil pode apresentar como efeitos adversos mais habituais: diarreia, náuseas, vômitos e leucopenia; outros efeitos adversos menos comuns são: dores abdominais, torácicas ou dorsais, cefaleia, anemia, trombocitopenia, hipertensão arterial, edema e constipação, linfoma e câncer devido a imunossupressão, Os efeitos adversos associados a coleta de sangue podem ser: desmaios, inflamação da veia, hematoma ou sangramento no local da punção, Os médicos e enfermeira do Serviço de Transplante Renal do HCFMUSP que fazem parte do protocolo atenderão qualquer problema e qualquer evento não desejado e prestarão informações quanto a medicação de estudo,

A exclusão do estudo foi realizada quando aconteceu alteração no estado de saúde do paciente ou foi observado dano comprovado de saúde das pessoas que participam do estudo, Cabe ao paciente comunicar ao médico qualquer desconforto ou efeito adverso com a medicação,

Os pacientes receberão toda assistência, mesmo após o término do estudo ou caso queiram deixar o protocolo. 


\section{ANEXO 3 - PARECER CONSUBSTANCIADO DO CEP}

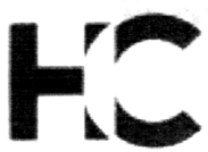

\section{HOSPITAL DAS CLÍNICAS DA FACULDADE DE MEDICINA DA USP - HCFMUSP}

\section{PARECER CONSUBSTANCIADO DO CEP}

\section{DADOS DO PROJETO DE PESQUISA}

Título da Pesquisa: Imunossupressão no Transplante Renal do Idoso - Tempo de Repensar

Pesquisador: Elias David Neto

Área Temática: Área 3. Fármacos, medicamentos, vacinas e testes diagnósticos novos (fases I, II e III) ou não registrados no pais (ainda que fase IV), ou quando a pesquisa for referente a seu uso com modalidades, indicações, doses ou vias de administração diferentes daquelas estabelecidas, incluindo seu emprego em combinações.

Versão: 5

CAAE: 00898312.4 .0000 .0068

Instituição Proponente: HOSPITAL DAS CLINICAS DA FACULDADE DE MEDICINA DA U S P

Patrocinador Principal: HOSPITAL DAS CLINICAS DA FACULDADE DE MEDICINA DA U SP FUNDACAO DE AMPARO A PESQUISA DO ESTADO DE SAO PAULO

\section{DADOS DA NOTIFICAÇÃO}

Tipo de Notificação: Outros

Detalhe: Notificação de subprojeto "Farmacocinética do imunossupressor ácido micofenólico em Justificativa: Encaminho a carta de notificação de subprojeto "Farmacocinética do Data do Envio: 10/09/2015

Situação da Notificação: Parecer Consubstanciado Emitido

\section{DADOS DO PARECER}

Número do Parecer: 1.230 .099

\section{Apresentação da Notificação:}

Nova requisição foi encaminhada

\section{Objetivo da Notificação:}

Objetiva solicitar aprovação da utilização do subprojeto intitulado "Farmacocinética do imunossupressor Ácido micofenólico em transplantados renais idosos" para tese de Doutorado da aluna Paschoalina Romano, orientada pelo Prof. Elias David Neto

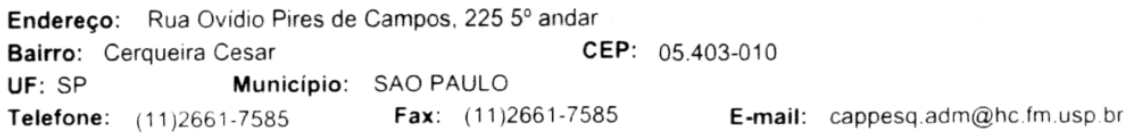




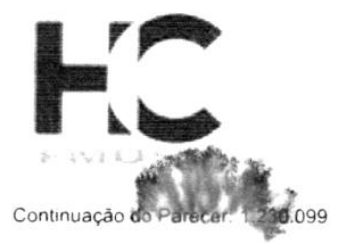

\section{HOSPITAL DAS CLÍNICAS DA FACULDADE DE MEDICINA DA USP - HCFMUSP}

Avaliação dos fiiscos e Beneficios:

Sem alteraçōes

Comentários e Consideraçōes sobre a Notificação:

Não há inconveniente na utilização solicitada, que merece aprovação

Considerações sobre os Termos de apresentação obrigatória:

Não se aplica

Recomendações:

Não há

Conclusões ou Pendências e Lista de Inadequações:

Não há pendências

Consideraçöes Finais a critério do CEP:

Este parecer foi elaborado baseado nos documentos abaixo relacionados:

\begin{tabular}{|l|l|c|l|c|}
\hline Tipo Documento & \multicolumn{1}{|c|}{ Arquivo } & Postagem & Autor & Situação \\
\hline Outros & Paschoalina0001.pdf & $10 / 09 / 2015$ & Elias David Neto & Aceito \\
& & $17: 53: 27$ & & \\
\hline
\end{tabular}

Situação do Parecer:

Aprovado

Necessita Apreciação da CONEP:

Não

SAO PAULO, 16 de Setembro de 2015

Assinado por:

ALFREDO JOSE MANSUR

(Coordenador)

Endereço: Rua Ovidio Pires de Campos, $2255^{\circ}$ andar

Bairro: Cerqueira Cesar

UF: SP Municipio: SAOPAULO

CEP: $\quad 05.403-010$

Telefone:

(11)2661.7585

Fax: (11)2661.7585

E-mail: cappesq.adm@hc.fm.usp.br 


\section{REFERÊNCIAS}

1. United Nation Population Fund - UNFPA Annual Report 2018 [acesso em 23 abr 2019]. Disponível em: https://nacoesunidas.org/agencia/unfpa/.

2. Camarano AA. Envelhecimento da população brasileira: uma contribuição demográfica. 2002[acesso em 12 dez 2017]. Disponível em: http://www.ipea.gov.br/pub/td/2002/td_0858.pdf

3. Wolfe AR, Ashby VB, Milford EL, Ojo AO, Ettenger RE, Agodoa LYC, et al. Comparison of Mortality in All Patients on Dialysis, Patients on Dialysis Awaiting Transplantation, and Recipients of a First Cadaveric Transplant. $N$ Engl J Med. 1999;341:1725-30.

4. Camarano AA. The new demographic paradigm. Cien Saude Colet. 2013 Dec;18(12):3447, 6.

5. Kurella Tamura M, Covinsky KE, Chertow GM, Yaffe K, Landefeld CS, McCulloch CE. Functional status of elderly adults before and after initiation of dialysis. $N$ Engl J Med. 2009 Oct 15;361(16):1539-47.

6. Kniepeiss D WD, Pienaar S, Thaler HW, Porubsky C, Tscheliessnigg KH, Roller RE. Solid organ transplantation: Technical progress meets human dignity a review of the literature considering elderly patients' health related quality of life following transplantation. Ageing Res Rev. 2012 Jan; 11(1):181-7.

7. Johnson JP, McCauley CR, Copley JB. The quality of life of hemodialysis and transplant patients. Kidney Int. 1982 Sep;22(3):286-91.

8. Savoye E, Tamarelle D, Chalem Y, Rebibou JM, Tuppin P. Survival benefits of kidney transplantation with expanded criteria deceased donors in patients aged 60 years and over. Transplantation. 2007 Dec 27;84(12):1618-24.

9. Humar A, Denny R, Matas AJ, Najarian JS. Graft and quality of life outcomes in older recipients of a kidney transplant. Exp Clin Transplant. 2003 Dec;1(2):69-72.

10. Rebollo P, Ortega F, Baltar JM, Diaz-Corte C, Navascues RA, Naves M, et al. Health-related quality of life (HRQOL) in end stage renal disease (ESRD) patients over 65 years. Geriatr Nephrol Urol. 1998;8(2):85-94.

11. Benedetti E, Matas AJ, Hakim N, Fasola C, Gillingham K, McHugh L, et al. Renal transplantation for patients 60 years of older. A single-institution experience. Ann Surg. 1994 Oct;220(4):445-58. 
12. Friedman AL. Cautious Renal Transplantation for the Elderly Is Realistic. Nephron Clin Prac. 2011;119: c8-c14.

13. Ekberg H, Tedesco-Silva H, Demirbas A, Vitko S, Nashan B, Gurkan A, et al. Reduced exposure to calcineurin inhibitors in renal transplantation. $N$ Engl J Med. 2007 Dec 20;357(25):2562-75.

14. van Gelder T, Silva HT, de Fijter JW, Budde K, Kuypers D, Tyden G, et al. Comparing mycophenolate mofetil regimens for de novo renal transplant recipients: the fixed-dose concentration-controlled trial. Transplantation. 2008 Oct 27;86(8):1043-51.

15. Danovitch GM, Gill J, Bunnapradist S. Immunosuppression of the elderly kidney transplant recipient. Transplantation. 2007 Aug 15;84(3):285-91.

16. David-Neto EA, F; Takaki K, M; de Paula, F.J; Nahas, W.C. 10y Follow -Up of renal Transplantation in the elderly.Time to re-think Transplantation. 2011;11(s2):410.

17. Aspinall R, Andrew D. Thymic involution in aging. J Clin Immunol. 2000 Jul;20(4):250-6.

18. Heinbokel T, Hock K, Liu G, Edtinger K, Elkhal A, Tullius SG. Impact of immunosenescence on transplant outcome. Transpl Int. 2013 Mar;26(3):242-53.

19. Yap M, Boeffard F, Clave E, Pallier A, Danger R, Giral M, et al. Expansion of highly differentiated cytotoxic terminally differentiated effector memory CD8+ T cells in a subset of clinically stable kidney transplant recipients: a potential marker for late graft dysfunction. J Am Soc Nephrol. 2014 Aug;25(8):1856-68.

20. Freitas GRR, da Luz Fernandes M, Agena F, Jaluul O, Silva SC, Lemos FBC, et al. Aging and End Stage Renal Disease Cause A Decrease in Absolute Circulating Lymphocyte Counts with A Shift to A Memory Profile and Diverge in Treg Population. Aging Dis. 2019 Feb;10(1):49-61.

21. Orlandi PF, Cristelli MP, Aldworth CAR, Freitas TVS, Felipe CR, Tedesco Silva $\mathrm{H}$, et al. Evolução a longo prazo no transplante renal de idosos. J Bras Nefrol. 2015;37(2):212-20.

22. Miura M, Satoh S, Kagaya H, Saito M, Inoue T, Tsuchiya N, et al. No impact of age on dose-adjusted pharmacokinetics of tacrolimus, mycophenolic acid and prednisolone 1 month after renal transplantation. Eur J Clin Pharmacol. 2009 Oct;65(10):1047-53.

23. Wang CX, Meng FH, Chen LZ, Ren B, Li SX, Fei JG, et al. Population pharmacokinetics of mycophenolic acid in senile Chinese kidney transplant recipients. Transplant Proc. 2007 Jun;39(5):1392-5.

24. Tang JT, de Winter BC, Hesselink DA, Sombogaard F, Wang LL, van Gelder T. The pharmacokinetics and pharmacodynamics of mycophenolate mofetil in younger and elderly renal transplant recipients. Br J Clin Pharmacol. 2017 Apr;83(4):812-22. 
25. Halloran PF. Immunosuppressive drugs for kidney transplantation. $N$ Engl J Med. 2004 Dec 23;351(26):2715-29.

26. Aliabadi AZ, Zuckermann AO, Grimm M. Immunosuppressive therapy in older cardiac transplant patients. Drugs Aging. 2007;24(11):913-32.

27. David-Neto E, Ianhez LE, Nahas WC, Krasilcic S, Sabbaga E, Arap S. Do steroids matter in one-haplotype pediatric renal allograft recipients on cyclosporine/azathioprine? Transplant Proc. 1994;26(1):95-6.

28. Lemos FBC, Ianhez LE, Sabbaga E, David-Neto E. Is the improvement of renal function in chronic allograft nephropathy, after MMF introduction, related to cyclosporin A reduction? (abstract). Transplantation. 1999;67(7):S-86.

29. David-Neto E, Lemos FB, Furusawa EA, Schwartzman BS, Cavalcante JS, Yagyu EM, et al. Impact of cyclosporin A pharmacokinetics on the presence of side effects in pediatric renal transplantation. J Am Soc Nephrol. 2000 Feb;11(2):343-9.

30. David-Neto E, Araujo LM, Lemos FC, David DS, Mazzucchi E, Nahas WC, et al. Introduction of mycophenolate mofetil and cyclosporin reduction in children with chronic transplant nephropathy. Pediatr Transplant. 2001;5(4):302-9.

31. Azevedo LS, Castro MC, Paula FJ, Ianhez LE, David-Neto E. Mycophenolate mofetil may protect against Pneumocystis carinii pneumonia in renal transplanted patients. Rev Inst Med Trop Sao Paulo. 2005 May-Jun;47(3):143-5.

32. David-Neto E, Pereira LM, Kakehashi E, Sumita NM, Mendes ME, Castro MC, et al. The need of mycophenolic acid monitoring in long-term renal transplants. Clin Transplant. 2005 Feb;19(1):19-25.

33. Pereira L, Castro M, Ventura C, Reis F, Sumita N, Sato MI, et al. the modify study in renal transplantation (modification of doses to improve function through the years). Am J Transplant. 2005;11(Suppl 5):466.

34. Saemann MD, Sunder-Plassmann G. Maintenance immunosuppressive therapy in adult renal transplantation: a single center analysis. Transpl Immunol. 2008 Nov;20(1-2):14-20.

35. David-Neto E, David DS, Ginani GF, Rodrigues H, Souza PS, Castro MC, et al. C4d staining in post-reperfusion renal biopsy is not useful for the early detection of antibody-mediated rejection when CDC crossmatching is negative. Nephrol Dial Transplant. 2011 Apr;26(4):1388-92.

36. Shaw LM, Sollinger HW, Halloran P, Morris RE, Yatscoff RW, Ransom J, et al. Mycophenolate mofetil: a report of the consensus panel. Ther Drug Monit. 1995 Dec;17(6):690-9.

37. European Mycophenolate Mofetil Cooperative Study Group. Mycophenolate mofetil in renal transplantation: 3-year results from the placebo-controlled trial. Transplantation. 1999;68(3):391-6. 
38. Kuypers DR, Naesens M, Vermeire S, Vanrenterghem Y. The impact of uridine diphosphate-glucuronosyltransferase 1A9 (UGT1A9) gene promoter region singlenucleotide polymorphisms T-275A and C-2152T on early mycophenolic acid doseinterval exposure in de novo renal allograft recipients. Clin Pharmacol Ther. 2005 Oct;78(4):351-61.

39. Mahalati K, Belitsky P, West K, Kiberd B, Fraser A, Sketris I, et al. Approaching the therapeutic window for cyclosporine in kidney transplantation: a prospective study. J Am Soc Nephrol. 2001 Apr;12(4):828-33.

40. Mahalati K, Kahan BD. Clinical pharmacokinetics of sirolimus. Clin Pharmacokinet. 2001;40(8):573-85.

41. van Gelder T, Klupp J, Barten MJ, Christians U, Morris RE. Comparison of the effects of tacrolimus and cyclosporine on the pharmacokinetics of mycophenolic acid. Ther Drug Monit. 2001 Apr;23(2):119-28.

42. van Gelder T, Le Meur Y, Shaw LM, Oellerich M, DeNofrio D, Holt C, et al. Therapeutic drug monitoring of mycophenolate mofetil in transplantation. Ther Drug Monit. 2006 Apr;28(2):145-54.

43. Meier-Kriesche HU, Li S, Gruessner RW, Fung JJ, Bustami RT, Barr ML, et al. Immunosuppression: evolution in practice and trends, 1994-2004. Am J Transplant. 2006;6(5 Pt 2):1111-31.

44. Turnheim K. Drug therapy in the elderly. Exp Gerontol. 2004 NovDec;39(11-12):1731-8.

45. Shi S, Morike K, Klotz U. The clinical implications of ageing for rational drug therapy. Eur J Clin Pharmacol. 2008 Feb;64(2):183-99.

46. Mangoni AA, Jackson SH. Age-related changes in pharmacokinetics and pharmacodynamics: basic principles and practical applications. $\mathrm{Br} J \mathrm{Clin}$ Pharmacol. 2004 Jan;57(1):6-14.

47. Meier-Kriesche HU, Ojo AO, Cibrik DM, Hanson JA, Leichtman AB, Magee JC, et al. Relationship of recipient age and development of chronic allograft failure. Transplantation. $2000 \mathrm{Jul}$ 27;70(2):306-10.

48. Kaplan B, Meier-Kriesche HU, Friedman G, Mulgaonkar S, Gruber S, Korecka M, et al. The effect of renal insufficiency on mycophenolic acid protein binding. J Clin Pharmacol. 1999 Jul;39(7):715-20.

49. Zoli M, Magalotti D, Bianchi G, Gueli C, Orlandini C, Grimaldi M, et al. Total and functional hepatic blood flow decrease in parallel with ageing. Age Ageing. 1999 Jan;28(1):29-33.

50. Zeeh J, Platt D. The aging liver: structural and functional changes and their consequences for drug treatment in old age. Gerontology. 2002 May-Jun;48(3):121-7. 
51. Goodman and Gilman's. The phases of drug metabolism - Conjugated Enzymesphase 2 reactions in The pharmacological basis of therapeutics. Laurence L. Brunton, Bruce A. Chabner, Björn C. Knollmann 12ed. New York, McGraw-Hill Companies, Inc; 2011:123-44.

52. Morales JM, Campistol JM, Andres A, Herrero JC. Immunosuppression in older renal transplant patients. Drugs Aging. 2000 Apr;16(4):279-87.

53. Ekberg H, Bernasconi C, Tedesco-Silva H, Vitko S, Hugo C, Demirbas A, et al. Calcineurin inhibitor minimization in the Symphony study: observational results 3 years after transplantation. Am J Transplant. 2009 Aug;9(8):1876-85.

54. Turnheim K. Drug dosage in the elderly. Is it rational? Drugs Aging. 1998 Nov;13(5):357-79.

55. Turnheim K. When drug therapy gets old: pharmacokinetics and pharmacodynamics in the elderly. Exp Gerontol. 2003 Aug;38(8):843-53.

56. Noble RE. Drug therapy in the elderly. Metabolism. 2003 Oct;52(10 Suppl 2):27-30.

57. Staatz CE, Tett SE. Pharmacokinetic considerations relating to tacrolimus dosing in the elderly. Drugs Aging. 2005;22(7):541-57.

58. Wei-lin W, Jing J, Shu-sen Z, Li-hua W, Ting-bo L, Song-feng Y, et al. Tacrolimus dose requirement in relation to donor and recipient ABCB1 and CYP3A5 gene polymorphisms in Chinese liver transplant patients. Liver Transpl. 2006 May;12(5):775-80.

59. Op den Buijsch RA, Christiaans MH, Stolk LM, de Vries JE, Cheung CY, Undre NA, et al. Tacrolimus pharmacokinetics and pharmacogenetics: influence of adenosine triphosphate-binding cassette B1 (ABCB1) and cytochrome (CYP) 3A polymorphisms. Fundam Clin Pharmacol. 2007 Aug;21(4):427-35.

60. David-Neto E, Romano P, Kamada Triboni AH, Ramos F, Agena F, Almeida Rezende Ebner P, et al. Longitudinal Pharmacokinetics of Tacrolimus in Elderly Compared With Younger Recipients in the First 6 Months After Renal Transplantation. Transplantation. 2017 Jun;101(6):1365-72.

61. David-Neto E, Agena F, Ramos F, Triboni AH, Romano P, Ebner PA, et al. Longitudinal Pharmacokinetics of Everolimus when Combined with Low-level of Tacrolimus in Elderly Renal Transplant Recipients. Transplantation. 2017;101(9):2133-8.

62. David-Neto E, Takaki KM, Agena F, Romano P, Sumita NM, Mendes ME, et al. Diminished mycophenolic acid exposure caused by omeprazole may be clinically relevant in the first week posttransplantation. Ther Drug Monit. 2012 Jun;34(3):331-6.

63. Rupprecht K, Schmidt C, Raspe A, Schweda F, Shipkova M, Fischer W, et al. Bioavailability of mycophenolate mofetil and enteric-coated mycophenolate sodium is differentially affected by pantoprazole in healthy volunteers. J Clin Pharmacol. 2009 Oct;49(10):1196-201. 
64. Mika A, Stepnowski P. Current methods of the analysis of immunosuppressive agents in clinical materials: A review. J Pharm Biomed Anal. 2016 Aug 05;127:207-31.

65. Oellerich M, Shipkova M, Schutz E, Wieland E, Weber L, Tonshoff B, et al. Pharmacokinetic and metabolic investigations of mycophenolic acid in pediatric patients after renal transplantation: implications for therapeutic drug monitoring. German Study Group on Mycophenolate Mofetil Therapy in Pediatric Renal Transplant Recipients. Ther Drug Monit. 2000 Feb;22(1):20-6.

66. Bullingham R, Monroe S, Nicholls A, Hale M. Pharmacokinetics and bioavailability of mycophenolate mofetil in healthy subjects after single-dose oral and intravenous administration. J Clin Pharmacol. 1996 Apr;36(4):315-24.

67. Allison AC, Eugui EM. Mechanisms of action of mycophenolate mofetil in preventing acute and chronic allograft rejection. Transplantation. 2005 Oct;80(2 Suppl):S181-90.

68. Ransom JT. Mechanism of action of mycophenolate mofetil. Ther Drug Monit. 1995 Dec;17(6):681-4.

69. Holt DW. Monitoring mycophenolic acid. Ann Clin Biochem. 2002 May;39 (Pt 3):173-83.

70. Mourad M, Wallemacq P, Konig J, de Frahan EH, Eddour DC, De Meyer M, et al. Therapeutic monitoring of mycophenolate mofetil in organ transplant recipients: is it necessary? Clin Pharmacokinet. 2002;41(5):319-27.

71. Le Meur Y, Buchler M, Thierry A, Caillard S, Villemain F, Lavaud S, et al. Individualized mycophenolate mofetil dosing based on drug exposure significantly improves patient outcomes after renal transplantation. Am J Transplant. 2007 Nov;7(11):2496-503.

72. David-Neto E, Sumita NM, Mendes ME, Castro MC, Alves CF, Romano P, et al. Mycophenolate acid (MPA) pharmacokinetics in stable renal transplanted children (Abstract). Am J Transplantation. 2002;2(Suppl 3):192.

73. David-Neto E. Mycophenolic acid (MPA) pharmacokinetics (PK) in stable renal transplanted (RTX) children. Am J Transpl. 2002;2(Suppl. 3):Abstract 214.

74. David-Neto E, Araujo LM, Sumita NM, Mendes ME, Ribeiro Castro MC, Alves CF, et al. Mycophenolic acid pharmacokinetics in stable pediatric renal transplantation. Pediatr Nephrol. 2003;18(3):266-72.

75. Bullingham RE, Nicholls A, Hale M. Pharmacokinetics of mycophenolate mofetil (RS61443): a short review. Transplant Proc. 1996 Apr;28(2):925-9.

76. Staatz CE, Tett SE. Clinical pharmacokinetics and pharmacodynamics of mycophenolate in solid organ transplant recipients. Clin Pharmacokinet. 2007;46(1):13-58. 
77. van Gelder T, Meur YL, Shaw LM, Oellerich M, DeNofrio D, Holt C, et al. Therapeutic drug monitoring of mycophenolate mofetil in transplantation. Ther Drug Monit. 2006 Apr;28(2):145-54.

78. Kuypers DR, Le Meur Y, Cantarovich M, Tredger MJ, Tett SE, Cattaneo D, et al. Consensus report on therapeutic drug monitoring of mycophenolic acid in solid organ transplantation. Clin J Am Soc Nephrol. 2010 Feb;5(2):341-58.

79. Zucker K, Rosen A, Tsaroucha A, de Faria L, Roth D, Ciancio G, et al. Unexpected augmentation of mycophenolic acid pharmacokinetics in renal transplant patients receiving tacrolimus and mycophenolate mofetil in combination therapy, and analogous in vitro findings. Transpl Immunol. 1997 Sep;5(3):225-32.

80. Hubner GI, Eismann R, Sziegoleit W. Drug interaction between mycophenolate mofetil and tacrolimus detectable within therapeutic mycophenolic acid monitoring in renal transplant patients. Ther Drug Monit. 1999 Oct;21(5):536-9.

81. Pereira LM. Co-interferências da farmacocinética dos inibidores de calcineurina em associação com micofenolato mofetil em pacientes transplantados renais (tese doutorado). São Paulo: Universidade de São Paulo; 2006.

82. Kuypers DR, Claes K, Evenepoel P, Maes B, Coosemans W, Pirenne J, et al. Longterm changes in mycophenolic acid exposure in combination with tacrolimus and corticosteroids are dose dependent and not reflected by trough plasma concentration: a prospective study in 100 de novo renal allograft recipients. J Clin Pharmacol. 2003 Aug;43(8):866-80.

83. Stoves J, Newstead CG, Baczkowski AJ, Owens G, Paraoan M, Hammad AQ. A randomized controlled trial of immunosuppression conversion for the treatment of chronic allograft nephropathy. Nephrol Dial Transplant. 2004 Aug;19(8):2113-20.

84. Westley IS, Sallustio BC, Morris RG. Validation of a high-performance liquid chromatography method for the measurement of mycophenolic acid and its glucuronide metabolites in plasma. Clin Biochem. 2005 Sep;38(9):824-9.

85. Premaud A, Rousseau A, Picard N, Marquet P. Determination of mycophenolic acid plasma levels in renal transplant recipients co-administered sirolimus: comparison of an enzyme multiplied immunoassay technique (EMIT) and liquid chromatography-tandem mass spectrometry. Ther Drug Monit. 2006 Apr;28(2):274-7.

86. Premaud A, Rousseau A, Le Meur Y, Lachatre G, Marquet P. Comparison of liquid chromatography-tandem mass spectrometry with a commercial enzyme-multiplied immunoassay for the determination of plasma MPA in renal transplant recipients and consequences for therapeutic drug monitoring. Ther Drug Monit. 2004 Dec;26(6):609-19.

87. van Gelder T. Mycophenolate mofetil: how to further improve using an already successful drug? Am J Transplant. 2005 Feb;5(2):199-200. 
88. Weber LT, Shipkova M, Armstrong VW, Wagner N, Schutz E, Mehls O, et al. Comparison of the Emit immunoassay with HPLC for therapeutic drug monitoring of mycophenolic acid in pediatric renal-transplant recipients on mycophenolate mofetil therapy. Clin Chem. 2002 Mar;48(3):517-25.

89. Mourad M, Malaise J, Chaib Eddour D, De Meyer M, Konig J, Schepers R, et al. Correlation of mycophenolic acid pharmacokinetic parameters with side effects in kidney transplant patients treated with mycophenolate mofetil. Clin Chem. 2001 Jan;47(1):88-94.

90. Ingle GR, Shah T. Enteric-coated mycophenolate sodium for transplant immunosuppression. Am J Health Syst Pharm. 2005 Nov 01;62(21):2252-9.

91. Patwardhan RV, Johnson RF, Hoyumpa A Jr, Sheehan PV, Wilkinson GR, Branch SA,et al. Normal metabolism of morphine in cirrhosis. Gastroenterology. 1981(81):1006.

92. Christians U, Strom T, Zhang YL, Steudel W, Schmitz V, Trump S, et al. Active drug transport of immunosuppressants: new insights for pharmacokinetics and pharmacodynamics. Ther Drug Monit. 2006 Feb;28(1):39-44.

93. Benoit-Biancamano MO, Caron P, Levesque E, Delage R, Couture F, Guillemette C. Sensitive high-performance liquid chromatography-tandem mass spectrometry method for quantitative analysis of mycophenolic acid and its glucuronide metabolites in human plasma and urine. J Chromatogr B Analyt Technol Biomed Life Sci. 2007 Oct 15;858(1-2):159-67.

94. Taylor PJ. Matrix effects: the Achilles heel of quantitative high-performance liquid chromatography-electrospray-tandem mass spectrometry. Clin Biochem. 2005 Apr;38(4):328-34.

95. United States Department of Health and Human Services. Food and Drug Administration Fed Reg. Bioavailability and bioequivalence requirements. 2018 [acesso em 23 de junho de 2018]. Disponível em: https://www.accessdata.fda.gov/scripts/cdrh/cfdocs/cfcfr/cfrsearch.cfm?cfrpart=320

96. Brasil. Ministério da Saúde . Agência Nacional de Vigilância Sanitária . Medicamentos ICdBL. Resolução n.899, 29 de maio de 2003, determina a publicação do "Guia para a validação de métodos analíticos e bioanalíticos". 2003 e anexo RDC 27 de maio 2012 [acesso em 23 de junho de 2013]. Disponível em: http://bvsms.saude.gov.br/bvs/saudelegis/anvisa/2012/rdc0027_17_05_2012.html

97. Clinical and Laboratory Standards Institutes (CLSI). Protocols for determination of limits of detection and limits of quantification; Approved Guideline, CLSI document EP-17-A2 2012 [acesso em 23 janeiro 2013]. Disponível em www.clsi.org.

98. Clinical and Laboratory Standards Institutes (CLSI). Evaluation of Linearity of Quantitative Measurement Procedures: A statistical Aproach. CLSI document EP06-A 2003 [acesso em 23 janeiro 2014]. Disponível em www.clsi.org. 
99. Clinical and Laboratory Standards Institutes (CLSI). Evaluation of precision performance of quantitative measurement methods. CLSI document EP05-A3.2014 [acesso em 23 outubro 2014]. Disponível em www.clsi.org.

100. Clinical and Laboratory Standards Institutes (CLSI). User verification for Precision and estimation of Bias; Approved Guideline, CLSI document EP-15 A3.2014 [acesso em 23 outubro 2014]. Disponível em www.clsi.org.

101. Clinical and Laboratory Standards Institutes (CLSI). Mass spectrometry in the clinical laboratory: general principle and guidance; Approved guideline. CLSI document C50-A. 2007(ISBN 1-56238-648-4) - Clinical and Laboratory Standards Institute, 2007 [acesso em 23 outubro 2014]. Disponível em www.clsi.org.

102. Application AB. A New LC/MS/MS Research Method for rapid quantititation of five immunosuppressant drugs, including Mycophenolic Acid (MPA). Corporation W. Acquity Sales brochure; versão impressa, 2004.

103. A New LCMS/MS Research Method for Rapid Quantification of Five Immnunossuppressant Drugs including Mycophenolic Acid (MPA) - Application Note- Clinical Research Applied Biosystem 2005[acesso em 23 outubro 2014]. Disponível em www.appliedbiosystem.com.

104. Keevil BG, Tierney DP, Cooper DP, Morris MR. Rapid liquid chromatographytandem mass spectrometry method for routine analysis of cyclosporin A over an extended concentration range. Clin Chem. 2002 Jan;48(1):69-76.

105. Koal TD, M; Casetta, B; Kaever, V. Simultaneous determination of four immunosupressants by means of high speed and robust on-line solid phase extraction-high performance liquid chromatography-tandem mass spectrometry. Journal of Chromatography B. 2004;805:215-22.

106. Thompson JM, JS; Eschelbach, JW; Jorgenson, JW. Recent advances in ultrahighpressure liquid chromatography. LCGV Nor Am 2006;24(84):16-20.

107. Tszyrsznic W, Borowiec A, Pawlowska E, Jazwiec R, Zochowska D, Bartlomiejczyk I, et al. Two rapid ultra performance liquid chromatography/tandem mass spectrometry (UPLC/MS/MS) methods with common sample pretreatment for therapeutic drug monitoring of immunosuppressants compared to immunoassay. J Chromatogr B Analyt Technol Biomed Life Sci. 2013 Jun;928:9-15.

108. Johnson-Davis KL, Juenke JM, Thomas RL, Bradshaw T. Everolimus method comparison between Waters MassTrak Immunosuppressants XE (IUO) kit and an in-house laboratory developed LC-MS/MS method in renal transplant patients. Ann Clin Lab Sci. 2015 Winter;45(1):27-31.

109. Vogl M, Weigel G, Seebacher G, Griesmacher A, Laufer G, Muller MM. Evaluation of the EMIT Mycophenolic Acid Assay from Dade Behring. Ther Drug Monit. 1999 Dec;21(6):638-43. 
110. Shipkova M, Schutz E, Armstrong VW, Niedmann PD, Wieland E, Oellerich M. Overestimation of mycophenolic acid by EMIT correlates with MPA metabolite. Transplant Proc. 1999 Feb-Mar;31(1-2):1135-7.

111. Hosotsubo H, Takahara S, Imamura R, Kyakuno M, Tanaka T, Yazawa K, et al. Analytic validation of the enzyme multiplied immunoassay technique for the determination of mycophenolic acid in plasma from renal transplant recipients compared with a high-performance liquid chromatographic assay. Ther Drug Monit. 2001 Dec;23(6):669-74.

112. Beal JL, Jones CE, Taylor PJ, Tett SE. Evaluation of an immunoassay (EMIT) for mycophenolic acid in plasma from renal transplant recipients compared with a high-performance liquid chromatography assay. Ther Drug Monit. 1998 Dec;20(6):685-90.

113. Schutz E, Shipkova M, Armstrong VW, Niedmann PD, Weber L, Tonshoff B, et al. Therapeutic drug monitoring of mycophenolic acid: comparison of HPLC and immunoassay reveals new MPA metabolites. Transplant Proc. 1998 Jun;30(4):1185-7.

114. Brasil Ministério da Saúde. Agência Nacional de Vigilância Sanitária. Resolução RE n. ${ }^{\circ}$ 1.170, Determina a publicação do Guia para provas de biodisponibilidade relativa/bioequivalência de medicamentos. Diário Oficial da União, Brasília, DF; 2006. [acesso em 12 de outubro de 2013]. Disponível em: http://www.lex.com.br/doc_839912_resolucao_1170_de_19_de_abril_de_2006.aspx

115. Miliken.G.A JDE. Analysis of Messy Data. Volume I: Designed Experiments. . London Chapman \& hall/ CRC; 1992.

116. Westgard JO, Barry PL, Hunt MR, Groth T. A multi-rule Shewhart chart for quality control in clinical chemistry. Clin Chem. 1981 Mar;27(3):493-501.

117. Clinical Laboratory Improvement Act program fee collection-HCFA. Final rule with comment. Fed Regist. 1992 Feb 28;57(40):7188-218.

118. Clinical and Laboratory Standards Institute (CLSI).Liquid Chromatography-Mass Spectrometry Methods; Approved guideline.CLSI document EP62-A. 2014 [acesso em outubro 2015].Disponível em: www.clsi.org.

119. Carl A. Burtis DEB. Tietz Fundamentals of Clinical Chemistry and Molecular Diagnostics - E-Book. 7 ed: Elsevier Health Sciences; 2014.

120. van Gelder T, Hilbrands LB, Vanrenterghem Y, Weimar W, de Fijter JW, Squifflet JP, et al. A randomized double-blind, multicenter plasma concentration controlled study of the safety and efficacy of oral mycophenolate mofetil for the prevention of acute rejection after kidney transplantation. Transplantation. 1999 Jul 27;68(2):261-6.

121. Kuypers DR, Le Meur Y, Cantarovich M, Tredger MJ, Tett SE, Cattaneo D, et al. Consensus report on therapeutic drug monitoring of mycophenolic acid in solid organ transplantation. Clin J Am Soc Nephrol. 2010 Feb;5(2):341-58. 
122. Danovitch GM, Cohen DJ, Weir MR, Stock PG, Bennett WM, Christensen LL, et al. Current status of kidney and pancreas transplantation in the United States, 1994-2003. Am J Transplant. 2005 Apr;5(4 Pt 2):904-15.

123. World Health Organization (WHO). Proposed working definition of an older person in Africa for the MDS Project. 2002. [acesso em outubro 2015].Disponível em: https://www.who.int/healthinfo/survey/ageingdefnolder/en/

124. Haubner R, Vera DR, Farshchi-Heydari S, Helbok A, Rangger C, Putzer D, et al. Development of (6)(8)Ga-labelled DTPA galactosyl human serum albumin for liver function imaging. Eur J Nucl Med Mol Imaging. 2013 Aug;40(8):1245-55.

125. Du S, Mao Y, Tong J, Li F, Che L, Li S, et al. A novel liver function evaluation system using radiopharmacokinetic modeling of technetium-99m-DTPAgalactosyl human serum albumin. Nucl Med Commun. 2013 Sep;34(9):893-9.

126. van Hest RM, Mathot RA, Pescovitz MD, Gordon R, Mamelok RD, van Gelder T. Explaining variability in mycophenolic acid exposure to optimize mycophenolate mofetil dosing: a population pharmacokinetic meta-analysis of mycophenolic acid in renal transplant recipients. J Am Soc Nephrol. 2006 Mar;17(3):871-80.

127. Beyth RJ, Shorr RI. Principles of drug therapy in older patients: rational drug prescribing. Clin Geriatr Med. 2002 Aug;18(3):577-92.

128. Sotaniemi EA, Arranto AJ, Pelkonen O, Pasanen M. Age and cytochrome P450linked drug metabolism in humans: an analysis of 226 subjects with equal histopathologic conditions. Clin Pharmacol Ther. 1997 Mar;61(3):331-9.

129. Ginsberg G, Hattis D, Russ A, Sonawane B. Pharmacokinetic and pharmacodynamic factors that can affect sensitivity to neurotoxic sequelae in elderly individuals. Environ Health Perspect. 2005 Sep;113(9):1243-9.

130. Romano P, Agena F, de Almeida Rezende Ebner P, Massakazu Sumita N, Kamada Triboni AH, Ramos F, et al. Longitudinal Pharmacokinetics of Mycophenolic Acid in Elderly Renal Transplant Recipients Compared to a Younger Control Group: Data from the nEverOld Trial. Eur J Drug Metab Pharmacokinet. 2019 Apr;44(2):189-99.

131. Goodman and Gilman's. The Dynamics of Drug Absorption, Distribution, Metabolism, and Elimination in The Pharmacological Basis of Therapeutics. Laurence L. Brunton, Bruce A. Chabner, Björn C. Knollmann 12ed. New York, McGraw-Hill Companies, Inc; 2011, capítulo 2:17-40.

132. Kroemer HK, Klotz U. Glucuronidation of drugs. A re-evaluation of the pharmacological significance of the conjugates and modulating factors. Clin Pharmacokinet. 1992 Oct;23(4):292-310.

133. Sellers EM GD, Giles HG, Naranjo CA, Kaplan H, MacLeod SM. Chlordiazepoxide and oxazepam disposition in cirrhosis. Clinical Pharmacology and Therapeutics. 1979;26:240-6. 
134. Meaney CJ, Sudchada P, Consiglio JD, Wilding GE, Cooper LM, Venuto RC, et al. Influence of Calcineurin Inhibitor and Sex on Mycophenolic Acid Pharmacokinetics and Adverse Effects Post-Renal Transplant. J Clin Pharmacol. 2019 May 6, doi: 10.1002/jcph.1428. [Epub ahead of print].

135. Naito T, Shinno K, Maeda T, Kagawa Y, Hashimoto H, Otsuka A, et al. . Effects of calcineurin inhibitors on pharmacokinetics of mycophenolic acid and its glucuronide metabolite during the maintenance period following renal transplantation.Biol Pharm Bul.2006 Febr; 29(2):275-80.

136. Kofler S, Deutsch MA, Bigdeli AK, Shvets N, Vogeser M, Mueller TH, et al. Proton pump inhibitor co-medication reduces mycophenolate acid drug exposure in heart transplant recipients. J Heart Lung Transplant. 2009 Jun;28(6):605-11.

137. Miura M, Satoh S, Inoue K, Kagaya H, Saito M, Suzuki T, et al. Influence of lansoprazole and rabeprazole on mycophenolic acid pharmacokinetics one year after renal transplantation. Ther Drug Monit. 2008 Feb;30(1):46-51.

138. Buchwald A, Winkler K, Epting T. Validation of an LC-MS/MS method to determine five immunosuppressants with deuterated internal standards including MPA. BMC Clin Pharmacol. 2012;12:2.

139. Shen B, Li S, Zhang Y, Yuan X, Fan Y, Liu Z, et al. Determination of total, free and saliva mycophenolic acid with a LC-MS/MS method: application to pharmacokinetic study in healthy volunteers and renal transplant patients. J Pharm Biomed Anal. 2009 Oct 15;50(3):515-21.

140. van Gelder T, Domke I, Engelmayer J, de Fijter H, Kuypers D, Budde K, et al. Clinical utility of a new enzymatic assay for determination of mycophenolic acid in comparison with an optimized LC-MS/MS method. Ther Drug Monit. 2009 Apr;31(2):218-23.

141. Hammond GC, LJ; Cooper, DP. A preliminary Investigation into a simple and robust protein precipitation method for the simultaneous determination of immnunosupressants in transplant patient blood using LC-MS/MS. Clinical Business Operations Group Corporation; 2007.

142. MD Dom ZI, Noll BD, Coller JK, Somogyi AA, Russ GR, Hesselink DA, et al. Validation of an LC-MS/MS method for the quantification of mycophenolic acid in human kidney transplant biopsies. J Chromatogr B Analyt Technol Biomed Life Sci. 2014 Jan 15;945-946:171-7.

143. Romano P. Avaliação da biodisponibilidade de uma nova formulação de micofenolato mofetil e de um método para sua monitorização terapêutica [dissertação mestrado]. São Paulo: Universidade de São Paulo; 2007.

144. Romano $\mathrm{P}$ e Ebner PAR. Monitoramento terapêutico de medicamentos in Recomendações da Sociedade Brasileira de Patologia Clínica e Medicina Laboratorial -fase pré-analítica. primeira ed. Barueri, São Paulo; 2018, capítulo $33: 386-47$. 
145. David-Neto E, Triboni AH, Ramos F, Agena F, Romano P. Development of an Abbreviated Mycophenolic Acid Area Under the Time-Concentration Curve for Renal Transplant Patients Under Enteric-Coated Mycophenolate Sodium: A Comparison With Critical Analysis of Available Equations. Ther Drug Monit. 2018 Aug;40(4):411-6.

146. Bernardo JF, McCauley J. Drug therapy in transplant recipients: special considerations in the elderly with comorbid conditions. Drugs Aging. 2004;21(5):323-48.

147. Borrows R, Chusney G, Loucaidou M, James A, Lee J, Tromp JV, et al. Mycophenolic acid 12-h trough level monitoring in renal transplantation: association with acute rejection and toxicity. Am J Transplant. 2006 Jan;6(1):121-8.

148. Falck P, Asberg A, Byberg KT, Bremer S, Bergan S, Reubsaet JL, et al. Reduced elimination of cyclosporine A in elderly ( $>65$ years) kidney transplant recipients. Transplantation. 2008 Nov 27;86(10):1379-83.

149. Budde K, Tedesco-Silva H, Pestana JM, Glander P, Neumayer HH, Felipe CR, et al. Enteric-coated mycophenolate sodium provides higher mycophenolic acid predose levels compared with mycophenolate mofetil: implications for therapeutic drug monitoring. Ther Drug Monit. 2007 Jun;29(3):381-4.

150. Tedesco-Silva H, Felipe CR, Park SI, Pinheiro-Machado PG, Garcia R, Slade A, et al. Randomized crossover study to assess the inter- and intrasubject variability of morning mycophenolic acid concentrations from enteric-coated mycophenolate sodium and mycophenolate mofetil in stable renal transplant recipients. Clin Transplant. 2010 Jul-Aug;24(4):E116-23.

151. Tedesco-Silva H, Bastien MC, Choi L, Felipe C, Campestrini J, Picard F, et al. Mycophenolic acid metabolite profile in renal transplant patients receiving enteric-coated mycophenolate sodium or mycophenolate mofetil. Transplant Proc. 2005 Mar;37(2):852-5.

152. Pescovitz MD, Guasch A, Gaston R, Rajagopalan P, Tomlanovich S, Weinstein S, et al. Equivalent pharmacokinetics of mycophenolate mofetil in African-American and Caucasian male and female stable renal allograft recipients. Am J Transplant. 2003 Dec;3(12):1581-6. 


\section{APÊNDICE}

\section{Apêndice 1- Artigo publicado}

European Journal of Drug Metabolism and Pharmacokinetics https://doi.org/10.1007/s13318-018-0506-6

ORIGINAL RESEARCH ARTICLE

\section{Longitudinal Pharmacokinetics of Mycophenolic Acid in Elderly Renal Transplant Recipients Compared to a Younger Control Group: Data from the nEverOld Trial}

Paschoalina Romano ${ }^{2,3}$ - Fabiana Agena ${ }^{1}$ - Pérsio de Almeida Rezende Ebner ${ }^{3}$. Nairo Massakazu Sumita ${ }^{3}$. Ana Heloísa Kamada Triboni ${ }^{1}$. Fernanda Ramos ${ }^{1}$. Márcio dos Santos Garcia ${ }^{3}$ - Nilo José Coelho Duarte ${ }^{3}$. Francine Brambate Carvalhinho Lemos ${ }^{1} \cdot$ Nelson Zocoler Galante ${ }^{1}$. Elias David-Neto ${ }^{1,2}$

๑) Springer Nature Switzerland AG 2018

\section{Abstract}

Background and Objectives Elderly patients are increasingly likely to be recipients of transplants. However, the pharmacokinetics of mycophenolic acid (MPA) in this population are yet to be studied in detail. The objective of this study was to assess whether there were differences in MPA pharmacokinetic parameter values between elderly recipients and youngeradult recipients during the 6 months immediately following renal transplantation.

Methods In this analysis, the longitudinal 12-h pharmacokinetics of MPA, administered as enteric-coated mycophenolate sodium (EC-MPS), were evaluated in 44 elderly renal transplant recipients and compared with the corresponding pharmacokinetics of MPA in 31 younger adult recipients. Measurements were performed at 7, 30, 60, 90, and 180 days posttransplantation. All patients received tacrolimus and prednisone.

Results The elderly patients were 30 years older than the younger controls, with a predominance of males and Caucasians. Elderly patients had lower serum albumin than the younger controls during the first 6 months after transplantation. The mean estimated total body MPA clearance of the elderly recipients was not significantly different from that of the controls at any analyzed time point (the mean clearance across all time points was $0.31 \pm 0.17 \mathrm{vs} 0.30 \pm 0.25 \mathrm{~L} / \mathrm{h} / \mathrm{kg}$ ). MPA exposure, as evaluated from the area under the 12-h time versus measured MPA concentration (adjusted for dose/body weight) curve, did not differ between the groups at any time point (mean exposure across all time points was $4.68 \pm 3.61 \mathrm{vs} 5.95 \pm 4.29 \mu \mathrm{g} \cdot \mathrm{h} /$ $\mathrm{mL}$ per $\mathrm{mg} / \mathrm{kg}$ for the elderly recipients and the controls).

Conclusions These data show that the pharmacokinetics of MPA in elderly renal transplant recipients were no different to those of younger-adult recipients in this study population.

Clinicaltrials.gov NCT 01631058.

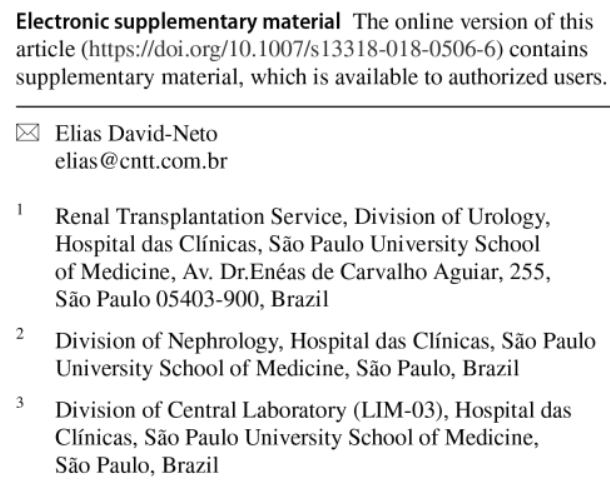

Renal Transplantation Service, Division of Urology, Hospital das Clínicas, São Paulo University School of Medicine, Av. Dr.Enéas de Carvalho Aguiar, 255, São Paulo 05403-900, Brazil

2 Division of Nephrology, Hospital das Clínicas, São Paulo University School of Medicine, São Paulo, Brazil

3 Division of Central Laboratory (LIM-03), Hospital das Clínicas, São Paulo University School of Medicine, São Paulo, Brazil

\section{Key Points}

Enteric-coated mycophenolate sodium can be used in both elderly and younger-adult renal transplant recipients in a similar manner

There are no differences in MPA absorption, metabolism, total apparent clearance adjusted for weight, and the second peak between elderly and younger-adult renal transplant recipients

Plasma concentration of MPA from EC-MPS reach the therapeutic window (AUC $30-60 \mu \mathrm{g} \cdot \mathrm{h} / \mathrm{mL}$ ) in $70 \%$ of elderly patients within the first week after transplantation 